UNIVERSIDADE DE SÃO PAULO

FACULDADE DE ECONOMIA, ADMINISTRAÇÃO E CONTABILIDADE DEPARTAMENTO DE ADMINISTRAÇÃO PROGRAMA DE PÓS-GRADUAÇÃO EM ADMINISTRAÇÃo

LUTA PELA SOBREVIVÊNCIA: UM MODELO DE ESTRATÉGIA COMPETITIVA PARA A RECUPERAÇÃO DE EMPRESAS

Fernando De Cesare Kolya

Orientadora: Prof ${ }^{\mathrm{a}}$. Dr ${ }^{\mathrm{a}}$. Maria Sylvia Macchione Saes

SÃO PAULO

2015 
Prof. Dr. Marco Antonio Zago Reitor da Universidade de São Paulo

Prof. Dr. Adalberto Américo Fischmann Diretor da Faculdade de Economia, Administração e Contabilidade

Prof. Dr. Roberto Sbragia

Chefe do Departamento de Administração

Prof. Dr. Moacir de Miranda Oliveira Júnior Coordenador do Programa de Pós-Graduação em Administração 
FERNANDO DE CESARE KOLYA

\section{LUTA PELA SOBREVIVÊNCIA: UM MODELO DE ESTRATÉGIA COMPETITIVA PARA A RECUPERAÇÃO DE EMPRESAS}

Dissertação apresentada ao Departamento de Administração da Faculdade de Economia, Administração e Contabilidade da Universidade de São Paulo como parte do requisito para obtenção do título de Mestre em Ciências.

Orientadora: Prof ${ }^{\mathrm{a}}$. Dra ${ }^{\mathrm{a}}$. Maria Sylvia Macchione Saes

Versão Corrigida

(versão original disponível na Faculdade de Economia, Administração e Contabilidade)

SÃO PAULO 


\section{FICHA CATALOGRÁFICA}

Elaborada pela Seção de Processamento Técnico do SBD/FEA/USP

\section{Kolya, Fernando De Cesare}

Luta pela sobrevivência: um modelo de estratégia competitiva para a recuperação de empresas / Fernando De Cesare Kolya. - São Paulo, 2015. $135 \mathrm{p}$.

Dissertação (Mestrado) - Universidade de São Paulo, 2015.

Orientador: Maria Sylvia Macchione Saes.

1. Estratégia organizacional 2. Declínio organizacional 3. Turnaround 4. Bibliometria I. Universidade de São Paulo. Faculdade de Economia, Administração e Contabilidade. II. Título.

$$
\text { CDD - 658.401 }
$$




\section{AGRADECIMENTOS}

Dedico este trabalho aos meus avós Tato e Lucia, à minha avó Cidinha e especialmente ao meu avô Elek, que transmitiram os valores que hoje preenchem a minha alma. Agradeço pelo carinho em suas palavras, apreço incontestável às escolhas que tomamos na vida e especialmente ao incentivo ao estudo.

Agradeço ao meu papai Eduardo por estar ao meu lado ao longo de minha formação e especialmente a minha mãe Regina, fiel incentivadora da minha busca por conhecimento. Aos dois sou grato pelo carinho recebido, sabedoria, ensinamentos e acima de tudo, à dedicação que, como filho, jamais poderei retribuir-lhes. Às minhas irmãs Elisa e Luiza e ao caçula José Eduardo, simplesmente por estarem ao meu lado, "enchendo minha bola", cantando e me incentivando. À Mariana, minha amada, que tornou a reta final desta trajetória muito mais agradável. Agradeço também à minha querida madrinha Mariângela, pelo incentivo.

À minha orientadora Sylvia que me acolheu de maneira tão natural e me fez sentir à vontade neste novo ambiente, sou grato. Também por permitir uma aproximação que foi além da obrigatória relação orientador-orientado. Foram momentos especiais poder participar dos almoços e jantares em sua casa, as viagens do CORS e o encontro inesperado em Ubatuba, junto à sua família. Acima de tudo, agradeço o conhecimento transmitido e a orientação para tornar este trabalho o melhor possível.

Aos meus grandes amigos Alan, Cynar, Ricardo e Saxê, obrigado pelo apoio, convites para “desestressar”, e compreensão pela ausência nos últimos tempos!

Agradeço à dedicação da Neca, sempre amorosa, disposta e solícita para auxiliar nas atividades cotidianas na salinha do CORS e por onde o grupo estivesse. Aos novos amigos do CORS e da pós graduação que tornam os momentos de alegria mais alegres e os momentos de tensão menos tensos. Meu muito obrigado ao Edinho e ao Leandro, pela amizade, incentivos e inumeráveis conversas no CORS, no Bar do Norte e até na praia. À Carol Moron, agradeço pelo companheirismo, cooperação e amizade ao longo dessa jornada que iniciamos e encerramos juntos. Aos demais amigos do CORS e PPGA, Anders Fredriksson, Ana Mascarin, Carol Foscaches, Camila Dias de Sá, Fabio Dolnikof, Fausto Makishi, Fernanda Lemos, Fernando da Rocha, Kassia Watanabe, Matheus Magalhães, Nubuiuki Ito, Paula 
Schneider, Rose Maria, Rubens Nunes, Rubia Rinaldi, Sara Gurfinkel, Selene Soares, Thiago Carvalho, Vivian Lara e Yasser Saleh, meu muito obrigado!

Aos professores da FEA, que deram sentido à noção de que o processo é mais importante que o produto final, agradeço. Meu especial agradecimento à Sylvia Saes, ao Decio Zylberstajn e à Bernardete Marinho, que foram verdadeiros mestres e educadores.

Agradeço aos amigos da Uni.Business, Fabio Mizumoto, Matheus Marino e Camila Dias de Sá, que me mostraram a beleza do caminho da academia e aos colegas de Markestrat que apoiam sem restrição o foco acadêmico.

Agradeço aos funcionários do PPGA que se esmeraram para oferecer um serviço de qualidade aos alunos.

Meu especial agradecimento à Cooperativa Agro Industrial Holambra (Paranapanema/SP), na figura de seu presidente Simon Veldt e superintendente Renzo Guazzelli por abrirem informações e compartilharem a história da cooperativa para que o caso discutido nesta dissertação fosse possível.

Por fim, sou grato ao povo paulista e ao povo brasileiro pelo financiamento compulsório aos meus estudos ao longo destes últimos dois anos e meio. Este trabalho não retorna o investimento depositado em mim e me sinto no dever de retribuir-lhes com a produção de conhecimento e trabalho para o meu estado e para o meu país. Meu muito obrigado à USP, à FEA e à CAPES. 


\section{EPÍGRAFE}

“A felicidade é aquele estado de consciência que procede da realização de nossos valores".

Ayn Rand 


\section{RESUMO}

KOLYA, F. D. C Luta pela sobrevivência: um modelo de estratégia competitiva para a recuperação de empresas. 2015. 135f. Dissertação (Mestrado) - Faculdade de Economia, Administração e Contabilidade, Universidade de São Paulo, São Paulo, 2015.

A capacidade de uma firma se recuperar de uma fase de declínio é denominada turnaround. Compreender as ações tomadas por empresas que se recuperaram de um período de declínio e as diferenças destas empresas em relação àquelas que faliram é um dos principais objetivos da literatura sobre o turnaround. Contudo, a definição de um modelo geral que pode ser aplicado a qualquer negócio parece ser algo ainda distante para os trabalhos que tratam do assunto. No limite, compreender a passagem do período de declínio para o de recuperação é definir como restaurar a vantagem competitiva de negócios. Estudos mostram que as abordagens dos trabalhos que tratam das vantagens competitivas oscilaram de maneira pendular ao longo das décadas de 1970 a 2000, ora com ênfase nas abordagens externas à firma como a Organização Industrial (OI), ora com abordagens internas como a Teoria Baseada em Recursos (TBR) e Capacidade Dinâmica (CD) ou evidenciando abordagens centrais como a Economia dos Custos de Transação (ECT). Aparentemente os estudos sobre turnaround foram influenciados por esta dinâmica pendular da evolução do conhecimento em estratégia, refletidos nas discussões existentes sobre o que seriam causas estratégicas ou operacionais do declínio das organizações. O presente trabalho propõe primeiramente um estudo bibliométrico a fim de compreender a evolução da literatura sobre o turnaround e as contribuições da literatura sobre estratégia para o tema. A partir da análise qualitativa dos principais trabalhos apontados pelo estudo bibliométrico e da relação destes com as abordagens de estratégia são derivadas proposições para um modelo de estratégia competitiva para o turnaround. Para discutir o modelo e as proposições, é desenvolvido um estudo de caso da Cooperativa Agro Industrial Holambra. Os resultados alcançados indicam caminhos para desenvolvimento de um modelo geral sobre o turnaround de empresas bem como aspectos que devem ser investigados com maior profundidade.

Palavras-chave: estratégia organizacional; declínio organizacional; turnaround; bibliometria. 


\begin{abstract}
KOLYA, F. D. C Struggle for survival: a competitive strategy model for business turnaround. 2015. 135f. Dissertação (Mestrado) - Faculdade de Economia, Administração e Contabilidade, Universidade de São Paulo, São Paulo, 2015.

The ability of a firm to recover from a declining financial performance is called turnaround. The understanding of the actions taken by such firms and the differences in between them and those that went bankrupt is one of the main goals addressed by the turnaround literature. However, a definition of a general model that can be applied to any business situation seems to be something still distant for research on the subject. Ultimately, understanding the transition from the period of decline to the recovery period is to set how to restore firms competitive advantage. Studies show the papers that address the approaches of competitive advantage, swung like a pendulum over the decades from 1970 to 2000, sometimes with emphasis on the external approaches to the company as Industrial Organization (IO), sometimes with internal approaches such as Resource Based View (RBV) and Dynamic Capacity (DC) or showing central approaches such as Transaction Cost Economics (TCE). Apparently studies about the turnaround were influenced by this pendulum dynamics of the strategy knowledge evolution, reflected, for example, in ongoing discussions about what would be strategic or operational causes of the organizations decline. This paper first proposes a bibliometric study in order to understand the evolution of the literature on the turnaround as well as the contributions of the literature on strategy field for the theme. From the qualitative analysis of the main papers and studies identified by the bibliometric study and their relationship with the strategy approaches, propositions are made for a competitive strategy model for the turnaround. To discuss the model and propositions, a case study is developed on an agribusiness cooperative - "Cooperativa Agro Industrial Holambra". The results achieved indicate paths for general model of development on the turnaround of firms as well as aspects that should be studied in greater depth.
\end{abstract}

Keywords: organizational strategy; organizational decline; turnaround; bibliometrics. 


\section{SUMÁRIO}

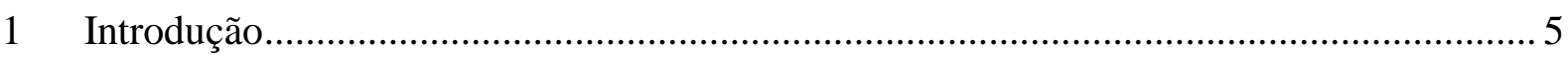

2 Estado da Arte das pesquisas sobre Turnaround de Empresas ...................................... 13

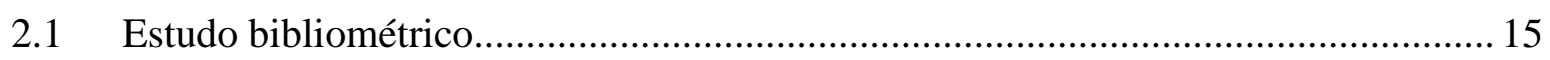

2.1.1 Base intelectual em turnaround de empresas................................................ 20

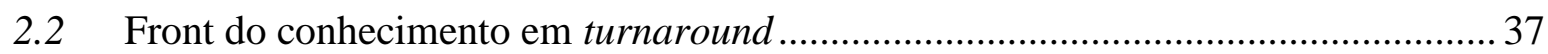

2.2.1 Declínio organizacional: causas, consequências, padrões e predição de falência 37

2.2.2 Recuperação de empresas: estratégias de turnaround e retrenchment .............. 41

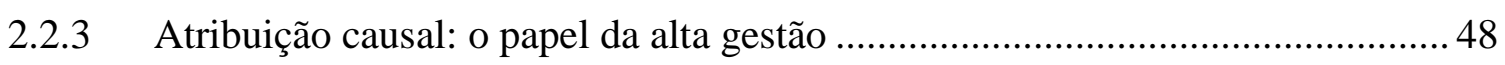

2.3 Turnaround: estado atual e caminhos para desenvolvimento ................................... 51

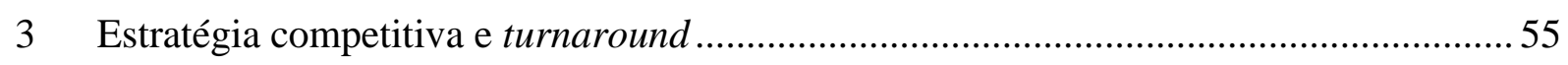

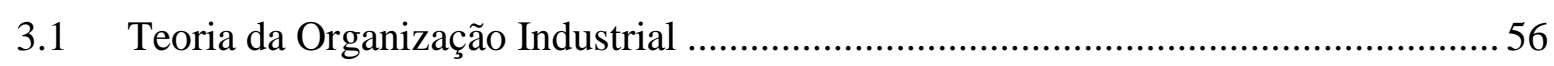

3.2 Economia dos Custos de Transação - ECT ............................................................ 58

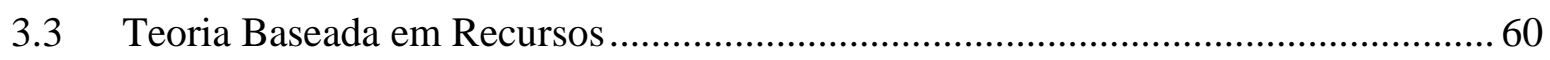

3.4 Contribuições da estratégia competitiva para o turnaround ...................................... 64

3.5 Um modelo de estratégia competitiva para o turnaround de empresas .................... 76

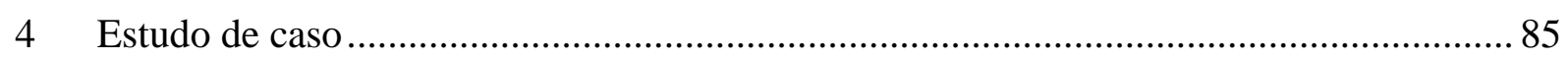

4.1 O caso da Cooperativa Agro Industrial Holambra ................................................ 87

4.1.1 Contexto econômico e a evolução da crise .................................................... 89

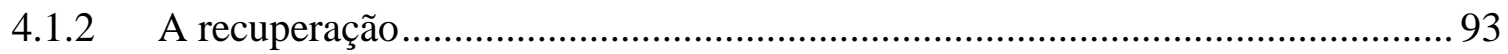

4.1.3 Discussão e conclusões do caso .................................................................... 102

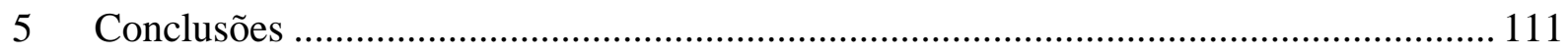

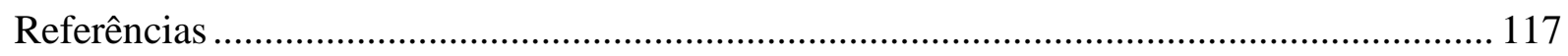

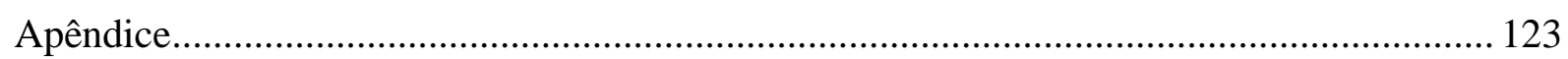




\section{LISTA DE QUADROS}

Quadro 1 - Fator de impacto e número de publicações dos dez principais periódicos que publicaram sobre turnaround de empresas entre 1983 e 2014 ............................................... 17

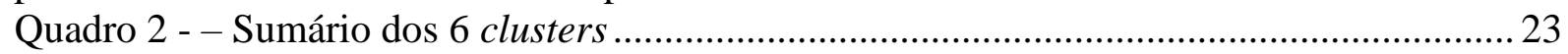

Quadro 3 - Tipo e característica da pesquisa, objetivos e principais conclusões dos trabalhos mais significativos de cada cluster (continua) .................................................................... 26 Quadro 4 - Frequência do tipo de pesquisa e abordagem dos dez principais trabalhos de cada

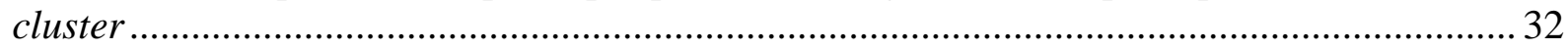

Quadro 5 - Resumo das principais escolas de estratégia ..................................................... 64 Quadro 6 - Frequência e autores das escolas de estratégia citados pelos trabalhos de

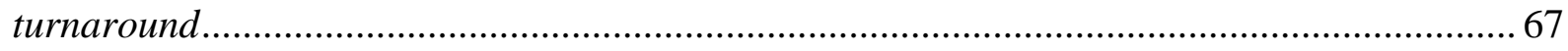

Quadro 7 - Relação dos principais trabalhos que citam as escolas de estratégia ..................... 68 Quadro 8 - Relação das fases do processo de turnaround com escolas de estratégia - declínio

Quadro 9 - Relação das fases do processo de turnaround com escolas de estratégia -

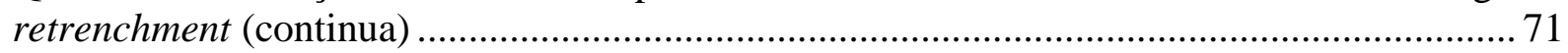

Quadro 10 - Relação das fases do processo de turnaround com escolas de estratégia -

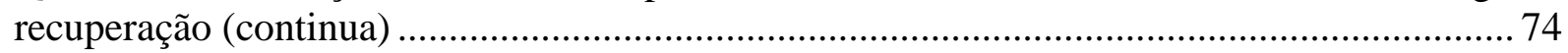
Quadro 11 - As fases do processo de turnaround que receberam suporte da literatura de

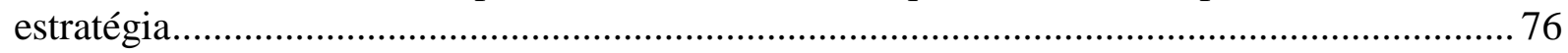

Quadro 12 - Programa de incentivo aos cooperados ......................................................... 97

\section{LISTA DE TABELAS}

Tabela 1 - Frequência e centralidade das palavras-chave mais utilizadas.............................. 20

Tabela 2 - Matriz de correlação entre a frequência de citação dos clusters ............................ 36

\section{LISTA DE FIGURAS}

Figura 1 - Evolução da pesquisa em gestão estratégica....................................................... 9

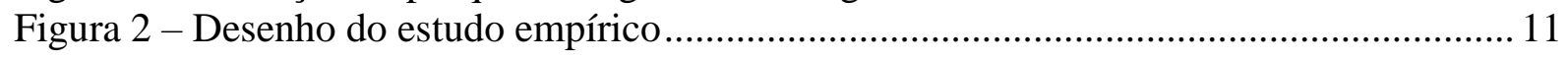

Figura 3 - Modelo Conceitual do CiteSpace II .................................................................. 13

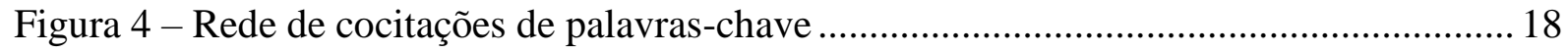

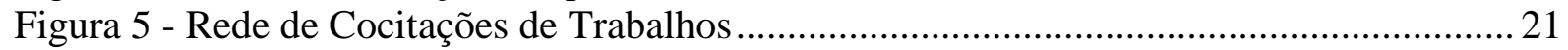

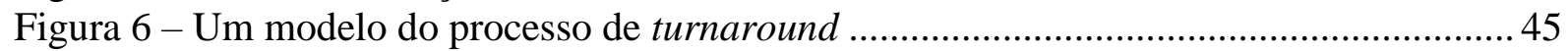

Figura 7 - Modelo proposto para o turnaround de empresas ............................................... 53

Figura 8 - Modelo proposto de turnaround ..................................................................... 78

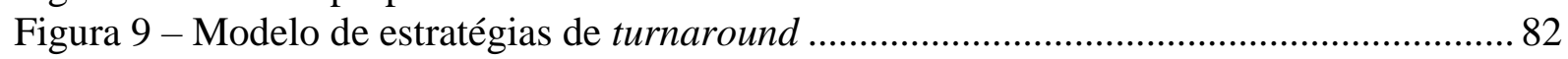

Figura 10 - O processo de turnaround da Holambra.......................................................... 110 


\section{INTRODUÇÃO}

Entre os anos de 1991 e 1993 a unidade de negócios da IBM-UK (International Business Machines - United Kingdom) do Reino Unido (multinacional americana no segmento tecnologia) acumulou um prejuízo de cerca de $£ 1.000$ milhão. O resultado foi negativo em aproximadamente duas vezes o excepcional desempenho de $£ 511,1$ milhões (lucro antes dos impostos) alcançado em 1988 (BALGOBIN; PANDIT, 2001). Contudo, tal situação adversa não decretou o fim da IBM-UK, que após uma série de medidas corretivas iniciadas em 1993, alcançou lucros antes dos impostos da ordem de $£ 351$ milhões em 1997. A capacidade de recuperação apresentada pela IBM-UK após o período de declínio não pôde ser observada no caso da KODAK, companhia americana fundada em 1888 que se especializou na produção de material para a indústria fotográfica ao longo do século XX. Durante a década de 1980 a KODAK era líder mundial em seu segmento e manteve participação de mercado de $89 \%$ até 1989, mas ao se mostrar incapaz de acompanhar sucessivas mudanças tecnológicas que aconteceram na indústria fotográfica, a empresa entrou com pedido de falência na justiça estadunidense no ano de 2012 (Hussain et al., 2014).

O caso da recuperação de performance da IBM-UK citado acima é reconhecido na literatura acadêmica e não acadêmica sob o termo em língua inglesa "turnaround", em tradução literal para o português, "volta por cima". O turnaround é "o processo pelo qual uma firma uma vez bem sucedida, experimenta severo declínio de sua performance por um período prolongado, mas consegue superar seus problemas e retorna ou ultrapassa o nível de performance anterior ao declínio" (PEARCE II; ROBBINS, 1993 p.22). Do ponto de vista social, a tentativa de salvar uma empresa pode ser mais eficiente do que a criação de uma nova, isto porque os empregos mantidos ao se salvar uma empresa são mais seguros e melhor remuneram em relação a uma firma recém-criada (ONeill, 1986).

Estudar o turnaround é compreender essencialmente as diferenças entre as ações tomadas por empresas que se recuperaram e por aquelas que faliram. Mas compreender estas diferenças ou, simplesmente identificar um padrão de comportamento comum às empresas que se recuperam de um período de declínio, exige a compreensão de tantos fatores que a construção

\footnotetext{
1 "The process by which once-successful firms, that experience severely declining performance for a protracted period of time, overcome their troubles and return to match or exceed their most prosperous periods of predownturn performance" (PEARCE II; ROBBINS, 1993, p.22).
} 
de generalizações pode parecer simplista e imprecisa. Talvez por isso a literatura sobre o tema se dedicou a entender de que maneira, diferentes aspectos isolados influenciam o processo de turnaround ou alguma de suas etapas. Mas também esforços foram feitos no sentido de "modelos gerais" ainda que reconhecendo suas limitações.

[...] por existirem diferenças entre os candidatos à turnaround e seus ambientes, diferentes modelos de turnaround podem ser necessários. Pesquisadores que selecionam tipos distintos de organizações para seus estudos ou que adotam critérios diferentes para a inclusão de candidatos, irão observar que diferentes modelos de processos de turnaround devem ser investigados. À medida que o entendimento do turnaround se torna mais completo, teóricos devem achar útil a união de diferentes modelos de turnaround com diferentes situações ou severidades de turnaround (PEARCE II e ROBBINS, 1993, p. 623) ${ }^{2}$.

A literatura explorou primeiramente o processo de turnaround a partir de modelos teóricos genéricos (Hofer, 1980; ONeill, 1986; Slatter, 1984), que apesar de contribuir com a ideia de que as estratégias de recuperação devem levar em consideração as causas do declínio e que a gravidade da situação de turnaround clama por diferentes estratégias, careciam de comprovação empírica. Trabalhos posteriores buscaram estabelecer relações causais empiricamente (Barker III e Duhaime, 1997; Barker III, Patterson e Mueller, 2001; Lim et al., 2013; Robbins e Pearce II, 1992) e buscam entender os fatores moderadores (natureza da geração de renda, papel da alta gestão, severidade do declínio) aprimorando os primeiros modelos de estratégias de recuperação (Arogyaswamy, Barker III e Yasai-ardekant, 1995; Cater e Schwab, 2008; Lim et al., 2013; Ndofor, Vanevenhoven e Barker III, 2013).

Outras abordagens para o problema do turnaround buscaram isolar uma de suas fases (declínio, retrenchment ${ }^{3}$ ou recuperação) e compreende-las. Hambrick e Daveni (1988) estudaram o declínio organizacional, seus padrões e as consequências que uma espiral descendente tem na estrutura, finanças e estratégia das organizações. Morrow et al. (2004) isolou a fase de retrenchment e avaliou como diferentes ações (corte de custos ou liquidações de ativos) impactam a performance pós retrenchment de firmas em uma indústria em expansão. Estes trabalhos dão sonoridade a ideia de Pearce II e Robbins (1993) de que a

\footnotetext{
2 "[...] differences in turnaround candidates and in their environmental contexts may necessitate different turnaround models. Researchers who choose different types of organizations to study or who place different requirements on their inclusion as turnaround candidates may find that different models of turnaround processes should be investigated. As the understanding of turnaround becomes more complete, theory builders may even find it useful to pair different turnaround models with different turnaround situation causes or severities" (PEARCE II; ROBBINS, 1993, p. 623).

${ }^{3} \mathrm{O}$ retrenchment é um termo utilizado pela literatura de turnaround para descrever as ações de corte de custos e liquidação de ativos que podem ser adotadas em um estágio inicial do processo de recuperação de um negócio. Esta fase está geralmente associada à interrupção do declínio e geração de caixa para resolver o problema financeiro mais urgente e criar condições para a implantação de estratégias de recuperação.
} 
literatura precisa desenvolver muitos modelos sobre o turnaround, aplicados às condições mais singulares até que seja possível consolidar-se uma proposta com aplicação geral.

Considerando que os primeiros trabalhos sobre o turnaround de empresas foram publicados no fim da década de 1970 e início de 1980 e que desde então a literatura avançou em várias frentes no sentido de construir modelos mais completos aplicáveis à realidade das empresas em geral, o presente trabalho tem como objetivo explorar a evolução deste campo teórico desde suas primeiras publicações até seus resultados mais contemporâneos. Segundo RamosRodrigues e Ruíz-Navarro (2004, p. 981) “uma vez que uma disciplina alcançou determinado nível de maturidade, é prática comum que acadêmicos voltem sua atenção à literatura produzida pela comunidade científica [...] para conduzir revisões da literatura com o objetivo de acessar seu estado da arte" ${ }^{4}$. Assim, o problema de pesquisa ao qual este trabalho irá se dedicar é:

\section{Qual o estado da arte do conhecimento acadêmico sobre turnaround de empresas?}

Compreender o estado da arte deve responder até que ponto a literatura avançou, sua abrangência, pontos consolidados, divergências, a fronteira do conhecimento e as avenidas a serem exploradas. No entanto, para compreender mais a fundo o "como" a base teórica avançou e as raízes que sustentam esta evolução é preciso investigar sua base intelectual.

Como mencionado, o turnaround é um fenômeno que envolve uma miríade de fatores. Rumelt (1995) propõe um modelo que explica a inércia das firmas e como deve ocorrer a transformação e conclui que não existe um modelo simples para a gestão e os processos organizacionais e que estudar a inércia e transformação requer avaliar uma variedade de disciplinas, sendo um processo muito complexo.

Dentre esta "variedade de disciplinas" apontadas por Rumelt (1995), há uma que se mostra presente nos trabalhos mais antigos e também nos mais recentes. O turnaround é um fenômeno intimamente ligado à estratégia competitiva, isto porque estuda-lo requer a compreensão de uma questão fundamental: como uma firma alcança e mantém desempenho

\footnotetext{
4 "Once a scientific discipline has reached a certain degree of maturity, it is common practice for its scholars to turn their attention towards the literature generated by the scientific community and, treating it as a research topic in its own right, to conduct reviews of the literature with a view to assessing the general state of the art (RAMOS-RODRÍGUEZ; RUÍZ-NAVARRO, 2004, p. 981)”.
} 
econômico? Uma das questões fundamentais das pesquisas que buscam o desenvolvimento de uma teoria sobre a estratégia das firmas diz respeito à vantagem competitiva, que tenta compreender os fatores responsáveis pela habilidade das firmas em criar rendas econômicas (FOSS, 2005 apud MONTEIRO; ZYLBERSZTAJN, 2012).

Além dos estudos na área de estratégia competitiva, a área do conhecimento rotulada como "gestão estratégica" que está intimamente ligada à primeira (Guerras-Martín, Madhok e Montoro-Sánchez, 2014), tem como questão principal explicar o sucesso ou fracasso das firmas (Rumelt, Schendel e Teece, 1994) evidenciando mais uma vez a proximidade da questão principal do turnaround de empresas com os estudos em estratégia competitiva e gestão estratégica.

A área de pesquisa voltada para o entendimento de estratégia (especificamente gestão estratégica) se desenvolveu ao longo do tempo de maneira pendular (termo cunhado por Hoskisson et al. (1999)), oscilando entre considerações internas e externas às firmas e entre considerações de nível micro e macro para explicar os "fatores de sucesso" das mesmas (Guerras-Martín, Madhok e Montoro-Sánchez, 2014).

A noção da oscilação de pêndulo duplo das pesquisas sobre estratégia ao longo das décadas de 1970 até a década iniciada em 2010 é representada na Figura 1 apresentada por GuerrasMartín et al. (2014). Os autores argumentam que na década de 1970 e 1980 o pêndulo esteve inclinado para o lado externo à firma, principalmente pela influência da escola de Organização Industrial (OI) com sua abordagem "estrutura-conduta-desempenho". Na década de 1980 e 1990 o pêndulo assumiu uma posição mais central, com a abordagem da escola de organização econômica formada pela Teoria da Agência (TA) e Economia dos Custos de Transação (ECT), que têm uma abordagem mais equilibrada entre "externo" e "interno". Finalmente, na década de 1990 os estudos em gestão estratégica passaram a uma abordagem claramente "interna”, com a expansão da Teoria Baseada em Recursos (TBR).

A mesma oscilação foi percebida entre o nível macro e micro, tendo no primeiro extremo a OI com sua abordagem focada na indústria e que considera as ações da firma como uma forma de adaptação à estrutura da mesma; e no outro extremo a abordagem de comportamento organizacional e micro fundações, cujo foco é o comportamento dos indivíduos e seu impacto na estratégia das firmas. Entre um extremo e outro, se posicionam a ECT e TA na medida em 
que abriram a "caixa preta" que era a firma para a OI, com o objetivo de compreender as relações contratuais entre os diferentes agentes (TA) ou entre empresas e mercados (ECT).

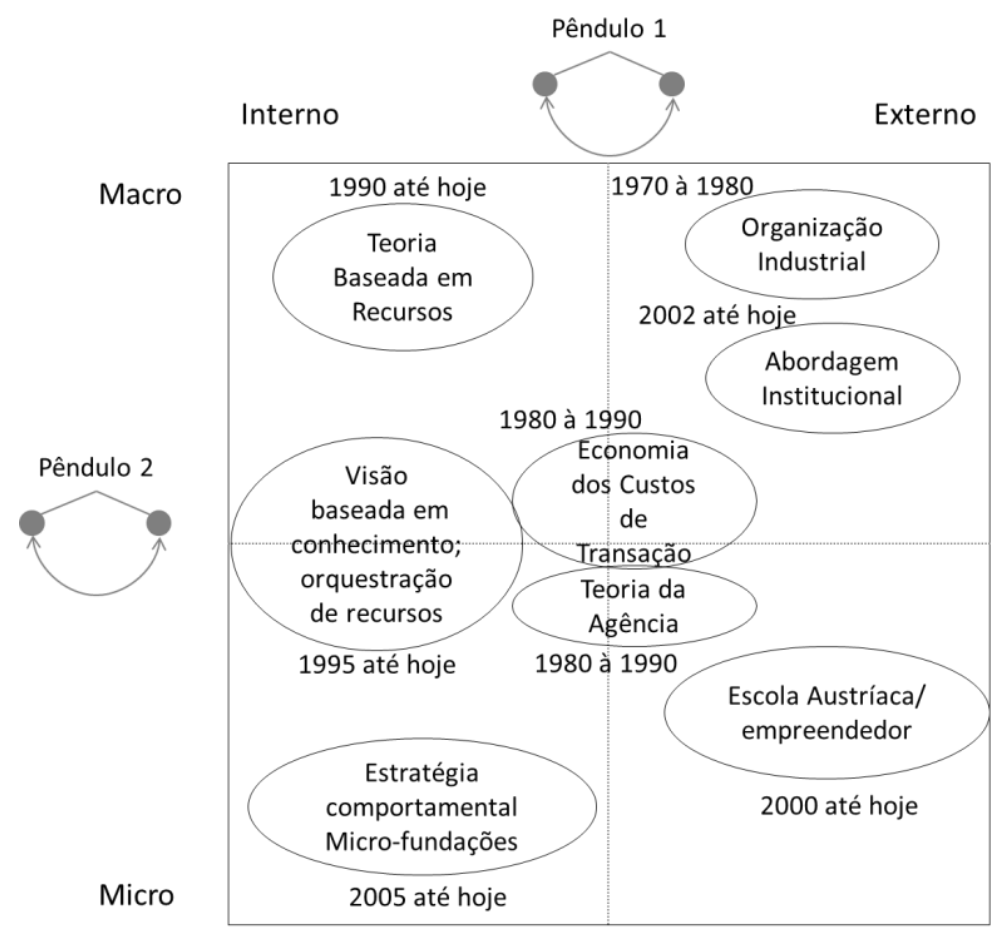

Figura 1 - Evolução da pesquisa em gestão estratégica

Fonte: Guerras-Martín et al. (2014, p. 71)

De certa maneira a oscilação dos dois pêndulos reverberou nos estudos sobre o turnaround de empresas. Um trabalho bastante citado na área propõe um modelo de turnaround em que as estratégias de recuperação levam em consideração principalmente a estrutura da indústria e ciclo de vida dos produtos (Hofer, 1980), acompanhando o movimento pendular das pesquisas em gestão estratégica, que naquele momento estavam inclinadas em direção à OI. Um trabalho posterior avalia o impacto de ações de retrenchment nos recursos das firmas, tidos como a fonte de vantagem competitiva da firma (Morrow, Johnson e Busenitz, 2004), em clara menção à TBR e acompanhando a oscilação do pêndulo (externo-interno).

Considerando que para se compreender a evolução das pesquisas em um determinado campo é importante a investigação de sua base intelectual, isto é, dos autores e conceitos que alicerceiam a construção daquele campo, e considerando o movimento pendular das pesquisas sobre estratégia e evidências de que estas pesquisas influenciaram o desenvolvimento dos trabalhos em turnaround de empresas, o presente trabalho deve responder em segundo lugar: 


\section{Qual a contribuição das teorias de estratégia para explicar o processo de turnaround de empresas?}

Para tal, o presente trabalho irá investigar de maneira sistemática como a literatura que trata do processo de turnaround evoluiu nos últimos 30 a 40 anos. A investigação pretende responder sobre a existência ou não de uma teoria consolidada sobre o turnaround de empresas, os aportes teóricos utilizados e eventuais relações entre eles. Para se avaliar o estado da arte da literatura existente sobre o turnaround e verificar a relação das escolas de estratégia com os trabalhos sobre o tema, optou-se pela análise bibliométrica (área 1 na Figura 2) que identifica padrões e tendências por meio de análises de citações diretas de autores e que demostra os mais influentes e a análise de cocitações (autores citados conjuntamente) demonstrando a aproximação de autores em grupos, que por sua vez ilustra a similaridade entre eles (Ramos-Rodríguez e Ruíz-Navarro, 2004; Serra et al., 2012).

Além da análise bibliométrica, serão discutidas as abordagens de estratégia competitiva e sua relação com os trabalhos sobre o turnaround (área 2 na Figura 2) com o objetivo de compreender a contribuição das teorias sobre estratégia competitiva para a recuperação de empresas. Para isto é preciso desenvolver brevemente o conceito de estratégia e suas escolas a fim de compreender de forma geral, quais os conceitos econômicos que as regem e a forma com a qual o conceito de estratégia é operacionalizado. Isto é, na visão das escolas de estratégia, qual deve ser a estratégia das firmas para alcançar performances superiores aos outros agentes do mercado. Compreender a maneira com a qual cada escola operacionaliza o conceito de estratégia é importante para avaliar os estudos já publicados sobre turnaround e discutir como os autores explicam o processo de turnaround. Por fim, as proposições serão exploradas em um estudo de caso (área 3 na Figura 2). 


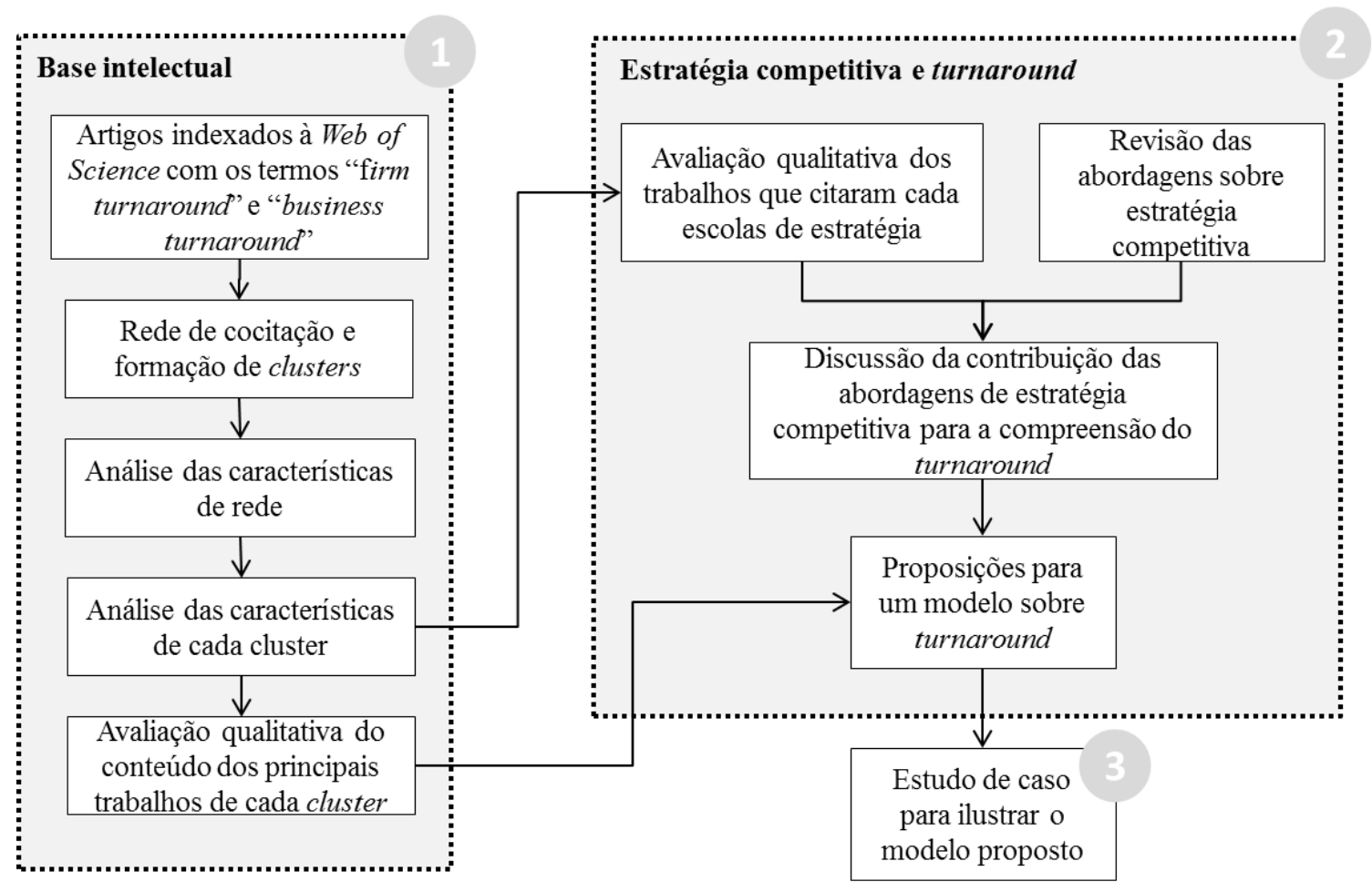

Fonte: elaborado pelo autor

Figura 2 - Desenho do estudo empírico

*O estudo de caso é utilizado conforme nomenclatura de Baker e Gil (2012): estudos clínicos como evidências para testar teorias.

Ao final será conduzido um estudo de caso com o objetivo de ilustrar algumas proposições teóricas levantadas ao longo do trabalho. Para atender a esses objetivos, o presente trabalho estará dividido em três capítulos somados a este capítulo introdutório e às conclusões finais.

No Capítulo 2 é realizada a análise bibliométrica e está dividido em três seções. A primeira (2.1) traz o estudo bibliométrico que tem como objetivo avaliar a base intelectual do turnaround. A segunda (2.2) discute o estado da arte (front do conhecimento) e sua evolução. A terceira (2.3) faz um esforço de consolidação da evolução das pesquisas sobre turnaround em um modelo do processo de turnaround e os fatores que influenciam cada fase segundo os avanços da literatura.

O Capítulo 3 discute as principais abordagens das escolas de estratégia competitiva (OI, ECT e TBR), debate a contribuição e a influência das pesquisas sobre estratégia nas pesquisas sobre turnaround e ao final propõe um modelo de estratégia competitiva para o turnaround de empresas. 
No Capítulo 4 é apresentado o estudo de caso de uma cooperativa que passou pelo processo de turnaround, à luz do modelo proposto no capítulo anterior. As principais conclusões do presente trabalho serão discutidas no Capítulo 5. 


\section{ESTADO DA ARTE DAS PESQUISAS SOBRE TURNAROUND DE EMPRESAS}

A análise bibliométrica toma como base um grupo de autores que trata de determinado tema e analisa suas citações. As fronteiras de uma pesquisa são delimitadas por: a) cluster de artigos cocitados; b) cluster de artigos cocitados e todos os artigos que citam o cluster; c) cluster que citam um grupo comum de artigos. A fronteira é tipicamente composta por artigos transitórios que tem alta citação em fase "jovem" (Chen, 2006). Assim, autores que são citados juntos em vários trabalhos acabam sendo agrupados em um mesmo cluster. A Figura 3 abaixo apresenta o modelo conceitual desenvolvido por Chen para o programa CiteSpace II.

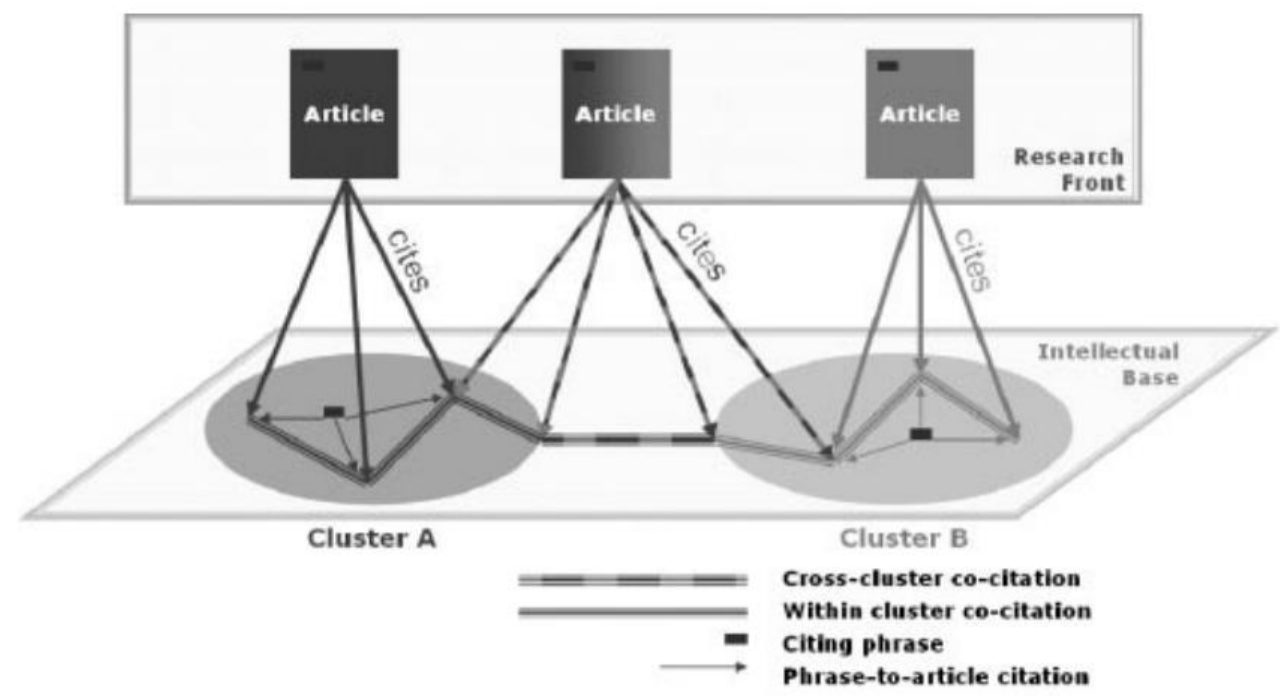

Fonte: Chen (2006, p. 364)

Figura 3 - Modelo Conceitual do CiteSpace II

Como citado anteriormente e visualizado na Figura 3, um cluster (cluster A ou B) é formado por artigos que foram citados conjuntamente por um mesmo trabalho (article). Assim, os clusters são formados por trabalhos mais antigos e compreendem a base intelectual (intellectual base) do tema estudado. Os artigos que foram utilizados para gerar a rede de cocitações compõem o front de conhecimento (research front) sobre aquele tema.

No presente trabalho, a matriz original de dados - compreendida como o front de conhecimento -, foi extraída da base de dados Web of Science da Thomson Reuters. Os termos "firm turnaround" e "business turnaround" foram utilizados para encontrar os trabalhos que tratam do tema do turnaround de negócios. Após a busca inicial foi aplicado um filtro para 
selecionar os tipos de documentos que seriam aceitos: artigos, revisões de livros e proceedings paper. Além disso, filtrou-se por categoria da Web of Science e os trabalhos deveriam estar listados em alguma das categorias elencadas a seguir: "management", "business", "social Sciences interdisciplinary", "business finance", "economics" ou "public administration". Após a aplicação dos filtros foram obtidos 153 trabalhos.

A fim de se obter um conjunto de trabalhos realmente associadas ao objeto de pesquisa (tratam do turnaround de empresas), os 153 trabalhos foram selecionados com base em leitura de título e resumo. Trabalhos que não estavam associados ao estudo de turnaround de empresas foram descartados da base e ao final chegou-se a 98 artigos.

O software utilizado para a análise bibliométrica foi o CiteSpace II que nos permite: a) identificar o estado da arte de um tópico de pesquisa; b) rotular especialidades associadas a determinada área do conhecimento; c) detectar temas nascentes e mudanças abruptas ao longo do tempo (Chen, 2006). No presente trabalho, o interesse maior esta em identificar o estado da arte do tema turnaround caracterizando suas especialidades e associação com as teorias de estratégia (item "a" e "b"). O item "c" não é foco no presente trabalho.

Os parâmetros utilizados para a geração da rede foram: somente sejam utilizadas as bibliografias de trabalhos citadas ao menos duas vezes. Assim, retira-se da amostra trabalhos pouco expressivos. Foram eliminados, portanto, 39 trabalhos citados uma ou nenhuma vez. Destes, nove são dos anos de 2013 e 2014. Como não há a intenção de se avaliar a evolução das citações ao longo do tempo, optou-se por gerar um conjunto de clusters para um período único 1983-2014 (32 anos). Este período corresponde aos anos da publicação do artigo mais antigo e do mais novo, respectivamente, na base de dados utilizados.

Outro parâmetro importante foi a limitação de número de trabalhos que comporiam a rede.

Uma rede muito extensa torna o trabalho de agrupamento (clustering) e interpretação muito complexo e, portanto, se deve encontrar o número mínimo que consiga responder ao problema de pesquisa e que seja consistente. A modularidade (Q) é uma variável importante na formação dos clusters, pois informa a adequação da divisão da rede em blocos independentes (clusters) (Newman, 2006), variando de 0 a 1 , sendo que o mais próximo a 1 indica uma rede com clusters bem divididos. No entanto, redes com Q igual ou quase igual a 1 podem indicar que a rede é dividida em autores isolados uns dos outros (Chen, Ibekwesanjuan e Hou, 2010). Foram geradas redes com 30, 50, 70, 90, 100, 110 e 120 membros com 
o intuito de encontrar a melhor relação entre modularidade e número de clusters. Chen (2006) aponta que redes com até 10 clusters são adequadas e, mais do que isso, a interpretação das diferenças entre os agrupamentos fica comprometida. Com relação à modularidade o valor de 0,7 ou superior indica uma forte adequação dos agrupamentos e, portanto, foi buscada a rede com clusters de modularidade acima de 0,7. A rede ideal foi obtida com 110 membros, geração de 6 clusters, $\mathrm{Q}=0,5161^{5}$ "o que sugere que sejam consideráveis, mas não excessivos" trabalho modularidade de $\mathrm{Q}=0,5691$.

$\mathrm{O}$ arquivo exportado da base Web of Science para o programa CiteSpace II gerou uma rede de cocitações que será apresentada a seguir. Como visto anteriormente, a rede estabelece ligações entre autores citados conjuntamente (cited articles) pelos autores da base de dados original (citing articles). O programa gera ainda clusters (agrupamento de autores) em função da frequência de citação de pares de autores. Assim, quanto mais frequente a citação de pares de autores, mas provável que fiquem próximos na rede de cocitações. Os autores da base original fazem parte do front de conhecimento enquanto os artigos citados por estes compõem a base intelectual sobre o tema. A seguir serão discutidos os resultados das análises relacionadas à base intelectual sobre o tema. Na sequencia o front do conhecimento sobre o turnaround será debatido.

\subsection{Estudo bibliométrico}

O termo turnaround utilizado para descrever o processo de recuperação de empresas que passaram por período de declínio é relativamente recente na literatura. A análise de publicações indexadas na base de dados Web of Science (WOS) revela que o primeiro estudo publicado data do ano de $1983^{7}$ e que desde então, apesar de crescente o número de publicações, a média anual até o ano de 2014 não passou de três, sendo que o maior número de publicações ocorreu no ano de 2012, com nove trabalhos. O periódico com maior número de trabalhos é a Harvard Business Review (HBR), uma revista voltada ao público de negócios e pouco acadêmica, que acumula $10 \%$ de todas as publicações entre 1983 e 2014 . O trabalho

\footnotetext{
${ }^{5}$ Os valores de modularidade e silhuetas individuais dos clusters serão discutidos nos resultados.

6 "suggesting that inter-cluster connections are considerable but not overwhelming".

${ }^{7} \mathrm{Nem}$ todos os periódicos existentes estão indexados à base WOS, assim, trabalhos posteriores a 1983 sobre o turnaround de empresas podem ter sido publicados e não constar nesta pesquisa. É importante destacar que trabalhos muito importantes sobre o turnaround de empresas não foram encontrados nos periódicos indexados à WOS tais como Schendel et al. (1976a), Schendel e Patton (1976) e Slatter (1984).
} 
mais citado - KOTTER, J. P. Leading change: why transformation efforts fail. Harvard Business Review, v. 73, n. 2, p. 231-248, 1995 -, que acumula 32\% de todas as citações, foi publicado nesta revista (HBR). A presença marcante de uma das principais revistas voltadas ao público de negócios entre os trabalhos que tratam do turnaround de empresas denota o interesse de gestores e líderes de negócios no conhecimento teórico e empírico sobre a recuperação de empresas.

Como visto, foram encontrados 98 trabalhos indexados à WOS, os quais conforme classificação da própria base de dados tiveram seus periódicos associados a oito diferentes áreas de pesquisa, são elas: Business \& Economics; Psychology; Social Sciences; Public Administration; Engineering; Operations Research \& Management Science; Mathematical Methods In Social Sciences; Operations Research \& Management Science. A abrangência com relação às áreas do conhecimento sugere que o tema é abordado sob diferentes perspectivas, ou mesmo que aproxima distintas áreas do conhecimento: de "negócios" à "psicologia". Esta constatação está de acordo com a afirmação de Rumelt (1995) na qual a inércia das firmas e o processo de transformação que leva ao rompimento de seu estado letárgico requer avaliar uma miríade de disciplinas, sendo um processo muito complexo. Como sugere Foss (2011), as pesquisas sobre vantagem competitiva das firmas partiram da avaliação da estrutura da indústria (Organização Industrial) movendo-se na direção de melhor compreender a heterogeneidade das firmas (Teoria Baseada em Recursos). Com isso, há uma tendência cada vez maior de se investigar os micro-fundamentos da heterogeneidade (microfundations) determinados pelas ações e interações entre os indivíduos. Assim, os estudos passaram a ter um interesse proeminente, dentre outros aspectos, na dimensão psicológica da gestão estratégica e como esta dimensão pode ser determinada por características dos indivíduos e seus comportamentos.

O Quadro 1 a seguir, apresenta os dez periódicos, em ordem de fator de impacto (do maior para o menor), o número de publicações que cada periódico publicou sobre turnaround e a porcentagem em relação ao total de publicações sobre o tema. Dentre as distintas áreas de conhecimento, a que recebe mais atenção de periódicos de alto impacto é a de Business \& Economics. O periódico com maior número de trabalhos (6\% do total) foi o Journal of Management Studies, que publica trabalhos empíricos e conceituais nas áreas de teoria organizacional (organization theory), comportamento organizacional (organizational behaviour), gestão de recursos humanos (human resource management), estratégia (strategy), 
negócios internacionais (international business), empreendedorismo (entrepreneurship), inovação (innovation) e estudos críticos sobre gestão (critical management studies).

Portanto, observa-se que, além de receber atenção de diversas áreas do conhecimento, nas últimas três décadas, o turnaround de empresas foi um tópico explorado por periódicos de elevada conceituação.

\begin{tabular}{lccc}
\hline \multicolumn{1}{c}{ PERIÓDICO } & Fator Impacto & Publicações (\#) & $\begin{array}{l}\text { Publicações } \\
(\mathbf{\%})\end{array}$ \\
\hline Academy of Management Review & 7,895 & 1 & 1,0 \\
Journal of Management & 6,704 & 3 & 3,1 \\
Academy of Management Journal & 5,906 & 1 & 1,0 \\
Administrative Science Quarterly & 4,182 & 1 & 1,0 \\
Journal of Management Studies & 3,799 & 6 & 6,1 \\
Management Decision & 3,787 & 1 & 1,0 \\
Long Range Planning & 3,667 & 4 & 4,1 \\
Strategic Management Journal & 3,367 & 5 & 5,1 \\
Organization Science & 3,351 & 1 & 1,0 \\
Journal of Business Venturing & 2,976 & 4 & 4,1 \\
\hline
\end{tabular}

Quadro 1 - Fator de impacto e número de publicações dos dez principais periódicos que publicaram sobre Fonte: Web of Science turnaround de empresas entre 1983 e 2014

Com o objetivo de compreender quais os termos mais centrais das pesquisas sobre turnaround de empresas e a associação entre eles, procedeu-se com a criação de uma rede de cocitação de palavras-chave ${ }^{8}$, a partir da base de dados originais e posteriormente separação da rede em clusters. O resultado é apresentado abaixo na Figura 4.

\footnotetext{
${ }^{8}$ A rede de cocitações de palavras chave foi gerada a partir da seleção dos trinta trabalhos mais citados na WOS. O software utilizado para a clusterização foi o Cite Space.
} 
Citespace, v. 3.8.R4 (64-bit)

C.UUserslFernando

Timespan: 1983-2014 (Slice Length $=32$ )

Network: $N=30, E=30$ (Density=0.069)

Pruning: Pathfinder

Mean Silhouette $=0.8486$

*BOARD TRAD; *CHARL ZUB ASS; *DUNL JOINT TRAD U; *EC INT UN; *GOV MAL; *K SALM ASS; *MON RESTR PRA

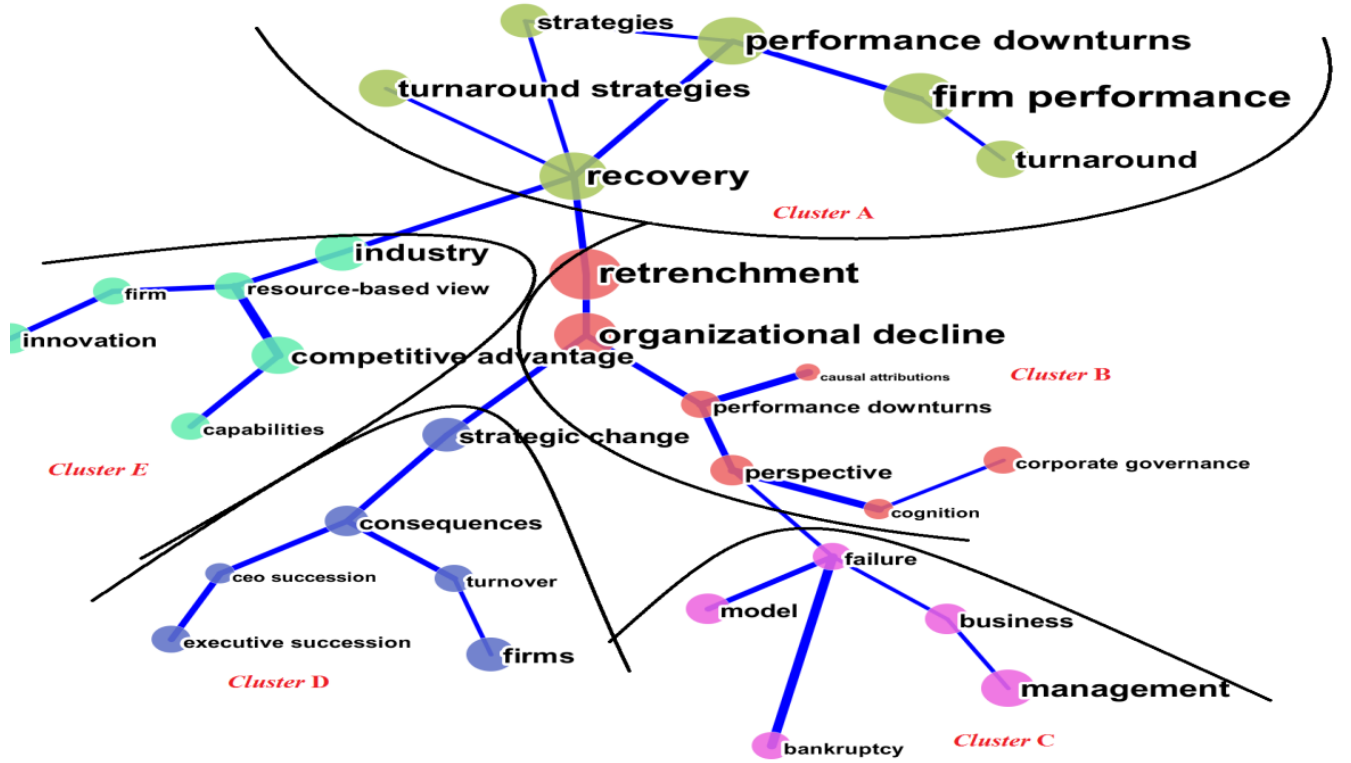

Figura 4 - Rede de cocitações de palavras-chave

Fonte: elaborado pelo autor com base em WOS

Como se pode observar na Figura 4, foram gerados cinco cluster de palavras-chave. Os agrupamentos representam palavras-chave que são citadas conjuntamente. As ligações entre palavras-chave de diferentes clusters significa que estes termos foram citados também conjuntamente por mais de um trabalho.

A presente rede foi gerada considerando somente os trinta trabalhos mais citados pela base de dados da $\operatorname{WOS}(\mathrm{N}=30)$ e foi utilizada uma técnica de ligação entre as cocitações que somente considera ligações muito fortes. Isso foi feito a fim de se identificar, de fato, somente os termos mais salientes entre os trabalhos, uma vez que o que se intenta é desenvolver algumas generalizações a respeito dos tópicos mais recorrentes na literatura.

Os termos mais centrais da rede são "organizational decline", "recovery" e "retrenchment" em ordem decrescente de centralidade conforme Tabela 1 abaixo. O que este resultado mostra é que o estudo do declínio organizacional, recuperação e fase de retrenchment, têm sido centrais na literatura sobre o turnaround de empresas. A rede gerada foi dividida em cinco agrupamentos. É possível notar que o primeiro (A) é formado por outros temas além da recuperação que remetem ao processo de turnaround e estratégias de recuperação. No cluster 
B, dois termos principais são bastante salientes. O termo "retrenchment" em primeiro lugar e o termo "declínio organizacional" (organizational decline) em segundo, termo esse que é também o de maior centralidade (ver Tabela 1). É importante mencionar que o termo retrenchment surge como um elo entre o cluster A e B. Isto pode indicar que há uma parcela de trabalhos que tratam de estratégias de recuperação e que abordam o papel do retrenchment mas, outros trabalhos focam no declínio das organizações e também tratam de retrenchment. Neste segundo caso possivelmente há uma abordagem do retrenchment como uma estratégia para interromper o declínio, como sugerido por Robbins e Pearce II (1992). Ainda no cluster B, observam-se os termos "atribuição causal" (causal attributions) e "cognição" (cognition). Assim, pressupõe-se que os trabalhos sobre declínio organizacional trazem abordagens sobre o impacto da cognição dos gestores na relação do declínio com suas causas e estratégias corretas de recuperação. Barker III e Patterson (1996) avaliam, por exemplo, a diferença de atribuição causal (declínio causado por erros internos versus declínio causado por fatores de mercado) entre empresas que trocaram o time de alta gestão para o processo de turnaround e empresas que mantiveram a equipe.

O cluster C aponta para trabalhos que tratam de modelos de predição de falência ("model"; "failure"; "bankrupcty") como, por exemplo, o trabalho de Altman (1968; 1983) que desenvolve modelos financeiros de predição de falência a partir dos dados financeiros das empresas. No entanto, o termo mais citado foi "gestão" (management), o que não permite alguma conclusão. Foi visto que o cluster A indicava a existência de um grupo de trabalhos ligados à estratégia de recuperação. $\mathrm{O}$ mesmo pode ser observado no cluster $\mathrm{D}$, mas neste último caso há maior especificidade, dado que o agrupamento é composto por termos como "mudança estratégica" (strategic change), "rotatividade da mão de obra" (turnover), e "sucessão da alta gestão" (ceo succession e executive successtion). Assim, observa-se que há um foco mais claro de respostas ao declínio com ações denominadas estratégicas e associadas à troca da alta gestão.

Por fim, o cluster $\mathrm{E}$ traz termos que claramente estão relacionados à estratégia competitiva. Termos como "indústria" (industry), "teoria baseada em recursos" (resource based view), "capacidades" (dynamics capabilities) e "vantagem competitiva" (competitive advantage), compõem este agrupamento e indicam a existência de trabalhos que são suportados por conceitos de estratégia competitiva para explicar a recuperação (recovery). 
Tabela 1 - Frequência e centralidade das palavras-chave mais utilizadas

Tabela 1 - Frequência e centralidade das palavras-chave mais utilizadas
\begin{tabular}{|l|c|c|}
\hline \multicolumn{1}{|c|}{ Palavra-Chave } & Frequência & Centralidade \\
\hline firm performance & $23\left(1^{\circ}\right)$ & 0.14 \\
\hline retrenchment & $20\left(2^{\circ}\right)$ & $1.00\left(3^{\circ}\right)$ \\
\hline performance downturns & $17\left(3^{\circ}\right)$ & 0.27 \\
\hline recovery & $17\left(3^{\circ}\right)$ & $1.14\left(2^{\circ}\right)$ \\
\hline organizational decline & $15\left(4^{\circ}\right)$ & $1.32\left(1^{\circ}\right)$ \\
\hline turnaround & 10 & 0.00 \\
\hline turnaround strategies & 10 & 0.00 \\
\hline management & 10 & 0.00 \\
\hline industry & 10 & 0.59 \\
\hline competitive advantage & 9 & 0.14 \\
\hline strategies & 8 & 0 \\
\hline firms & 8 & 0 \\
\hline strategic change & 7 & 0.59 \\
\hline
\end{tabular}

Fonte: elaborado pelo autor com base em Web of Science.

A partir da avaliação da rede de palavras-chave, frequência e centralidade dos principais termos utilizados pela base teórica sobre a qual os trabalhos de turnaround se fundamentaram é possível propor que os trabalhos têm quatro pilares fundamentais: 1) trabalhos sobre o declínio das organizações e predição de falência; 2) trabalhos sobre estratégias de recuperação e retrenchment; 3) trabalhos sobre estratégia competitiva; 4) trabalhos sobre o papel da alta gestão e atribuição causal. A proposição da existência destes quatro pilares será explorada a seguir.

\subsubsection{Base intelectual em turnaround de empresas}

Com o objetivo de compreender a base intelectual do turnaround de empresas - principais trabalhos e autores -, foi gerada uma rede de cocitação de trabalhos e seus respectivos clusters delimitados (Figura 5). Esta rede aproxima pares de autores que são citados frequentemente juntos, pelas pesquisas sobre turnaround indexadas à WOS. 


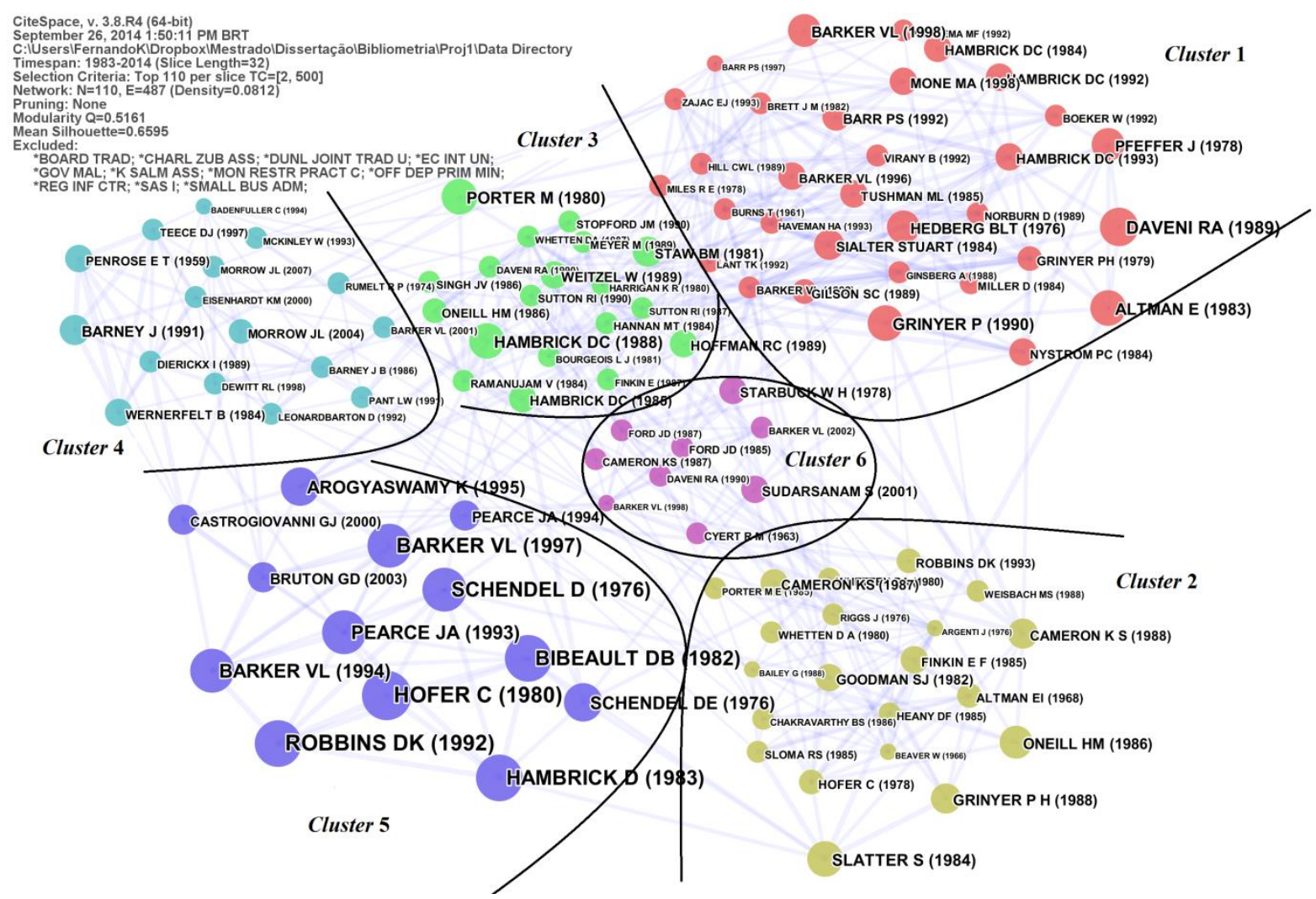

Figura 5 - Rede de Cocitações de Trabalhos

Fonte: Elaborado pelo autor com base em Web of Science

Como é possível observar na Figura 5, a rede de cocitação gerada pode ser dividida em seis clusters (C1 a C6). De maneira geral a rede não apresenta modularidade elevada, foi obtido um valor de modularidade de 0,51 (Q=0,5161), o que indica que a separação entre os agrupamentos não é forte, mas também não é fraca. $\mathrm{O}$ valor de modularidade corrobora com a impressão visual de que não há clara separação entre os clusters, os quais estão bastante interligados. Na Figura 5, vemos que os autores estão interligados com seus pares dentro de seu cluster, mas também se conectam com os autores dos outros clusters de maneira bastante frequente (linhas cinza claro) ${ }^{9}$.

O valor de silhueta estima a incerteza com relação à identificação da natureza de um cluster e varia de -1 a 1 (Chen, Ibekwe-sanjuan e Hou, 2010). Assim, a baixa silhueta revela elevada incerteza para que se consiga identificar a natureza daquele grupo, ou seja, os agrupamentos não são homogêneos. Na rede gerada, a silhueta média é de 0,65 (Mean Silhouette $=0,6595$ ). Chen et al. (2010) defende que a nomeação dos clusters é mais adequada quando o

${ }^{9}$ É possível observar as linhas cinza claro em transparência ligando os autores que foram citados conjuntamente. A despeito do esforço de separar os clusters manualmente, ainda assim é possível verificar que eles estão bastante conectados não sendo possível inferir qualquer tipo de conclusão a respeito da existência de grupos isolados ou mesmo de autores que fazer a "ponte" entre autores que tratam de abordagens distintas. 
agrupamento apresenta silhueta a partir de 0,7. Assim, qualquer tentativa de nomear os clusters terá resultados tão significativos quanto o valor da silhueta.

A seguir, no Quadro 2, serão exploradas as características gerais de cada cluster. Os rótulos gerados pela técnica $\mathrm{tf}^{*} \mathrm{idf}$ (term frequency-inverse document frequency) tendem a representar o aspecto mais saliente de um cluster enquanto as técnicas LLR (log-likelihood ratio) e MI (mutual information) tendem a evidenciar aspectos únicos de cada cluster (Chen, Ibekwe-sanjuan e Hou, 2010). Os rótulos são gerados pela análise dos documentos que citam os artigos que compõem a rede (citing papers to the cluster). A "meia vida" dos trabalhos está relacionada ao tempo que uma determinada literatura leva para alcançar metade de todas as citações. É esperado que a literatura "clássica" sobre um tema apresente uma meia vida mais longa que a literatura considerada "efêmera" (Bruton e Kebler, 1960), isto por que, a literatura com meia vida curta, representa uma área do conhecimento que teve um pico de atividades (citações) no início de seus trabalhos e logo deixou de estar em evidência. Ou então se refere a um campo de pesquisa bastante novo e compõe o "front de conhecimento" sobre um tema. 


\begin{tabular}{|c|c|c|c|c|c|c|c|c|c|}
\hline Cluster & Tamanho & $S^{10}$ & $\begin{array}{l}\text { Idade } \\
\text { Média }\end{array}$ & $\underset{11}{\text { MVM }}$ & $\begin{array}{l}\text { Citações } \\
\text { média }\end{array}$ & Rótulo (TFIDF) ${ }^{12}$ & Rótulo (LLR) ${ }^{13}$ & $\begin{array}{l}\text { Rótulo } \\
(\mathrm{MI})^{14}\end{array}$ & Principal trabalho \\
\hline $\mathrm{C} 1$ & 32 & 0.626 & 1987 & 13,68 & 7 & $\begin{array}{c}\text { (1.69) strategic reorientation; } \\
\text { (1.69) attempting turnaround; } \\
\text { (1.31) top management team } \\
\text { replacement; }(1.31) \\
\text { organizational cause; }(1.31) \\
\text { strategic consequence }\end{array}$ & $\begin{array}{c}\text { top management team } \\
\text { replacement }(158.01,1.0 E- \\
\text { 4); organizational cause } \\
(158.01,1.0 E-4) ; \text { strategic } \\
\text { consequence }(158.01,1.0 E- \\
4) ;\end{array}$ & $\begin{array}{l}\text { Declining } \\
\quad \text { Firm }\end{array}$ & $\begin{array}{l}\text { The aftermath of organizational } \\
\text { decline: a longitudinal study of } \\
\text { the strategic and managerial } \\
\text { characteristics of declining firms. } \\
\text { (Daveni, 1989) }\end{array}$ \\
\hline $\mathrm{C} 2$ & 21 & 0.633 & 1982 & 13,95 & 6,23 & $\begin{array}{l}\text { (5.48) entrepreneurial } \\
\text { retrenchment; }(3.2) \\
\text { turnaround strategies; }(3.2) \\
\text { empirical analysis; }\end{array}$ & $\begin{array}{c}\text { turnaround strategies } \\
(76.51,1.0 E-4) ; \text { empirical } \\
\text { analysis }(76.51,1.0 E-4) ; \\
\text { corporate financial distress } \\
(76.51,1.0 E-4) ;\end{array}$ & $\begin{array}{l}\text { Entre- } \\
\text { preneurial } \\
\text { Recoverys } \\
\text { Strategies }\end{array}$ & $\begin{array}{c}\text { Corporate Recovery: Successful } \\
\text { Turnaround Strategies and their } \\
\text { Implementation } \\
\text { (Slatter, 1984) }\end{array}$ \\
\hline $\mathrm{C} 3$ & 19 & 0.579 & 1985 & 11,3 & 6,36 & $\begin{array}{l}\text { (5.48) turnaround process; } \\
\text { (4.42) upper echelon; }(4.42) \\
\text { board characteristic; }(4.42) \\
\text { nonturnaround declining } \\
\text { firm; }(4.42) \text { strategic change }\end{array}$ & $\begin{array}{c}\text { turnaround }(29.16,1.0 E- \\
\text { 4); upper echelon }(19.44, \\
\text { 1.0E-4); board } \\
\text { characteristic }(19.44,1.0 E- \\
4) ;\end{array}$ & Theory & $\begin{array}{l}\text { Competitive strategy: techniques } \\
\text { for analyzing industries and } \\
\text { competitors (Porter, 1980) }\end{array}$ \\
\hline $\mathrm{C} 4$ & 16 & 0.626 & 1991 & 17,62 & 4,93 & $\begin{array}{l}\text { (5.59) lesson; (4.42) nokia; } \\
\text { (4.42) strategic management; }\end{array}$ & $\begin{array}{l}\text { wrong lesson }(73.44,1.0 E- \\
\text { 4); history }(73.44,1.0 E-4) ; \\
\text { business turnaround (26.8, } \\
\text { 1.0E-4); }\end{array}$ & $\begin{array}{l}\text { Absorptive } \\
\text { Capacity }\end{array}$ & $\begin{array}{c}\text { Firm resources and sustained } \\
\text { competitive advantage (Barney, } \\
\text { 1991) }\end{array}$ \\
\hline $\mathrm{C} 5$ & 13 & 0.764 & 1989 & 15,46 & 23,38 & $\begin{array}{c}\text { (0.52) top management team } \\
\text { replacement; }(0.52) \\
\text { organizational cause } ;(0.52) \\
\text { strategic consequence; }(0.52) \\
\text { extent; }(0.52) \text { turnaround } \\
\text { attempt }\end{array}$ & $\begin{array}{l}\text { following acquisition } \\
\quad(51.24,1.0 E-4) ; \\
\text { retrenchment }(51.24,1.0 E- \\
\text { 4); role }(44.92,1.0 E-4) ;\end{array}$ & Hong Kong & $\begin{array}{l}\text { Turnaround strategies } \\
\quad \text { (Hofer, 1980) }\end{array}$ \\
\hline C6 & 9 & 0.728 & 1987 & 18,7 & 5,1 & $\begin{array}{c}\text { (2.39) personality; (2.39) } \\
\text { perception; (2.39) response; } \\
\text { (2.39) retrenchment decision; } \\
\text { (2.39) decision-making study }\end{array}$ & $\begin{array}{c}\text { manager }(32.41,1.0 E-4) ; \\
\text { personality }(32.41,1.0 E- \\
4) ; \text { perception }(32.41 \\
1.0 E-4) ;\end{array}$ & Manager & $\begin{array}{c}\text { Responding to crises } \\
\text { (Starbuck, Greve e Hedberg, } \\
\text { 1978) }\end{array}$ \\
\hline
\end{tabular}

Fonte: elaborado pelo autor com base em Web of Science

Quadro 2 - - Sumário dos 6 clusters

\footnotetext{
${ }^{10}$ Silhueta: diz respeito à homogeneidade interna do cluster

${ }^{11}$ Meia Vida Média (MVM): período em que ocorrem 50\% das citações dos autores do cluster.

${ }^{12}$ Rotulo gerado pela técnica "term frequency-inverse document frequency" que representa os termos mais salientes do cluster

${ }^{13}$ Rótulo gerado pela técnica "log-likelihood ratio" que capta os aspectos que mais diferenciam o cluster

${ }^{14}$ Rótulo gerado pela técnica "mutual information" que capta os aspectos que mais diferenciam o cluster
} 
O tamanho do cluster indica o número de autores que são citados conjuntamente (cocitados) e como pode ser observado no Quadro 2, o cluster 1 é o maior, formado por 32 autores. Os clusters apresentados no quadro estão em ordem decrescente em número de membros e, assim, o cluster 6 é o menor com 9 membros seguindo pelo cluster 5 com 13 membros. Os menores clusters apresentam por sua vez a maior silhueta, o que indica que são os mais homogêneos.

A silhueta de 0.764 e 0.728 para os clusters 4 e 5 (C5 e C6), respectivamente, estão dentro do ideal para qualificar agrupamentos. Os outros clusters não tem a mesma homogeneidade do C5 e C6, sendo que o cluster 3 é o menos homogêneo (silhueta igual a 0.579) e, portanto, os autores deste agrupamento devem ter semelhança menos saliente entre si. Os demais clusters apresentam silhueta inferior ao ideal de 0,7, mas superior a 0.6. O cluster 2 é formado pelos autores mais antigos e o ano médio das citações é 1982, enquanto o cluster 4 é o mais novo com idade média de citações o ano de 1991. Assim, espera-se que este último agrupamento apresente mais consolidação, trabalhos empíricos e proposição de teorias do que o cluster 2 .

A meia vida do cluster indica o tempo médio que os membros do agrupamento levaram para alcançar metade das citações acumuladas ao longo de sua vida. Quanto maior a meia vida de um cluster mais tempo aquele agrupamento influenciou o corpo teórico. O cluster 6 apresentou a maior meia vida média e portanto foi o mais influente ao longo do tempo, seguido pelo cluster 4 e 5, respectivamente. O cluster mais efêmero é o 3, com meia vida média de 11,3 anos. O cluster 5, além de ser o mais homogêneo e ter sido o terceiro mais influente ao longo do tempo, apresenta o maior número de citações com média de 23,38 (3,3 vezes superior à segunda maior média encontrada no cluster 1).

O Quadro 2 traz ainda o rótulo dos clusters segundo três técnicas diferentes utilizadas pelo software. Como pode ser observado, o cluster 1 está associado à reorientação estratégica (strategic reorientation), troca da alta gestão (top management team replacement) e declínio (declining firms). Portanto, os trabalhos deste agrupamento estão relacionados às estratégias de recuperação que passam pela troca da alta gestão da firma e também devem focar a atenção para as causas e consequências do declínio. O trabalho mais citado do cluster é sobre declínio. como pode ser interpretado a partir do título. O cluster 2 é caracterizado por rótulos que estão relacionado às estratégias de recuperação baseada em estratégias empreendedoras (entrepeneurial) de cerceamento de ativos e custos (retrenchment) e envolvem estudos 
empíricos (empirical analysis). O trabalho mais citado do cluster trata de estratégias de recuperação. A formação ou proposição de teorias (theory) é característica do cluster 3, que trata também do processo de turnaround como um todo (turnaround process) e o papel da alta liderança (board characteristic e upper echelon). Seu principal trabalho é uma obra clássica da organização industrial e trata de análise de indústrias e padrões de competição. $\mathrm{O}$ cluster 4 trata da capacidade das firmas em absorver conhecimento (absorptive capacity) como maneira de responder a mudanças do ambiente, gestão estratégica (strategic management) e também o papel de lições ruins (wrong lessons) e a história da empresa (history) no processo do turnaround. Seu principal trabalho é sobre a visão da teoria baseada em recursos para a estratégia competitiva. O cluster 5 assim como 3 trata de estratégias de recuperação (retrenchment e top management team replacement), mas também deve associalas às causas do declínio (organizational cause e strategic consequence). Seu principal trabalho trata de estratégias para recuperação. Por fim, o cluster 6, denota claramente preocupação com o papel do gestor (manager) na interpretação dos sinais de declínio (perception) e na tomada de decisão (response e decision making study) em processo de turnaround. O principal trabalho trata de resposta a crises.

Como pode ser observado pela análise do rótulo dos clusters, as abordagens aparentam ser diferentes. No entanto, chama a atenção a recorrência do tema da troca da alta gestão (top magagement team replacement), presente no cluster 1 e 5, e foco no alto escalão (upper echelon, board characteristic e manager), observado nos clusters 2 e 5 . O cerceamento de custos e ativos (retrenchment) também recebe atenção de diferentes clusters (1, 4 e 5). Com o objetivo de melhor compreender a abordagem de cada cluster, o Quadro 3 a seguir apresenta de maneira consolidada o tipo, a característica, os objetivos e os principais resultados dos dois trabalhos mais citados em cada um dos seis clusters. 


\begin{tabular}{|c|c|c|}
\hline Pesquisa & \multirow[b]{2}{*}{ Objetivos } & \multirow[b]{2}{*}{ Principais Conclusões ou Implicações } \\
\hline Tipo/Característica & & \\
\hline \multicolumn{3}{|c|}{ Cluster 1 - Declínio das organizações e predição de falência } \\
\hline \multicolumn{3}{|c|}{ Daveni (1989): The aftermath of organizational decline: a longitudinal study of the strategic and managerial characteristics of declining firms } \\
\hline$C, M / C$ & $\begin{array}{l}\text { O tema central de investigação deste artigo é o padrão de declínio das } \\
\text { organizações. O autor se propõe a compreender três questões } \\
\text { fundamentais sobre o declínio mensurado pelos recursos internos: a) } \\
\text { quais as consequências do declínio na gestão e na estratégia das } \\
\text { firmas; b) a relação entre os padrões de declínio e seu impacto no } \\
\text { tempo necessário para que as consequências surjam; c) os fatores que } \\
\text { afetam o momento em que a falência ocorre. }\end{array}$ & $\begin{array}{l}\text { Os autores observam a existência de três padrões de declínio (lento, } \\
\text { gradual e prolongado) e que as consequências do declínio surgem em } \\
\text { diferentes momentos em função do padrão. Conclui que a menor taxa de } \\
\text { fusões e aquisições pelas firmas pós-declínio indica uma condição de } \\
\text { paralisia estratégica e que as firmas empreendem açôes de } \\
\text { "enxugamento"- que podem ser notada pela maior taxa de liquidação e } \\
\text { desinvestimentos -, desbalanceamento entre as áreas da gestão com maior } \\
\text { número de pessoas na área financeira quando se compara o declínio } \\
\text { prolongado ao gradual. Na mesma comparação observou-se menor } \\
\text { número de colaboradores em P\&D, marketing e área de produção entre o } \\
\text { primeiro sobre o segundo o que evidencia maior concentração pelo CEO. } \\
\text { O trabalho conclui também que os padrões de declínio estão relacionados } \\
\text { com o tempo que a consequências levam a aparecer, tais como } \\
\text { desequilíbrio na gestão, ações relacionados à eficiência, efeitos de } \\
\text { centralização, e paralisia estratégica. Tudo isso refletindo em resposta } \\
\text { rígida frente à ameaça. Apesar de o trabalho sugerir que as ações } \\
\text { gerenciais são a fonte do turnaround, o autor argumenta que é preciso } \\
\text { reconhecer que as variáveis gerenciais não são sozinhas responsáveis por } \\
\text { ações estratégicas, barreiras à saída da indústria, por exemplo, pode } \\
\text { prender as firmas em situações que não podem escapar. }\end{array}$ \\
\hline \multicolumn{3}{|c|}{ Altman (1983): Corporate Financial Distress and Bankruptcy: Predict and Avoid Bankruptcy, Analyze and Invest in Distressed Debt } \\
\hline $\mathrm{M} / \mathrm{C}$ & $\begin{array}{c}\text { O livro de Altman faz uma extensa análise das estatísticas de falência } \\
\text { nos Estados Unidos e descreve as políticas de recuperação de } \\
\text { empresas, práticas de gestão e indicadores financeiros para a predição } \\
\text { de falência. }\end{array}$ & $\begin{array}{c}\text { Dentre os assuntos apresentados no livro, o que recebe maior atenção pela } \\
\text { literatura sobre turnaround é o indicador de predição de falência, } \\
\text { denominado Z-score. O índice foi desenvolvido a partir de dados da } \\
\text { indústria de manufatura e é representado da seguinte maneira: } \\
\mathrm{Z}=1,2^{*}(\text { capital de giro/ativos })+1,4 *(\text { lucros acumulados/ativos })+ \\
3,3 *(\text { EBIT/ativos })+0,6 * \text { (patrimônio líquido/passivo total })+ \\
1,0 * \text { (vendas/ativos). }\end{array}$ \\
\hline
\end{tabular}

Quadro 3 - Tipo e característica da pesquisa, objetivos e principais conclusões dos trabalhos mais significativos de cada cluster (continua) 


\begin{tabular}{|c|c|c|}
\hline Pesquisa & \multirow[b]{2}{*}{ Objetivos } & \multirow[b]{2}{*}{ Principais Conclusões ou Implicações } \\
\hline Tipo/Característica & & \\
\hline \multicolumn{3}{|c|}{ Cluster 2 - estratégias de recuperação, declínio e estratégia } \\
\hline \multicolumn{3}{|c|}{ Slatter (1984): Corporate recovery: successful turnaround strategies and their implementation } \\
\hline$E T / E$ & $\begin{array}{l}\text { O livro de Slatter é uma obra voltada a gestores e traz estratégias } \\
\text { genéricas de turnaround e sua implementação. O livro se baseia na } \\
\text { experiência do autor e avaliação da literatura existente sobre o tema e } \\
\text { fornece uma lista de questões e abordagens para o problema de } \\
\text { declínio das organizações (JOHNSON, 1986). O livro é dividido em } \\
\text { quatro partes, das quais três são teóricas em torno do conceito de } \\
\text { turnaround e a quarta parte traz uma discussão de casos de sucesso e } \\
\text { fracasso em turnaround. A primeira parte discute os fatores } \\
\text { determinantes do declínio e da recuperação. Na sequência Slatter } \\
\text { discute as estratégias para implementação das estratégias de } \\
\text { turnaround e a terceira parte apresenta o papel do Estado na } \\
\text { recuperação. }\end{array}$ & $\begin{array}{l}\text { O autor defende que a recuperação sustentável depende da vantagem } \\
\text { competitiva das firmas que pode ser alcançada em três esferas: a) } \\
\text { econômica, relacionada à vantagem em custos absolutos, relativos } \\
\text { (economias de escala) e diferenciação dos produtos; b) organizacional, } \\
\text { relacionada à expertise e qualidade da gestão e fatores políticos; c) legal, } \\
\text { que compreende situações do ambiente institucional que influencia o } \\
\text { desenvolvimento e competitividade das firmas. O autor apresenta o } \\
\text { processo de turnaround dividido em quatro etapas sequenciais, mas que } \\
\text { podem se sobrepor e com duração variável em função do tamanho da } \\
\text { firma e características da indústria: a) análise; b) emergência; c) mudança } \\
\text { estratégica; d) crescimento. A identificação das estratégias de turnaround } \\
\text { que devem ser utilizadas passa por uma verificação dos fatores que } \\
\text { levaram ao declínio. Assim o autor relaciona as onze "causas do declínio" } \\
\text { mais frequentes e que podem ser revertidas por dez estratégias genéricas } \\
\text { de turnaround. }\end{array}$ \\
\hline \multicolumn{3}{|c|}{ ONeill (1986): Turnaround and recovery: what strategy do you need? } \\
\hline $\mathrm{C}, \mathrm{R} / \mathrm{E}$ & $\begin{array}{c}\text { O autor compara casos de empresas que se recuperaram e outras que } \\
\text { não para desenvolver um modelo que aponta estratégias de } \\
\text { turnaround e quando cada estratégia é mais provável de ser bem } \\
\text { sucedida. O modelo combina o resultado dos casos com outros } \\
\text { modelos já apresentados na literatura. }\end{array}$ & $\begin{array}{l}\text { Analisando o caso de empresas que se recuperaram e outras que não, os } \\
\text { autores identificam grupos de sub-estratégias que depois serão } \\
\text { classificadas dentro de categorias de estratégias de turnaround. O modelo } \\
\text { apresentado se mostrou adequado para explicar os casos avaliados e o } \\
\text { autor fornece um "guia prático" sobre como avaliar indústrias. O trabalho } \\
\text { reúne alguns conceitos de estratégia em turnaround já abordados na } \\
\text { literatura com os fatores críticos de sucesso. Essa união faz o trabalho } \\
\text { inovador, pois permite avançar sobre a questão de, em que situação uma } \\
\text { determinada estratégia pode ser adequada ou não. }\end{array}$ \\
\hline
\end{tabular}

Quadro 3 - Tipo e característica da pesquisa, objetivos e principais conclusões dos trabalhos mais significativos de cada cluster (continuação) 


\begin{tabular}{|c|c|c|}
\hline Pesquisa & \multirow[b]{2}{*}{ Objetivos } & \multirow[b]{2}{*}{ Principais Conclusões ou Implicações } \\
\hline Tipo/Característica & & \\
\hline \multicolumn{3}{|c|}{ Cluster 3 - declínio e recuperação: análises empíricas } \\
\hline \multicolumn{3}{|c|}{ Porter (1980): Competitive strategy: techniques for analyzing industries and competitors } \\
\hline$E T / E$ & $\begin{array}{c}\text { Livro dedicado à analise da estrutura da indústria e à } \\
\text { vantagem competitiva das firmas. Não é abordado o processo } \\
\text { de turnaround, mas há um capítulo dedicado à vantagem } \\
\text { competitiva em indústrias em declínio (declínio absoluto em } \\
\text { unidades vendidas por um longo período). O capítulo não trata } \\
\text { por tanto de uma firma em declínio, mas sim do processo de } \\
\text { encolhimento pelo qual passa a indústria à qual a firma } \\
\text { pertence. }\end{array}$ & $\begin{array}{l}\text { O autor apresenta o modelo das cinco forças competitivas que é uma ferramenta } \\
\text { destinada a avaliar a estrutura da indústria e a competição entre as firmas. Em } \\
\text { função das forças competitivas das firmas três estratégias genéricas são } \\
\text { sugeridas: liderança em custo, diferenciação e foco. Para Porter as firmas } \\
\text { alcançam performance superior pelo seu posicionamento estratégico e portanto as } \\
\text { estratégias de posicionamento devem levar em conta o padrão de competição da } \\
\text { indústria. }\end{array}$ \\
\hline \multicolumn{3}{|c|}{ Hambrick;D’Aveni (1988): Large corporate failures as downward spirals } \\
\hline $\mathrm{ET}, \mathrm{M} / \mathrm{C}$ & $\begin{array}{l}\text { O estudo objetiva testar empiricamente quatro constructos } \\
\text { preditivos de falência para grandes empresas, o que segundo o } \\
\text { autor não foi devidamente atendido pela literatura, que traz } \\
\text { geralmente estudos em grandes empresas de cunho qualitativo } \\
\text { ou somente baseado em indicadores financeiros. O autor } \\
\text { pretende avançar sobre esta lacuna para explicar o que leva as } \\
\text { empresas a entrarem em uma espiral descendente. Para isso } \\
\text { com base em literaturas anteriores descreve características e } \\
\text { contexto da falência em grandes empresas e testa um modelo } \\
\text { LOGIT em uma amostra de empresas que passaram por } \\
\text { recuperação judicial. O embasamento teórico utilizado segue a } \\
\text { linha da escola de comportamento das organizações } \\
\text { (organizational behavior) }\end{array}$ & $\begin{array}{l}\text { O trabalho mostra que a fraqueza das empresas que vão a falência aparece muito } \\
\text { cedo (até } 10 \text { anos antes da falência) e por tanto todos os comportamentos } \\
\text { subsequentes podem ser compreendidos como causa e efeito do declínio (espiral } \\
\text { descendente). As grandes empresas tem um longo período de aviso antes de falir } \\
\text { e, portanto estratégias de turnaround podem ser utilizadas. Em geral observou-se } \\
\text { que as firmas sob condição de estresse tomam atitudes extremas e vacilantes ou } \\
\text { suspendem suas ações, o que suporta parcialmente a ideia de que as organizações } \\
\text { falem por assumir muito risco ou por inercia. Outro achado foi de que falsos } \\
\text { encorajamentos levam empresas à falência ora por um ambiente } \\
\text { momentaneamente próspero, orapor folga financeira suficiente para cobrir } \\
\text { obrigações. Por fim, o rápido declínio do ambiente pode ser a razão para a } \\
\text { falência. A partir dos resultados empíricos os autores derivam um modelo que } \\
\text { apresenta o declínio organizacional como uma espiral descendente dividida em } \\
\text { quatro fases ao longo de dez anos. }\end{array}$ \\
\hline
\end{tabular}

Quadro 3 - Tipo e característica da pesquisa, objetivos e principais conclusões dos trabalhos mais significativos de cada cluster (continuação) 


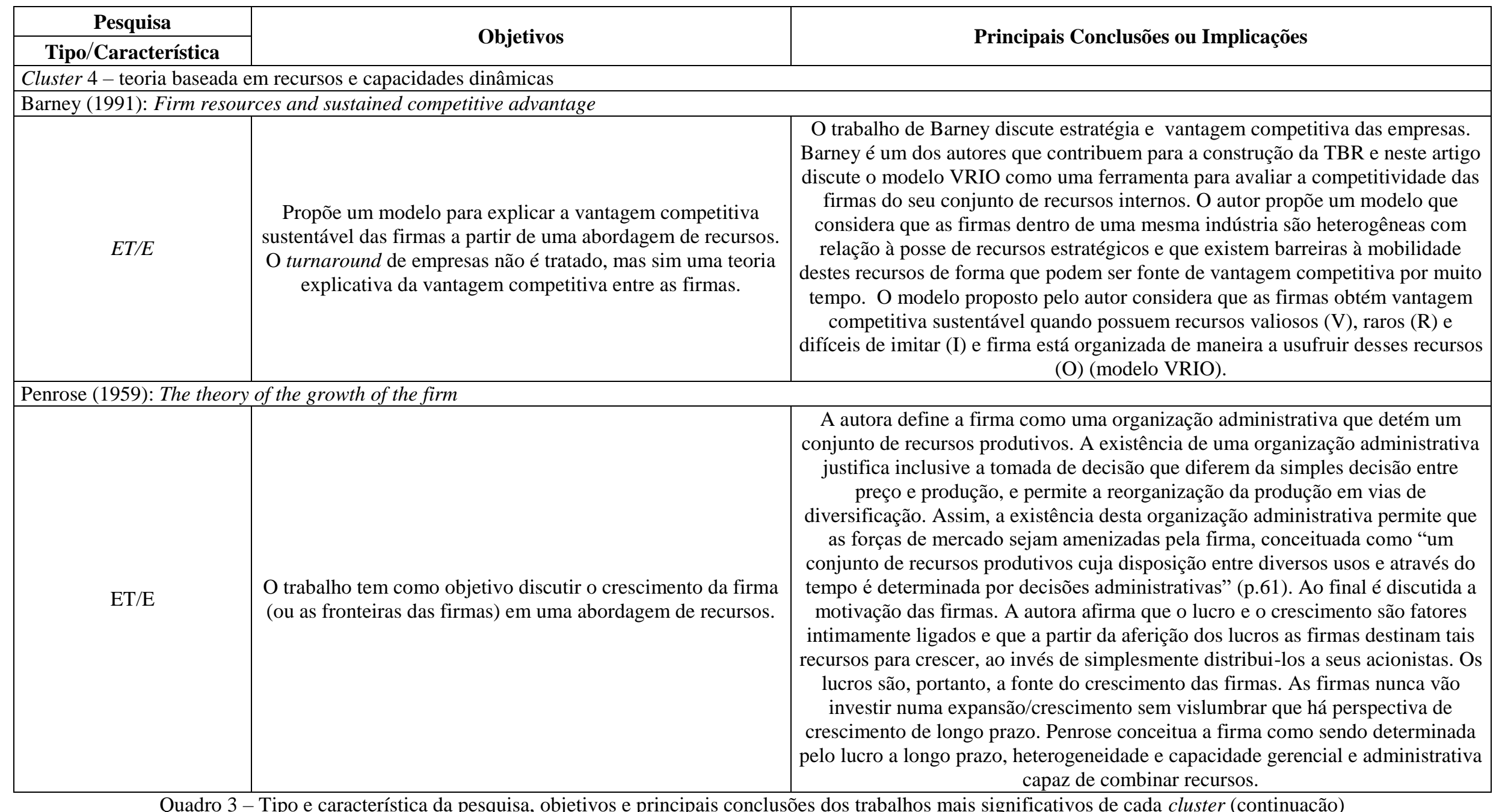

Quadro 3 - Tipo e característica da pesquisa, objetivos e principais conclusões dos trabalhos mais significativos de cada cluster (continuação) 


\begin{tabular}{|c|c|c|}
\hline $\begin{array}{c}\text { Pesquisa } \\
\text { Tipo/ Característica }\end{array}$ & Objetivos & Principais Conclusões ou Implicações \\
\hline \multicolumn{3}{|c|}{ Cluster 5 - estratégias de recuperação e retrenchment } \\
\hline \multicolumn{3}{|c|}{ Hofer (1980): Turnaround strategies } \\
\hline$C, E T / E$ & $\begin{array}{l}\text { Hofer (1980) desenvolve um modelo que busca ser preditivo } \\
\text { para desenhar as estratégias de turnaround em função da } \\
\text { natureza da situação de turnaround. O autor defende que a } \\
\text { estratégia de recuperação exige a avaliação da situação de } \\
\text { turnaround compreendida como a saúde operacional e saúde } \\
\text { estratégica das firmas. O autor testa seu modelo empiricamente } \\
\text { em } 12 \text { casos de } 10 \text { empresas em diferentes indústrias. }\end{array}$ & $\begin{array}{l}\text { Os resultados alcançados corroboraram com o modelo proposto. No geral os } \\
\text { resultados mostraram que } 10 \text { das } 12 \text { empresas avaliadas optaram por estratégias } \\
\text { de turnaround operacional e que } 4 \text { de } 6 \text { casos de fracasso em turnaround } \\
\text { ocorreu em empresas que optaram por turnaround operacional quando na } \\
\text { verdade era recomendado o estratégico. Quando era indicada a necessidade de } \\
\text { turnaround operacional e foi feito turnaround estratégico, o efeito não foi } \\
\text { negativo. As principais conclusões do autor são: a) erro em identificar } \\
\text { estratégias necessárias pode levar à falência; b) a condição pós turnaround } \\
\text { quando estratégias são erradas torna a situação menos atrativa e viável em } \\
\text { relação ao período anterior à tentativa de turnaround; c) antes de empreender } \\
\text { um turnaround estratégico é preciso verificar o estágio da indústria (evolução) } \\
\text { e sua estrutura competitiva. }\end{array}$ \\
\hline \multicolumn{3}{|c|}{ Robbins e Pearce (1992): Turnaround: retrenchment and recovery } \\
\hline $\mathrm{ET}, \mathrm{M} / \mathrm{C}$ & $\begin{array}{l}\text { O trabalho busca associar a causa e severidade do declínio com } \\
\text { a fase de "retrenchment", com a recuperação e a chance de } \\
\text { sucesso do trunaround. O trabalho é empírico e testa a hipótese } \\
\text { de que o retrenchment (fase entendida como o cerceamento de } \\
\text { custos e liquidação de ativos) seja um componente integral do } \\
\text { processo de turnaround e não uma ação isolada. O autor } \\
\text { pretende, com o trabalho, avançar na construção de uma teoria } \\
\text { geral do turnaround de empresas. O método utilizado pelo autor } \\
\text { merece destaque, pois mescla dados públicos com informações } \\
\text { primárias geradas a partir de entrevistas que somadas são } \\
\text { utilizadas para rodar modelos estatísticos. Outros trabalhos } \\
\text { geralmente tentam acessar somente dados disponíveis } \\
\text { publicamente, mas estes dados podem não ser capazes de } \\
\text { refletir as particularidades do processo de turnaround. }\end{array}$ & $\begin{array}{l}\text { A fase de retrenchment se mostrou importante, sobretudo para as firmas que } \\
\text { estavam em grave situação de turnaround e foi determinante na performance da } \\
\text { recuperação para firmas que atribuem a causa do declínio a fatores internos e } \\
\text { menos a fatores externos. O cerceamento de custos tem efeito profundo para ser } \\
\text { considerado indispensável. O sucesso do retrenchment está associado a custos } \\
\text { de estoque e despesa com juros. Quando corte de custos não é suficiente para } \\
\text { cobrir obrigações atuais, é preciso redução de ativos para ter sucesso no } \\
\text { turnaround. Procedimentos de redução de estoque, recebíveis, planta e } \\
\text { equipamentos foram usados para reduzir obrigações de longo prazo e despesas } \\
\text { com juros. O retrenchment de custos e ativos juntos resultaram na maior média } \\
\text { de performance do turnaround. O trabalho faz uma contribuição importante ao } \\
\text { operacionalizar a fase de retrenchment em duas ações distintas (custo e ativos) } \\
\text { e ao relacionar sua importância à gravidade da situação de turnaround medida } \\
\text { por um indicador de probabilidade de falência Z-Score (Altman, 1968). }\end{array}$ \\
\hline
\end{tabular}

Quadro 3 - Tipo e característica da pesquisa, objetivos e principais conclusões dos trabalhos mais significativos de cada cluster (continuação) 


\begin{tabular}{|c|c|c|}
\hline $\begin{array}{c}\text { Pesquisa } \\
\text { Tipo/ Característica }\end{array}$ & Objetivos & Principais Conclusões ou Implicações \\
\hline \multicolumn{3}{|c|}{ Cluster 6 - tomada de decisão/atribuição causal } \\
\hline \multicolumn{3}{|c|}{ Sudarsanam e Lai (2001): Corporate financial distress and turnaround strategies: an empirical analysis } \\
\hline$M / C$ & $\begin{array}{l}\text { O trabalho de Sudarsanam e Lai (2001) busca preencher uma } \\
\text { lacuna que os autores atribuem aos estudos passados sobre } \\
\text { turnaround. Os autores incluem Hofer (1980), principal autor do } \\
\text { cluster 5, na lista de trabalhos que trouxeram importantes } \\
\text { contribuições teóricas } 2 \text { mas que carecem de comprovações } \\
\text { empíricas. A partir de trabalhos anteriores que afirmam que as } \\
\text { espirais descendentes são causadas por inação da gerencia, } \\
\text { ausência de sincronismo, baixa intensidade e implementação de } \\
\text { estratégias pobres, os autores se propõem a fornecer evidencias } \\
\text { empíricas em larga escala e responder as seguintes questões: a) } \\
\text { após passar por dificuldade financeira, as firmas que se recuperam } \\
\text { adotam diferentes estratégias de turnaround quando comparadas } \\
\text { àquelas que continuaram em declínio?; b) há diferenças de } \\
\text { intensidade e sincronismo das estratégias entre os grupos que se } \\
\text { recuperam e os que continuam em decadência?; c) quais dessas } \\
\text { estratégias contribuem para o turnaround? }\end{array}$ & $\begin{array}{l}\text { Os autores testam a diferença de adoção de quatro ações de recuperação entre } \\
\text { as firmas que se recuperaram e as que não: a) reestruturação operacional; b) } \\
\text { de ativos; c) gerencial; e d) financeira. Os resultados mostram que a maior } \\
\text { proporção de firmas que não se recuperam tenta a estratégia de reestruturação } \\
\text { operacional, corte/omissão de dividendos e reestruturação de débitos. Além } \\
\text { disso, parecem empreender as ações mais intensivamente no caso operacional } \\
\text { e de dividendos. A maior diferença entre as firmas que se recuperam e as que } \\
\text { não, está no fato de a ineficiência da reestruturação das últimas nos primeiros } \\
\text { anos levar a uma intensificação das estratégias. No entanto, quando a } \\
\text { intensificação da reestruturação se acumula sobre os anos pós crise essas } \\
\text { estratégias acabam não contribuindo para a recuperação. As decisões das que } \\
\text { se recuperam diferem ao longo do tempo daquelas que não. As primeiras } \\
\text { fazem investimentos e aquisições que as tiram do declínio, enquanto as } \\
\text { últimas são focadas em ações mais internas, operacionais e de reestruturação } \\
\text { financeira. Isso sugere que as firmas que se recuperam são focadas no longo } \\
\text { prazo enquanto as que falem, focam em aspectos de mudança interna, com } \\
\text { efeito no curto prazo. }\end{array}$ \\
\hline \multicolumn{3}{|c|}{ Cyert e Marchal (1963): Behavioral theory of the firm } \\
\hline ET/E & $\begin{array}{l}\text { O trabalho dos autores visa compreender a tomada de decisão nas } \\
\text { organizações. Se os mercados determinassem por completo o } \\
\text { comportamento econômico das firmas, aspectos internos relativos } \\
\text { à tomada de decisão seriam irrelevantes. Assim, o livro visa } \\
\text { construir, a partir da contribuição de diversos autores, uma teoria } \\
\text { geral sobre a tomada de decisão das firmas. }\end{array}$ & $\begin{array}{l}\text { Dentre os autores que participaram do projeto do livro, Oliver E. Williamson, } \\
\text { reconhecido como um dos principais autores da escola de Economia dos } \\
\text { Custos de Transação apresenta um modelo do comportamento racional dos } \\
\text { gerentes. Compreendendo a firma como unidade de análise, os autores } \\
\text { esperam ter mostrado que os constructos ou modelos teóricos e avaliações } \\
\text { empíricas sobre o comportamento das firmas, permitem explicar a tomada de } \\
\text { decisão de organizações econômicas e que este é um caminho promissor para } \\
\text { a condução de trabalhos empíricos. }\end{array}$ \\
\hline
\end{tabular}

Quadro 3 - Tipo e característica da pesquisa, objetivos e principais conclusões dos trabalhos mais significativos de cada cluster (conclusão)

Legenda: Casos (C) Revisão de Literatura (R), Ensaio Teórico (ET), Modelagem métodos analíticos (M), Exploratória (E): é útil quando as questões de pesquisa são vagas ou quando há pouca teoria disponível para orientar as previsões. Descritiva (D): descreve alguma situação. Geralmente as coisas são descritas com a mensuração de um evento ou atividade (frequência, média, moda e desvio padrão). Causal (C): testa se um evento causa o outro. 
Como a análise qualitativa de dois trabalhos apresentados no Quadro 3 pode sofrer viés de seleção, isto é, eventualmente os dois trabalhos mais citados pouco tem em comum com os demais, optou-se por fazer a categorização dos dez trabalhos com o maior número de citações em cada cluster, de maneira que se possa melhor distingui-los. A categorização buscou separar aqueles trabalhos que eram empíricos dos que são teóricos. Mas, principalmente, buscou-se avaliar a abordagem de cada trabalho em cinco categorias conforme o objeto de estudo mais saliente. O Quadro 4 abaixo apresenta a frequência observada do tipo de pesquisa e abordagem utilizada pelos dez trabalhos mais citados de cada cluster e a porcentagem do total de citações do cluster que estes dez trabalhos representam (\% citações avaliadas).

\begin{tabular}{|c|c|c|c|c|c|c|c|c|}
\hline \multirow{2}{*}{\multicolumn{2}{|c|}{ Parâmetros }} & \multicolumn{6}{|c|}{ Cluster } & \multirow{4}{*}{$\begin{array}{c}\begin{array}{c}\% \\
\text { total }\end{array} \\
48 \% \\
52 \%\end{array}$} \\
\hline & & \multirow{3}{*}{\begin{tabular}{|c|} 
C1 \\
$55 \%$ \\
$45 \%$ \\
\end{tabular}} & \multirow{3}{*}{$\begin{array}{c}\text { C2 } \\
45 \% \\
55 \% \\
\end{array}$} & \multirow{3}{*}{$\begin{array}{c}\mathbf{C 3} \\
55 \% \\
45 \% \\
\end{array}$} & \multirow{3}{*}{$\begin{array}{c}\text { C4 } \\
30 \% \\
70 \% \\
\end{array}$} & \multirow{3}{*}{$\begin{array}{c}\text { C5 } \\
60 \% \\
40 \% \\
\end{array}$} & \multirow{3}{*}{$\begin{array}{c}\text { C6 } \\
43 \% \\
57 \% \\
\end{array}$} & \\
\hline Tipo & Empírico & & & & & & & \\
\hline pesquisa & Teórico & & & & & & & \\
\hline \multirow{5}{*}{ Abordagem } & Declínio & $50 \%$ & $27 \%$ & $40 \%$ & $0 \%$ & $8 \%$ & $10 \%$ & $22 \%$ \\
\hline & Estratégia $^{15}$ & $0 \%$ & $18 \%$ & $10 \%$ & $83 \%$ & $0 \%$ & $0 \%$ & $19 \%$ \\
\hline & Retrenchment & $0 \%$ & $9 \%$ & $0 \%$ & $8 \%$ & $15 \%$ & $0 \%$ & $6 \%$ \\
\hline & Recuperação & $25 \%$ & $45 \%$ & $30 \%$ & $8 \%$ & $77 \%$ & $10 \%$ & $34 \%$ \\
\hline & $\begin{array}{c}\text { Atribuição } \\
\text { Causal }\end{array}$ & $25 \%$ & $0 \%$ & $20 \%$ & $0 \%$ & $0 \%$ & $80 \%$ & $19 \%$ \\
\hline \multicolumn{2}{|c|}{ \% citações avaliadas } & $50 \%$ & $68 \%$ & $65 \%$ & $71 \%$ & $90 \%$ & $100 \%$ & \\
\hline
\end{tabular}

Quadro 4 - Frequência do tipo de pesquisa e abordagem dos dez principais trabalhos de cada cluster Fonte: elaborado pelo autor

A análise do Quadro 2, Quadro 3 e Quadro 4 nos permite estabelecer mais claramente as diferenças ou semelhanças entre os seis clusters avaliados com o objetivo de qualificar a base teórica sobre o turnaround de empresas. Como antecipado pela análise do Quadro 2, o cluster 1 aborda dentre os principais trabalhos a questão do declínio das organizações e da predição de falência. Com pesquisas do tipo caso e modelagem, os autores buscam estabelecer relações causais e os modelos apresentados visam consolidar o conhecimento sobre o tema e direcionar para a construção de teorias. Outras abordagens recorrentes são a de relação entre declínio e estratégias de recuperação (25\%) e o aspecto da tomada de decisão dos gestores (25\%). A maioria dos trabalhos do C1 é empírica (55\%) conforme apresentado no Quadro 4.

\footnotetext{
${ }^{15}$ Abordagem relacionada à estratégia competitiva (OI, ECT, TBR ou CD)
} 
O cluster 2 traz entre os principais trabalhos duas pesquisas exploratórias a partir de revisão de literatura, ensaio teórico e avaliação de casos. Como visto, este cluster é o mais antigo e analisando-se os autores mais citados verifica-se a tentativa de construção de uma teoria sobre estratégias de recuperação de empresas, uma vez que os dois trabalhos apresentados fazem generalizações e buscam estabelecer relações entre causa, consequência e ações. A avaliação dos conteúdos dos principais trabalhos revelou que a abordagem predominante é sobre estratégias de recuperação, mas também os trabalhos abordam declínio, retrenchment e estratégia competitiva (

Quadro 4)

Como visto o cluster 3 é o mais efêmero e de menor silhueta. A análise de seus principais artigos não mostra de fato uma tendência. O principal trabalho é o livro de PORTER (1980) sobre estrutura de indústria e vantagem competitiva das firmas, portanto um trabalho exploratório, enquanto o segundo Hambrick e Daveni (1988) busca estabelecer relações causais da falência das organizações. Não é clara neste caso a semelhança entre esses trabalhos, uma vez que representam argumentos de estratégia distintos. Esse último trabalho tem como fundamentação teórica autores da escola de comportamento das organizações (organizational behavior) que, como visto, é uma abordagem diametralmente oposta à OI (Figura 1).

O cluster 4, apesar de apresentar silhueta abaixo de 0,7, se mostra bastante homogêneo pela análise qualitativa de seus principais autores. O agrupamento é formado pelos principais autores da Teoria Baseada em Recursos (TBR). Além de Barney (1991) e Penrose (1995), fazem parte do cluster outros importantes autores da TBR, tais como: Wernerfelt (1984), Teece et al.(1997) e Eisenhardt e Martin (2000). E também da perspectiva de capacidades dinâmicas (dynamic capabilities) pelo autor Dierickx e Coll (1989). Dentre os dezesseis trabalhos que compõem o cluster alguns não estão ligados à estratégia competitiva e, como observado no

Quadro 4, mais de $80 \%$ dos trabalhos tratam de estratégia competitiva.

Como visto, a maior homogeneidade foi observada no cluster 5 que também tem a maior média de citações por trabalho. Como pôde ser observado nas análises dos quadros (Quadro 2 e Quadro 3), os trabalhos principais buscam estabelecer a relação entre causa, consequência e estratégias de turnaround. Dentre os dois trabalhos avaliados no cluster 5, o primeiro é 
quantitativo causal e o segundo qualitativo exploratório. Ambos os trabalhos buscam à sua maneira uma definição mais completa do "processo" de turnaround. No primeiro, há a tentativa de qualificar as estratégias de turnaround entre estratégicas e operacionais bem como definir quando uma ou outra é necessária. No segundo, avalia-se o retrenchment e suas variações como ação necessária no processo de recuperação. Mais de 90\% dos trabalhos tratam de recuperação ou retrenchment (

Quadro 4).

Por fim, o cluster 6, que como visto, é o que permaneceu mais tempo sendo citado e que tem a segunda maior silhueta, traz entre os principais autores um trabalho empírico causal e outro teórico exploratório. O primeiro estabelece as diferenças de estratégias adotadas entre as firmas que se recuperam e as que falem e ainda aponta a relação causal entre a intensidade e momento das ações com sua eficiência na recuperação da performance. O segundo trata-se de um livro teórico que busca criar maior entendimento sobre o comportamento das firmas, em especial o comportamento de tomada de decisão dos gestores. Dentre todos os trabalhos que compõem o cluster $80 \%$ trata de atribuição causal e o papel do tomador de decisão no processo de turnaround (

Quadro 4).

A análise de clusters mostrou a existência de seis agrupamentos, sendo que um deles (C4) com a maior parte dos autores representantes TBR. Além disso, nos clusters 2 e 3 (C2 e C3) foi observada a presença de pelo menos um autor representante da OI (Porter 1980; 1985). A hipótese de que os trabalhos sobre o turnaround de empresas utilizam a base teórica das escolas de estratégia competitiva para desenvolver as estratégias de turnaround recebe algum suporte por estas evidências, mas será mais bem explorado na seção 3.4. O fato de o cluster 3 ter apresentado a menor meia vida média $(11,3)$ indica que este agrupamento foi mais efêmero em relação por exemplo ao cluster $4(17,62)$, isto é, influenciou por menos tempo o corpo teórico do turnaround de empresas. O principal trabalho do cluster 3 é de Michael Porter, ao passo que o principal trabalho do cluster 4 é de Jay Barney. O primeiro autor é ligado à OI e o segundo à TBR, e indica que a teoria de recursos tem influenciado por mais tempo os trabalhos sobre turnaround. Este achado está em linha com o argumento de RamosRodríguez e Ruíz-Navarro (2004), de que recentemente, a literatura sobre estratégia pende para o lado da TBR. No capítulo 3 a relação entre os trabalhos de turnaround e estratégia competitiva será explorado em maior profundidade. 
Os resultados permitem identificar a existência de diferentes bases sustentando os trabalhos sobre o turnaround de empresas. Os clusters 5 e 6 (C5 e C6), como visto no Quadro 2, são os mais homogêneos e pode-se concluir com mais assertividade acerca do conteúdo preponderante dos trabalhos a partir da análise qualitativa apresentada no Quadro 3. O C5 reúne autores que tratam do processo de turnaround, discute suas fases e como as mesmas se relacionam. É o cluster com o maior número de citações pela base original e isto denota que predomina o interesse em compreender o processo de turnaround, relação entre causa, consequências e estratégias de recuperação. Por sua vez, o C6 traz à tona os aspectos de tomada de decisão pelas firmas e encontra em Cyert e March (1963), forte base teórica sobre a complexidade da tomada de decisão nas firmas, as quais são vistas pelos autores como um organismo formado por "coalizões de indivíduos ou grupos" e que tem que tomar decisões com relação a preços, produção e alocação de recursos. A baixa homogeneidade dos clusters é um indicativo de que os autores citam trabalhos com diferentes abordagens. Se observarmos o trabalho de maior citação ponderada (número de citações*fator de impacto do periódico de publicação), observamos que o trabalho de Hambrick e Schecter (1983) cita um autor do C1, dois do C3 e três do C5.

No capítulo introdutório foi aventada a hipótese de que os trabalhos que tratam sobre o turnaround de empresas se valem de uma base teórica múltipla, isto é, trabalham o processo de recuperação de firmas decadentes sob diferentes perspectivas. Isto seria explicado pela diversidade de fatores que podem levar uma firma a uma condição de performance declinante.

Para verificar a existência de múltiplas abordagens pelos trabalhos sobre o tema, selecionouse $20 \%$ dos artigos (20 artigos) da base de dados da Web of Knowledge que representam $80 \%$ do total de citações e analisou-se a qual dos cinco clusters identificados pertenciam os autores citados por estes 20. Procedeu-se a classificação dos artigos do maior para o menor pelo indicador ponderado e selecionou-se os $20 \%$. Foi montada uma tabela de frequência para cada um dos vinte artigos indicando quantos autores de cada cluster o artigo citou. Uma maneira de se avaliar se os autores utilizam diferentes abordagens para tratar do tema do turnaround é verificar se há correlação entre a frequência de citação dos clusters. Assim, procedeu-se com a análise de correlação e os resultados são apresentados na Tabela 2. 
Tabela 2 - Matriz de correlação entre a frequência de citação dos clusters

\begin{tabular}{|c|c|c|c|c|c|c|}
\hline Cluster & $\mathrm{C} 1$ & $\mathrm{C} 2$ & $\mathrm{C} 3$ & $\mathrm{C} 4$ & $\mathrm{C} 5$ & C6 \\
\hline $\mathrm{C} 1$ & 1 & & & & & \\
\hline \multirow{2}{*}{$\mathrm{C} 2$} & $-0,0491$ & 1 & & & & \\
\hline & 0,8372 & & & & & \\
\hline \multirow{2}{*}{$\mathrm{C} 3$} & 0,3002 & 0,2009 & 1 & & & \\
\hline & 0,1984 & 0,3958 & & & & \\
\hline \multirow{2}{*}{$\mathrm{C} 4$} & 0,0064 & $-0,2649$ & 0,1092 & 1 & & \\
\hline & 0,9787 & 0,2591 & 0,6467 & & & \\
\hline \multirow{2}{*}{$\mathrm{C} 5$} & 0,2718 & $0,4207^{*}$ & $0,4252 *$ & 0,3375 & 1 & \\
\hline & 0,2463 & 0,0647 & 0,0617 & 0,1457 & & \\
\hline \multirow{2}{*}{ C6 } & 0,2971 & $-0,0997$ & $0,5517 * *$ & 0,1008 & 0,2007 & 1 \\
\hline & 0,2033 & 0,6758 & 0,0117 & 0,6725 & 0,3963 & \\
\hline
\end{tabular}

$* \mathrm{P}<10 \% ; * * \mathrm{p}<\overline{5 \%}$

Fonte: Elaborado pelo autor

Como pode ser observado na matriz de correlação apresentada na Tabela 2 acima, existe correlação de fraca a moderada entre os clusters 2 e 5 e 3 e 5 e moderada entre o cluster 3 e 6. Nos dois primeiros casos, a significância é de $10 \%$ e no terceiro, 5\%. A correlação entre os clusters indica que os autores que citam trabalhos do cluster 2 e 3 também citam trabalhos do cluster 5 e do cluster 6 (somente cluster 3). Apesar da correlação não ser forte nos três casos, os resultados indicam que os principais autores que compõem o "front de conhecimento" sobre o turnaround de empresas utilizam mais de um grupo de autores da "base intelectual".

Da análise realizada acima, observou-se cinco pilares que suportam as pesquisas em turnaround. Um pilar associado a escolas de estratégia competitiva, TBR, capacidades dinâmicas e OI e um segundo associado à teoria comportamental da firma para explicar a tomada de decisão. Um terceiro pilar composto por trabalhos com interesse na predição da falência e declínio das organizações. A busca por uma relação causal entre declínio, consequências e estratégias, dando a noção de um processo, é o foco do quarto pilar. E, por fim, compreender as ações de redução de custos e liquidação de ativos como fator determinante para a recuperação de empresas (retrenchment) é o quinto pilar.

Compreendida a base teórica sob a qual os trabalhos de turnaround de empresas têm evoluído, a seguir serão discutidas as principais abordagens dos trabalhos de turnaround no sentido de criar um entendimento sobre como e até que ponto a literatura avançou sobre o tema. 


\subsection{Front do conhecimento em turnaround}

A presente seção tem por objetivo discutir as principais questões abordadas pelos trabalhos que atualmente compõem o front do conhecimento sobre o turnaround e refletem os tópicos que surgiram no estudo bibliométrico, são eles: declínio organizacional: causas, padrões e predição de falência; recuperação de empresas: estratégias de turnaround e retrenchment; e atribuição causal: o papel da alta gestão. No decorrer da discussão sobre a evolução dos temas, serão derivadas recomendações para um modelo de turnaround de empresas, que refletem até onde a literatura avançou e quais suas recomendações acerca de como recuperar firmas em declínio.

\subsubsection{Declínio organizacional: causas, consequências, padrões e predição de falência}

O termo "declínio organizacional" é o que apresenta maior centralidade, como visto na Tabela 1. Dentre seus trabalhos mais clássicos estão os estudos de Altman (1968; 1983) relacionados à predição da falência das firmas. $\mathrm{O}$ autor desenvolve um indicador denominado Z-score, construído a partir de um banco de dados de empresas do Reino Unido e que prevê o risco de falência de uma empresa em função de aspectos da saúde financeira. O modelo se mostra bastante aceito entre os trabalhos sobre turnaround de empresas como um indicativo da proximidade da falência (Barker III e Duhaime, 1997; Barker III, Patterson e Mueller, 2001; Sudarsanam e Lai, 2001) ou de maneira semelhante como um indicativo da severidade da "situação de turnaround" (Pearce II e Robbins, 1993; Robbins e Pearce II, 1992). O indicador é adequado e restrito à avaliação de empresas com ações negociadas em bolsa, uma vez que se utiliza o valor das ações no mercado de capitais como uma de suas métricas.

A predição do risco de falência em função da saúde financeira mensurada pelo Z-score alcançou posição bastante consolidada entre os autores e com relação a isto nada mudou desde que os dois trabalhos foram publicados. O desenvolvimento de uma teoria sobre o turnaround de empresas, que explique como reverter e superar o declínio das firmas continua sendo no entanto, tema de muita discussão na literatura.

Os primeiros trabalhos sobre turnaround foram basicamente exploratórios, com avaliação de casos e tentativas de generalizações, como um primeiro passo para a construção de uma teoria 
sobre o declínio e recuperação de empresas. Schendel et al. (1976) desenvolveram um modelo que buscou a relação entre a situação de performance declinante e causas do declínio. Os autores, a partir da avaliação de casos, propuseram uma lista de ações estratégicas para os casos nos quais o declínio era resultado de estratégias ruins bem como uma lista de ações operacionais para alcançar o turnaround para o caso no qual o declínio foi causado por ineficiência operacional (Robbins e Pearce II, 1992). Hofer (1980) adota a mesma terminologia e define causas estratégicas como sendo o aumento da competição, queda da rentabilidade, elevação do valor dos salários, suprimento de matéria prima e dificuldades de gestão. Causas operacionais compreendem a redução de preços, recessão, greve e problemas de mão de obra e excesso de capacidade produtiva.

A distinção estratégica-operacional não foi completamente aceita pela literatura que buscou aprimorar o entendimento, uma vez que aquilo que parecia operacional para uma firma poderia ser estratégico para outra. O trabalho de Slatter (1984) apresentou onze fatores genéricos aos quais são atribuídos o declínio das organizações. São eles: má gestão; controles financeiros inadequados; competição; estrutura da organização onerosa; mudança no padrão da demanda; instabilidade de preços; pouco esforço em marketing; grandes projetos; aquisições; política financeira; e operação acima da capacidade de geração de caixa. Nesta abordagem o autor coloca aspectos de naturezas diversas como causas do declínio, isto é, causas que podem ser reconhecidas como internas, tais como, má gestão e política financeira, ou causas externas como mudança no padrão da demanda e instabilidade de preços. Trabalhos subsequentes apoiaram este entendimento das causas do declínio (Pearce II e Robbins, 1994; Robbins e Pearce II, 1992).

A preocupação com o entendimento das causas do declínio advém do fato de que as pesquisas sobre o turnaround buscam compreender quais estratégias devem ser adotadas por empresa em performance declinante e para isso se torna crucial estabelecer a relação causa-estratégia de recuperação. No entanto, Barker III e Duhaime (1997) criticam os trabalhos anteriores que não tomaram o devido cuidado na seleção da amostra de empresas avaliadas a fim de identificar as estratégias de turnaround e que de alguma maneira misturaram firmas com níveis distintos de necessidade por mudanças estratégicas. Um ramo de pesquisas surgiu propondo que o declínio das organizações pode ser tanto baseado em questões internas da firma quanto em aspectos do mercado (firm-based decline versus industry contraction-based decline) (BARKER III; DUHAIME, 1997 apud WHETTEN, 1987; CAMERON et al., 1988). 
Isto por que a necessidade de mudança estratégica para uma firma em declínio em uma indústria estável ou em crescimento, será muito superior à de uma firma com performance superior às suas concorrentes, mas que se encontra em uma indústria em contração. Assim, o declínio com base em questões internas da firma está associado à má adaptação às modificações do ambiente ao passo que o declínio derivado da contração do mercado atenta para sua capacidade de suportar o número inicial de firmas levando uma parte delas à deterioração de performance. Por isso o entendimento das causas do declínio como decorrentes de questões internas da firma ou de retração do mercado, se mostra mais adequado. Assim, dois aspectos importantes podem ser depreendidos da evolução dos trabalhos sobre o declínio organizacional: a severidade do declínio que define a probabilidade de recuperação; e as causas do declínio (internas versus retração do mercado) que são determinantes para o estabelecimento de ações de recuperação.

\section{Recomendação 1: Um modelo sobre o turnaround de empresas deve considerar as causas do declínio (aspectos internos ou mudanças do mercado) e severidade do declínio como fator moderador.}

A proposta de Altman $(1968 ; 1983)$ que define a probabilidade de falência, foi utilizada pela literatura como um indicador de severidade da situação de turnaround, mas exige informações que somente empresas com capital listado em bolsa possuem. Assim, uma maneira de avaliar a severidade do declínio e a performance durante e após o turnaround é utilizar o indicador de retorno sobre investimentos (ROI - return on investiments) (Barker III e Duhaime, 1997; Hambrick e Schecter, 1983; Morrow, Johnson e Busenitz, 2004; Robbins e Pearce II, 1992).

Além das pesquisas sobre severidade e causas do declínio um terceiro grupo de pesquisadores desenvolveu pesquisas e modelos para compreender o padrão de declínio das organizações e as suas consequências às firmas. Hambrick e Daveni (1988) definem o declínio das organizações como uma espiral descendente que pode durar mais de dez anos até que a falência ocorra. Dada esta característica do processo de declínio, causas e consequências se misturam uma vez que a consequência no início do declínio pode levar a mais declínio. A origem da decadência está na deficiência de recursos financeiros e na deterioração do retorno sobre o ativo empregado (lucro líquido/ativos), que levará a uma situação de tomadas de decisões extremas e inseguras. Se o ambiente não expressar muitas alterações e a firma 
encontrar um equilíbrio momentâneo com a disponibilidade de fluxo de caixa, isto dará falsos encorajamentos que posteriormente podem prejudicar ainda mais a situação caso haja um encolhimento do mercado e isto poderá levar a falência.

Daveni (1989) avalia o padrão de declínio das organizações mensurado pela alteração na "magnitude dos recursos internos", que considera os recursos financeiros e gerenciais das firmas. $\mathrm{O}$ autor se propõe a compreender três questões fundamentais sobre o declínio: a) quais as consequências do declínio na gestão e na estratégia das firmas; b) a relação entre os padrões de declínio e seu impacto no tempo necessário para que as consequências surjam; c) os fatores que afetam o momento em que a falência ocorre. Para tal, o autor avaliando o declínio de diversas organizações, constata a existência de três padrões distintos: repentino rápido colapso seguido de falência; gradual - declínio lento e incremental com falência imediatamente após o declínio atingir seu pior nível; prolongado - declínio pode ser repentino ou gradual e após isso a firma se mantem por muito tempo antes de falir. $\mathrm{O}$ autor concluiu que a menor taxa de fusões e aquisições pelas firmas pós-declínio indica uma condição de paralisia estratégica em relação às sobreviventes. Além disso, há um processo de redução de tamanho com liquidações e desinvestimentos, mas não necessariamente nos negócios onde tem pior desempenho, reforçando a ideia de paralisia estratégica. Observou-se também menor número de colaboradores em $\mathrm{P} \& \mathrm{D}$, marketing e área de produção e maior quantidade de colaboradores na área de finanças além de maior concentração pelo presidente. $\mathrm{O}$ trabalho conclui ainda que os padrões de declínio estão relacionados com o tempo que a consequências levam a aparecer, tais como desequilíbrio na gestão, ações relacionados à eficiência, efeitos de centralização, e paralisia estratégica. Tudo isso refletindo em resposta rígida frente à ameaça. Apesar de o trabalho sugerir que as ações gerenciais são a fonte do turnaround, o autor argumenta que é preciso reconhecer que as variáveis gerenciais não são sozinhas responsáveis por ações estratégicas, barreiras à saída da indústria, por exemplo, podem prender as firmas em situações difíceis de escapar. E ainda, os resultados mostraram que algumas firmas podem postergar ou até mesmo evitar a falência em situações em que o mercado é suficientemente abundante para acomodar uma firma deficiente em recursos.

Esta abordagem demonstra que o processo de declínio é dependente de alguma maneira dos sinais do ambiente externo e das reações que as empresas expressam. Esta visão é complementada por Arogyaswamy et al. (1995) citando Cameron et al. (1988) que diz que o declínio da performance das firmas ocorre quando estas se tornam mal adaptadas ao ambiente, 
quando o ambiente se torna hostil, ou ambos os fatores (fim-based decline e market contraction-based decline). Estas causas levarão à erosão do suporte de stakeholders, crescimento de ineficiências internas e deterioração do clima organizacional e do processo de tomada de decisão. Os autores propõem um modelo de recuperação de empresas que antes da definição das estratégias de recuperação passa por um processo de interrupção do declínio, por meio da reabilitação da confiança dos stakeholders, da eliminação de ineficiências e a estabilização do clima organizacional e do processo de tomada de decisão. Assim, considerando-se que o declínio é um processo que geralmente leva a um estágio de paralisia estratégica, independentemente de suas causas iniciais, o processo de turnaround deve propor ações de quebra inércia para interrupção do declínio.

Recomendação 2: Um modelo sobre o turnaround de empresas deve propor ações de quebra da inércia, com a reabilitação da confiança com stakeholders, eliminação de ineficiências, estabilização do clima interno e da tomada de decisão para interrupção do declínio.

Como visto, o declínio das organizações é um tópico que recebe abordagens distintas. Observa-se que o declínio pode ser considerado um processo (Hambrick e Daveni, 1988) com diferentes padrões e consequências (Daveni, 1989). As suas causas não são unânimes, mas é possível separá-las em: declínio em decorrência de estratégias equivocadas e má adaptação da firma ao ambiente e de outro lado, o declínio em decorrência de mudanças do mercado. Em aproximação simplificada o entendimento da literatura é de que o declínio pode ocorrer por forças do ambiente externo ou por problemas internos das firmas. Ademais, a severidade do declínio é um fator importante a ser considerado no desenho das estratégias de recuperação.

\subsubsection{Recuperação de empresas: estratégias de turnaround e retrenchment}

As ações de recuperação das firmas a partir de uma situação de performance decadente são sem dúvida o objeto de maior interesse deste estudo. A literatura sobre o tema buscou a compreensão do processo de turnaround e ainda estabelecer a relação entre as causas do declínio e as estratégias de recuperação e adiciona ainda fatores moderadores como a severidade do declínio, o papel da alta gestão, dos stakeholders (Hofer, 1980; Robbins e Pearce II, 1992; Trahms, Ndofor e Sirmon, 2013). Além disso, outra preocupação foiaprofundar o entendimento das estratégias de turnaround em si e com o retrenchment, ação 
conhecida como sendo o corte de custos ou liquidação de ativos (Hambrick e Schecter, 1983; Lim et al., 2013; Morrow, Johnson e Busenitz, 2004).

Em um dos primeiros trabalhos sobre estratégias de turnaround, Hofer (1980) adiciona à abordagem recuperação estratégica-operacional proposta por Schendel et al. (1976), a noção de severidade da "situação de turnaround". Este termo é bem compreendido pela literatura como sendo o momento em que a performance da firma depreciou-se ao ponto em que esforços de recuperação são necessários (Robbins e Pearce II, 1992). Firmas em situação de turnaround sustentam uma perda de recursos que levará à falência se não combatida (AROGYASWAMY et al., 1995). Em seu trabalho, Hofer (1980) além de desenvolver os tipos de estratégias de turnaround existentes, propõe que a natureza da situação de turnaround passe pela avaliação da saúde operacional e da saúde estratégica da organização. A firma opta por ações operacionais ou ações estratégica ou ainda uma combinação de ambas. A estratégia operacional foca em ações de redução de custos e geração de caixa com o objetivo de alcançar o ponto de equilíbrio, ao passo que a estratégica foca em recuperar posição competitiva, segmentação do mercado ou foco em nichos específicos. Esta mudança pode ser difícil segundo os autores, caso os competidores possuam recursos estratégicos superiores. Outra importante contribuição do trabalho foi a conceptualização da noção de que a redução de custos e liquidação de ativos (retrenchment) é uma ação dentro do processo de turnaround, contingenciada pela severidade da situação de turnaround. Este conceito será discutido mais adiante.

Hambrick e Schecter (1983) contestam essa dicotomia "estratégica-operacional" para as ações de recuperação. Os autores justificam que diferenciar o que é estratégico daquilo que é operacional pode ser confuso. Um exemplo é o caso de uma empresa que compra máquinas automatizadas e aprimora seus controles de custos. Esta ação pode facilmente ser compreendida como operacional, contudo, pode ser vista também como uma estratégia de liderança em custos como proposto por Porter (1980). Além disso, as estratégias defendidas por Hofer (1980) fogem à realidade de indústrias maduras. Assim os autores propõem que as ações podem ser compreendidas como empreendedoras que visam a geração de renda ou o foco em produtos ou mercados, ou ainda ações de eficiência com o corte de ativos e custos. Hambrick e Schecter (1983) foram os primeiros a testar empiricamente as proposições de Schendel et al. (1976) e Hofer (1980) e observaram que em indústrias maduras, as estratégias de turnaround que tiveram efeito foram a redução de custos e ativos, corte de linha de 
produtos, saída de mercados e estratégia incremental. Os cortes de custos e ativos foram utilizados por empresas com baixo nível de utilzação de capacidade instalada. O corte de produtos e mercados foi utilizado principalmente por empresas com alta taxa de utilização de capacidade instalada. A estratégia incremental foi adotada pelas empresas com elevada participação de mercado que empreenderam ações de geração de receita pela elevação de utlização de capacidade instalada e produtividade da mão de obra. Neste trabalho o autor não explorou no entanto a relação entre causas do declinio e estratégias.

Construindo sobre os trabalhos de Schendel et al. (1976), Hofer (1980) e Hambrick e Schecter (1983), a pesquisa de Oneill (1986) propõem um modelo com seis fatores contingenciais que determinam as quatro estratégias de turnaround possíveis: 1) gestão (nova liderança, redefinição do negócio, novo time gestor e motivação dos colaboradores); 2) cortes (redução de custos, controles financeiros e de despesas e substituição de filiais ruins); 3) crescimento (novos métodos de promoção de produtos, novos produtos, aquisições e novos mercados); 4) reestruturação (mudança na estrutura organizacional e novos métodos de produção). Os fatores contingenciais consideram: 5) a causa do declínio (administrativa, cíclica, competitiva ou política); 6) a posição competitiva (forte, média ou fraca), o ciclo de vida do produto (crescimento, maturidade ou declínio), a estrutura da indústria (concentrada ou fragmentada), o estágio da organização (três níveis) e o grupo estratégico dentro da indústria (estável ou dinâmico). Um exemplo citado é de uma empresa com forte posição competitiva mas que está em declínio, não precisa de ações de reestruturação, mas sim de melhorias na gestão e corte de custos. Oneill (1986), no entanto, não valida empiricamente o modelo proposto, mas revisa casos anteriores para sustentar as proposições. $\mathrm{O}$ autor elenca diversos fatores moderadores a fim de construir uma imagem completa da situação de turnaround, que permitirá o desenho das estratégias de recuperação para empresa em diferentes estágios, com diferentes posições competitivas, em indústrias com padrões de competição distintos.

Arogyaswamy et al. (1995) revisando trabalhos anteriores argumentam que as estratégias de turnaround podem ser definidas em termos de dois atributos: a necessidade de mudança estratégica e o impacto da contração ou expansão da indústria, geralmente envolvido na implantação das estratégias. Assim, a posição competitiva da firma e a causa do declínio são fatores moderadores para as estratégias de turnaround. A opção por estratégias incrementais deve ser a mais adequada em situações de turnaround causada pela contração da indústria quando a posição competitiva for forte. Considerando que em épocas de crise, os 
competidores com forte posição competitiva estão lutando por sobrevivência com estratégias incrementais, empresas com posição competitiva fraca devem reduzir seu escopo de atividades para as quais seus recursos e capacidades são melhor valorados.

\section{Recomendação 3: Um modelo sobre o turnaround de empresas deve considerar os fatores moderadores tais como causas do declínio e posição competitiva, para o desenho de estratégias de recuperação.}

Os fatores condicionantes propostos por Oneil (1986) são compreendidos como possíveis causas do declínio (isto é, a inadequação a parte deles) por Robbins e Pearce II (1992), as quais são divididas entre fatores internos e externos para os quais um conjunto de estratégias de manutenção de eficiência ou de expansão empreendedora, serão necessárias para o primeiro e segundo casos, respectivamente. Para os autores a severidade da situação de turnaround mensurada pelo indicador Z-Score, proposto por Altman (1968; 1983) é fator moderador para a necessidade e intensidade da ação de corte de custos ou liquidação de ativos, conhecido como retrenchment. Ao analisar casos de recuperação na indústria textil, os autores observaram que o retrenchmnet é menos comum em empresas que tem o declínio associado a fatores externos e firmas que executam o retrenchment tem perfomance de turnaround superior, assim aquelas cujo declínio estava associado a causas internas apresentaram melhor performance de recuperação em relação às demais. Observou-se que o retrenchent de custo foi associado ao sucesso e recuperação de empresas com diferentes níveis de severidade ao passo que o retrenchment de ativos somente se mostrou viável para níveis elevados de severidade. Os autores concluiram que as firmas devem executar retrenchment independente da situação de turnaround e que firmas próximas à falência devem complementar o corte de custos com liquidação de ativos.

Outra importante contribuição do trabalho de Robbins e Pearce II (1992), foi estabelecer a relação entre fases do processo de turnaround e fatores contingenciais. A partir dos resultados anteriores alcançados pelas pesquisas sobre turnaround, os autores propõem um modelo em duas fases: situação de turnaround e resposta de turnaround. A primeira composta por causas do declínio e severidade da situação. A segunda pela fase de retrenchment, estabilidade e recuperação. O modelo proposto é apresentado na Figura 6, a seguir. 


\begin{tabular}{|lr|rr|}
\hline \multicolumn{2}{|c|}{ Situação de turnaround } & \multicolumn{2}{c|}{ Repostas de turnaround } \\
Causa & Severidade & Fase de retrechment & Fase de recuperação \\
\hline
\end{tabular}

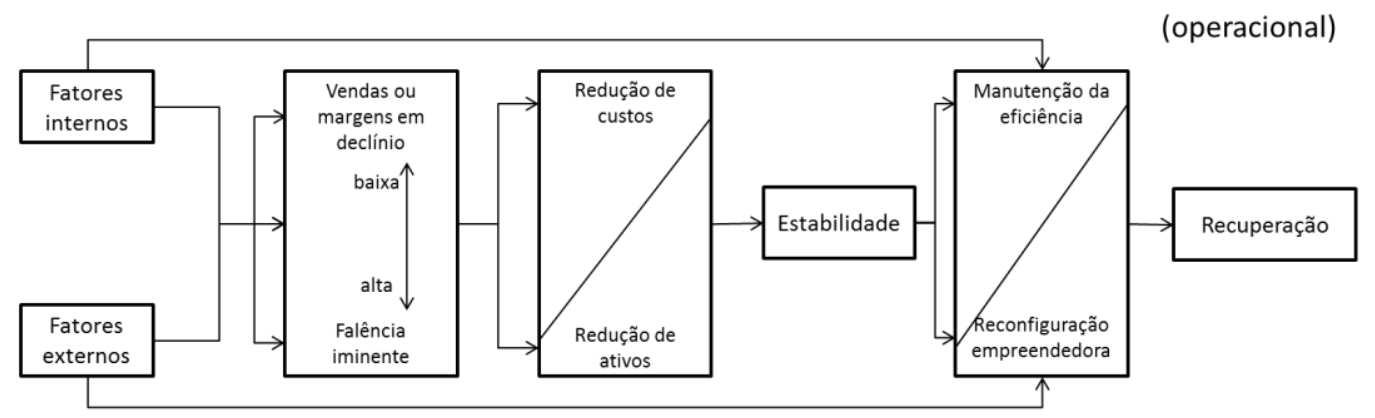

(estratégico)

Fonte: Robbins e Pearce II (1992)

Figura 6 - Um modelo do processo de turnaround

A contribuição do trabalho se deu principalmente na consolidação dos resultados esparsos apresentados até então por outros autores, em um modelo testável, o qual se mostrou válido nos testes empíricos realizados. Contudo o teste em uma única indústria gerou algum nível de viés nos resultados. Ainda assim, dessa abordagem depreende-se que ações de corte de custos e liquidação de ativos compreendida como retrenchment devem ser consideradas em um estágio inicial do processo de turnaround.

\section{Recomendação 4: Um modelo sobre o turnaround de empresas deve considerar ações de corte de custos e liquidação de ativos (retrenchment) em um primeiro estágio do processo de recuperação.}

Morrow et al. (2004) encontraram suporte estatístico para os resultados de trabalhos anteriores que apresentam o retrenchment como uma estratégia de recuperação (Hofer, 1980; ONeill, 1986; Pearce II e Robbins, 1993; Robbins e Pearce II, 1992; Schendel, Patton e Riggs, 1976a). No entanto, argumentando que em tais estudos anteriores a possibilidade de generalização é restrita, pois foram conduzidos em uma única indústria e com poucas empresas de maneira que desconsideraram a influência da dinâmica competitiva da indústria como um fator moderador do sucesso das ações de retrenchment. Assim, os autores propõem que as estratégias de retrenchment em uma indústria em declínio são diferentes das estratégias em uma indústria madura ou em expansão. Considerando que em indústrias nascentes ou em expansão, a dinâmica competitiva impõe a necessidade de inovação, marketing, desenvolvimento de novos produtos como forma de impor barreiras à entrada e reduzir a força 
dos concorrentes, os autores argumentam que a opção por corte de custos deverá ter um impacto negativo na vantagem competitiva da firma. No entanto, a opção pelo corte de ativos pode ser interessante, pois, em uma indústria em expansão, ativos prontamente disponíveis são valorizados pelo mercado. Em indústrias em declínio, nas quais existe um grande número de competidores e o nível de inovação é baixo, a opção por corte de custos será uma estratégia acertada, ao passo que a liquidação de ativos não, pois nessas indústrias o valor do ativo no mercado deve ser menor que o valor potencial de sua utilização pela firma em declínio.

Os autores testam as hipóteses com uma amostra de 412 firmas em indústrias em diferentes estágios de desenvolvimento, nos EUA. Os resultados alcançados além de corroborar com estudos anteriores que apontaram para as ações de redução de custos e ativos como estratégias de turnaround em indústrias maduras, observaram que em indústrias em declínio o corte de custos é uma estratégia que funciona, mas redução de ativos não, como havia sido previsto. No caso de indústrias em expansão, o resultado corroborou parcialmente com as hipóteses: a performance foi superior quando houve liquidação de ativos, provavelmente devido ao forte mercado de venda de ativos nessas indústrias, mas o corte de custos não teve relação negativa com a performance de turnaround como havia sido previsto (neste caso o resultado foi inconclusivo).

Argumentando que os estudos sobre o impacto do turnaround no desempenho da recuperação foram inconclusivos pois desconsideraram a causa do declínio, Ndofor et al. (2013) adiciona a causa do declínio como fator moderador para testar o impacto de ações operacionais (retrenchment de custos e ativos) e estratégicas (aquisições, alianças estratégias e lançamento de novos produtos) na performance do turnaround. Assim, a partir de um grupo de empresas performando abaixo da média em uma indústria de alta rentabilidade e em expansão, os autores testam a hipótese de que ações de retrenchment levarão à pior performance de turnaround ao passo que ações estratégicas levarão a uma performance de turnaround superior. Os autores consideram que ações de retrenchment são parte da estratégia de turnaround e não somente uma fase como proposto por Robbins e Pearce II (1992). A hipótese de que o retrenchment terá um efeito negativo na performance do turnaround é sustentada pelo argumento de que empresas em decadência em uma indústria em expansão, se encontram em tal situação em função de seu posicionamento estratégico fraco (causa do declínio) e a luta por eficiência não irá resolver o problema de estratégias mal adaptadas. Os resultados obtidos a partir da avaliação de uma amostra de empresas no setor de informática nos EUA corroborou com as hipóteses levantadas e fortaleceram a importância de se 
considerar fatores moderadores como a causa do declínio no desenho de estratégias de turnaround e ainda, que em indústrias de alta tecnologia, ações de eficiência não devem levar à performance superior na tentativa de turnaround.

Na mesma direção - compreender o papel de fatores moderadores no sucesso das estratégias de retrenchment-, Lim et. al. (2013) propõem um modelo no qual o mecanismo de geração de renda (recursos ou capacidades) é o principal fator moderador do sucesso do turnaround. Os autores suportam seu modelo na existência de duas fontes de geração de renda: a Ricardiana, associada à capacidade da firma em explorar recursos superiores que levam a firma a uma situação de custo médio inferior; e de outro lado a renda Schumpeteriana, alcançada pela ação de tomada de risco empreendedor, suportada por capacidades únicas, que permitem que a firma alcance valores superiores por seus produtos e serviços. Esta natureza de renda está geralmente associada a um ambiente dinâmico e confere às firmas a capacidade de se adaptar e inovar. Os autores testaram seus modelos com um grupo de 2406 empresas japonesas listadas na bolsa Nikkei e obtiveram suporte parcial para suas hipóteses. Firmas que tem natureza de renda schumpeteriana, mas que adotaram o corte de custos tiveram sua performance pós retrenchment inferior a seus pares. Esse efeito foi acentuado quando a indústria a qual a firma pertencia tinha padrão de competição tipicamente baseado na geração de renda Schumpeteriana. A hipótese sobre o impacto negativo do corte de ativos quando a natureza de geração de renda é Ricardiana não foi suportada pelos resultados. Os autores avaliam que a renda Ricardiana é baseada na busca seletiva de ativos no mercado de recursos estratégicos, mas também pela opção de não adquirir recursos não produtivos e que esta segunda alternativa pode explicar uma parte dos resultados não conclusivos.

As ações de redução de custos e de ativos denominadas retrenchment encontram duas abordagens pela literatura. Uma visão aponta a redução de custos e ativos como a estratégia de turnaorund (Lim et al., 2013; Ndofor, Vanevenhoven e Barker III, 2013) mas a outra defende que o retrenchment não é a restratégia de turnaround em si, mas uma condição que pode ser necessária para posterior condução de ações estratégicas e o foco (retrenchment de ativos ou de custos) dependerá da gravidade da situação de turnaround (Robbins e Pearce II, 1992). Então, parte da literatura mantém a redução de custos e ativos como uma ação de estratégia de recuperação ao passo que outra entende que se trata de uma fase anterior à fase de recuperação. De maneira geral os trabalhos apontam para fatores moderadores tal qual a característica da indústria, ciclo de vida dos produtos e natureza do mecanismo de geração de 
renda da firma, que definem em que circunstâncias uma estratégia de retrenchment deve ou não ser adotada. Mas como sugere Morrow et al. (2004), Lim et al. (2013) e Ndofor et al. (2013), o mecanismo de geração de renda é o aspecto mais importante uma vez que o ciclo de vida da indústria, produtos e tipo de indústria são fatores que não capturam a estratégia de geração de renda da firma.

\section{Recomendação 5: O retrenchment como ação integrante em um modelo de turnaround de empresas deve considerar o impacto do corte de custos e da liquidação de ativos na natureza de geração de renda da firma.}

\subsubsection{Atribuição causal: o papel da alta gestão}

Outro ponto que foi explorado por diversos autores é a importância ou necessidade de substituição da alta gestão, presidência e membros do conselho para se alcançar o sucesso do turnaround. Os trabalhos empíricos-exploratórios justificam que a troca da alta gestão se faz necessária dada as crenças que os líderes de uma empresa tem a respeito de como o negócio deve ser conduzido, mas que devem estar enganados vis à vis a situação em que a empresa se encontra e, a maneira de melhorar o entendimento da situação é trazer uma nova equipe de alta gestão (Hofer, 1980). A troca é razoável também pela perda de credibilidade do gestor que colocou a firma em situação decadente (ONeill, 1986). Além disso, os gestores atuais são menos motivados a empreender ações de turnaround em função de seu comprometimento com as estratégias anteriores e ao trocá-los pode ter um efeito positivo em mudanças de novas estratégias e sinalizações importantes para stakeholders externos (Cater e Schwab, 2008).

Como mencionado anteriormente, o trabalho de Arogyaswamy et al. (1995) propõe um modelo teórico de turnaround que passa por estratégias de interrupção de declínio e de recuperação. Os autores argumentam que firmas que alcançam o turnaround devem apresentar estratégias de interrupção do declínio que: a) renove o suporte dos principais stakeholders; b) eleve a eficiência; c) estabilize o clima interno e processo de tomada de decisão. Para tanto, a troca do presidente e da alta gestão elevam a efetividade das estratégias quando no caso de declínio baseado em fatores internos da firma, dado que a situação de performance declinante foi resultado da tomada de decisão dos atuais gestores. Nos casos em que o declínio teve sua origem atribuída ao mercado, a estabilidade do presidente e da alta gestão levará a maior sucesso, pois os custos de mudança são superiores aos benefícios 
gerados, salvo na hipótese de declínio prolongado e/ou fraca posição competitiva da firma que requerem mudanças estratégicas. O modelo, no entanto, carece de comprovação empírica.

Investigando empiricamente a relação entre o declínio e a troca da presidência e conselho, Daily e Dalton (1995) não encontraram diferença significativa na relação de turnover (porcentagem de membros trocados em relação ao total) das posições de presidência e do conselho, entre firmas que faliram e que não faliram, sugerindo que como defendido por outros estudos, o declínio é uma espiral descendente na qual as empresas tem dificuldade de mudar e sair, mesmo com a troca de gestores, não explica o sucesso ou fracasso do turnaround. No entanto, os autores não diferenciaram as firmas que declinaram por fatores internos ou por questões de mercado, como sugerido por Arogyaswamy et al. (1995).

Com o objetivo de compreender outras questões relacionadas à estrutura de decisão e diferenças entre empresas que se recuperaram e que não, em seu trabalho, Mueller e Barker (1997) avaliam empiricamente 33 pares de empresas (empresas que faliram versus empresas que se recuperaram) com o objetivo de identificar diferenças com relação à composição e tamanho do conselho, dualidade de funções do presidente (quando o presidente-executivo é também presidente do conselho), tamanho e mudança do time de alta gestão (Top Management Team - TMT). Os resultados indicaram que as firmas que conseguiram o turnaround tem maior probabilidade de ter seu presidente também como membro do conselho, o conselho tem tamanho mediano, e maior controle externo, como a presença de acionistas. A teoria da agência apregoa que o presidente da companhia não deve ser ao mesmo tempo presidente do conselho por conflitos de agência, por outro lado há uma visão que defende que esta situação é interessante no caso de empresas em situação de turnaround, pois confere uma liderança mais forte e unida e a existência de um presidente no conselho e outro na empresa pode gerar algum tipo de conflito sobre quem de fato é o tomador de decisão. A presença de externos no conselho pode ser explicada pela teoria de agência e teoria de recursos. No primeiro caso, os externos funcionam como monitores (principal) do CEO e demais diretores (agentes). Pela teoria de recursos, a presença de externos pode ser interessante, uma vez que estes têm capacidades de influenciar outras organizações à quais a firma pode ter alguma dependência de recursos. Mais especificamente os externos podem conferir legitimidade, habilidade de acesso a capital e outros recursos chave que afetam a sobrevivência da firma. Outro resultado encontrado foi de que ao final do processo de recuperação, as firmas apresentaram menor proporção do TMT em relação ao momento 
anterior ao declínio. Sugerindo que a recuperação é mais provável com a troca de pelo menos uma parte do TMT. A presença do presidente da empresa no conselho e a atuação de externos no conselho sugere que as empresas que se recuperam desenvolvem estruturas de tomada de decisão que são mais ágeis e influenciadas por perspectivas externas.

O objetivo por trás da troca do TMT está em promover a quebra da inércia causada pela permanência de um time cognitivamente enviesado e portanto incapaz de corretamente relacionar o declínio a causas internas, reduzindo a probabilidade de a firma empreender ações de mudança estratégica. Assim, o trabalho de Barker III e Patterson (1996) visa, a partir de dados de campo e estudos de caso, identificar as diferenças entre atribuição causal do declínio para TMT mais velhos e mais novos na empresa. Resgatando argumentos do campo da psicologia social e trabalhos sobre declínio organizacional e turnaround, os autores encontram sustentação empírica (ainda que não estatística), para a hipótese de que TMT mais jovens tendem a atribuir as causas do declínio a fatores internos, controláveis e estáveis e, portanto, há menor probabilidade de atribuírem o declínio à fatores de mercado. Além disso, o estudo mostrou que a chegada de novos gestores esteve associada a mudanças no entendimento dos problemas da firma, fortalecendo a hipótese de que a atribuição causal entre gestores mais novos e antigos tende a ser diferente. Além disso, o resultado coloca argumentos contrários a uma parte da literatura que defende que a substituição da alta gestão funciona como um ritual de sacrifício necessário, em que o TMT vira um bode expiatório somente para satisfazer parte os stakeholders e manter o emprego dos gestores com mais poder.

Barker III e Duhaime (1997) conduziram um trabalho para avaliar os efeitos da troca da TMT na mudança estratégica das firmas e encontraram suporte estatístico para justificar a substituição do presidente, uma vez que o nível de mudanças estratégicas em empresas que iniciaram o turnaround foi superior naquelas em que seu presidente havia sido substituído. Resultado semelhante foi encontrado por Barker III et al. (2001). Os autores investigaram fatores inerciais e forças de mudanças que influenciam a troca da alta gestão, que por sua vez tem relação com o nível de mudanças estratégicas. Os resultados de trabalho empírico com amostra de 154 empresas americanas mostraram que em firmas maiores e que tiveram maior período de implantação das estratégias pré-declínio, a troca da alta gestão tende a ser menos provável (força inercial), ao passo que o aumento de participantes externos no conselho se relacionou positivamente com mudanças no TMT (forças de mudança). Os autores haviam 
previsto que as firmas que entraram com pedido de recuperação teriam maior taxa de mudança da TMT (força de mudança), mas os resultados não corroboraram com esta hipótese. Por fim, níveis mais altos de substituição da TMT estiveram mais associados a mudanças nas estratégias de negócio e estrutura e controles internos. Portanto, deve-se considerar que a estratégia de quebra da inércia anunciada na recomendação 2, deve considerar a opção por troca da alta gestão (ainda que parcialmente) e aproximação de externos ao conselho (conselheiros não sócios).

\section{Recomendação 6: Um modelo de turnaround deve considerar a troca da alta gestão e participação de externos no conselho como estratégia para interrupção do declínio e tomada de ação para recuperação.}

\subsection{Turnaround: estado atual e caminhos para desenvolvimento}

As seções anteriores do presente capítulo avaliaram a base intelectual do estudo acadêmico sobre o turnaround de empresas a partir da técnica de bibliometria e o front do conhecimento, pela leitura dos trabalhos mais citados na WOS e outros trabalhos de maior relevância. Na presente seção, será apresentado um modelo de turnaround de empresas que leva em consideração as seis recomendações apresentadas anteriormente e que de alguma maneira consolidam o estágio de desenvolvimento da pesquisa acadêmica sobre o turnaround. Mas antes disso, serão discutidas algumas conclusões a cerca da evolução dos trabalhos sobre o turnaround.

$\mathrm{O}$ aspecto que se mostrou mais saliente pela análise bibliométrica talvez seja o fato de que como aventado, estudar o turnaround requer a compreensão de uma miríade de fatores e que, portanto, deve receber abordagens distintas. Nota-se que a espinha dorsal do conhecimento produzido pelas pesquisas em turnaround é composta por três vértebras: investigação do declínio, do retrenchment e das estratégias de recuperação. E que houve um esforço da literatura em avaliar o efeito moderador e/ou impactos de outros elementos em cada um destas três vertebras. Assim, os estudos adicionam questões como a severidade do declínio e disponibilidade de folga financeira como fator importante no desenho do retrenchment $\mathrm{e}$ ações de recuperação. Estudaram o papel da alta gestão no processo de turnaround, a posição competitiva da firma na definição de estratégias, a relação entre a causa do declínio e as estratégias de recuperação, o efeito de estratégias distintas em indústria em expansão e em 
indústria em contração. Observou-se que os estudos foram de certa forma equilibrados entre abordagens teóricas e empíricas, mas que estudos causais são menos comuns e devem trazer contribuições importantes para a consolidação das propostas da literatura.

A contribuição do pensamento de estratégia para o turnaround ficou evidente, sobretudo pela presença de um cluster composto majoritariamente por pesquisadores da TBR e ainda pela presença de autores da OI e teoria comportamental. A TBR, como foi mencionado na seção 2.1.1, se mostrou o aporte teórico mais influente ao longo do tempo, em relação à OI, pela análise da meia vida média dos clusters. Portanto, há indícios de que o efeito do pêndulo duplo apontado na introdução reverberou nas pesquisas sobre turnaround e que atualmente a TBR tem dominado a discussão sobre estratégia também nos estudos sobre turnaround. Esta discussão será aprofundada no capítulo 3.

A construção da argumentação acerca do front do conhecimento se pautou nos principais trabalhos e em ordem cronológica foram levantadas as principais contribuições dos trabalhos e derivadas seis "recomendações" para um modelo de turnaround pautado nos avanços da literatura. A seguir serão resgatadas as seis contribuições às quais serão posteriormente consolidadas na forma de um modelo (Figura 7) para turnaround de empresas. O modelo que será proposto divide o processo de turnaround em três etapas (ações de quebra da inércia, retrenchment e estratégia de recuperação), cada qual contingenciada pelas demais recomendações.

Recomendação 1: um modelo sobre o turnaround de empresas deve considerar as causas do declínio (aspectos internos ou mudanças do mercado) e severidade do declínio como fator moderador.

Recomendação 2: um modelo sobre o turnaround de empresas deve propor ações de quebra da inércia, com a reabilitação da confiança com stakeholders, eliminação de ineficiências, estabilização do clima interno e da tomada de decisão para interrupção do declínio.

Recomendação 3: um modelo sobre o turnaround de empresas deve considerar os fatores moderadores tais como causas do declínio e posição competitiva, para o desenho de estratégias de recuperação. 
Recomendação 4: um modelo sobre o turnaround de empresas deve considerar ações de corte de custos e liquidação de ativos (retrenchment) em um primeiro estágio do processo de recuperação.

Recomendação 5: O retrenchment como ação integrante em um modelo de turnaround de empresas deve considerar o impacto do corte de custos e da liquidação de ativos na natureza de geração de renda da firma.

Recomendação 6: um modelo de turnaround deve considerar a troca da alta gestão e participação de externos no conselho como estratégia para interrupção do declínio e tomada de ação para recuperação.

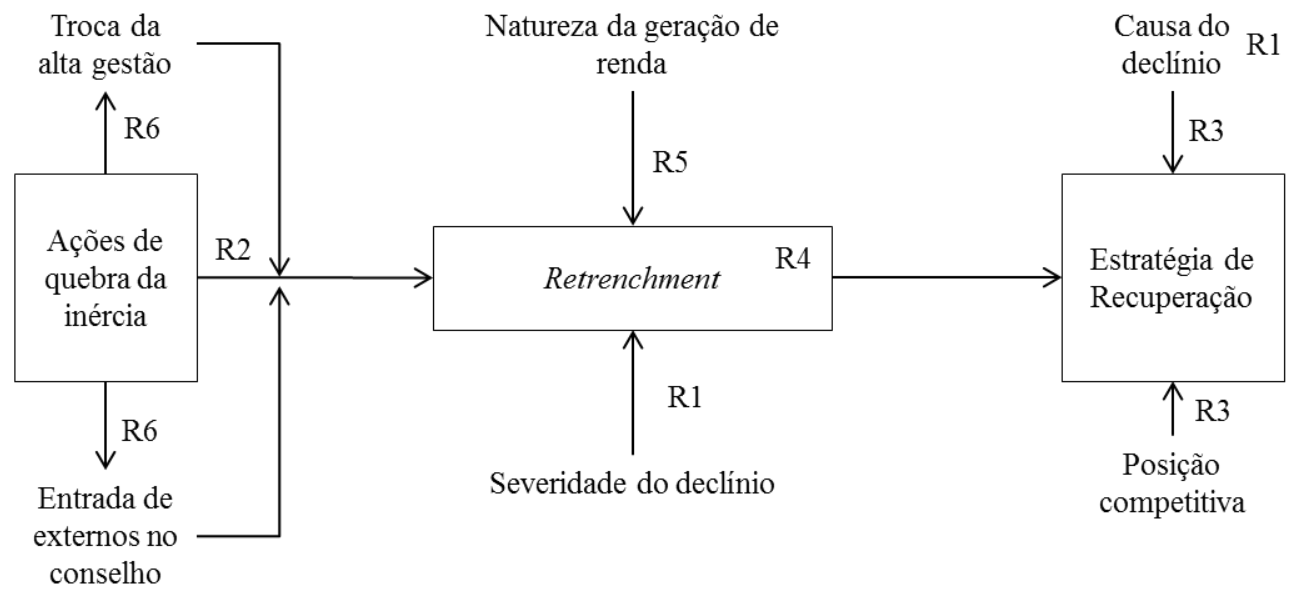

Figura 7 - Modelo proposto para o turnaround de empresas

Fonte: elaborado pelo autor

Conforme pôde ser observado o modelo baseado nas recomendações da literatura considera que as ações de retrenchment e estratégias de recuperação dificilmente são iniciadas sem que se tomem ações para romper a inércia da firma, e como visto, a troca da alta gestão e entrada de pessoas externas no conselho tem efeito positivo sobre a capacidade das firmas em empreender ações de recuperação.

As ações de quebra de inércia propostas foram a troca da alta gestão e entrada de externos no conselho de administração. Esta ação é considerada o gatilho para a tomada de ações subsequentes (fase de retrenchment e recuperação). Assim, espera-se que firmas em situação de turnaround que aproximem externos ao conselho e que troquem o TMT, deverão ter performance de recuperação superior àquelas que não adotaram tais medidas. 
O retrenchment é uma ação que depende primeiramente da severidade da situação de turnaround, isto é, quando mais depreciada estiver a condição financeira da firma, mais provável será a necessidade de adotar ações de redução de custos e ativos, mas a natureza de geração da firma deve ser considerada a fim de que não se atente para a fonte de vantagem competitiva da firma. Como proposto por Lim et al. (2013), o modelo considera o mecanismo de geração de renda "ricardiana" baseada na exploração de recursos e renda "schumpeteriana" baseada na exploração de capacidades dinâmicas. Sempre que uma firma apresenta o mecanismo de geração de renda ricardiana, sua estratégia de retrenchment deve focar em ações de redução de custo, visto que os ativos representam sua fonte de geração de renda. Quando os mecanismos de geração de renda é schumpeteriano, as estratégias de retrenchment devem focar em ações de liquidação de ativos, pois sua fonte de vantagem competitiva advém de rotinas e capacidades internas e o corte de custos levaria a perdas em suas capacidades dinâmicas.

As estratégias de recuperação por sua vez, são consideradas como ações dependentes das causas do declínio e da posição competitiva da firma. Assim, quando a causa do declínio é interna significa que a firma adotou ações/estratégias impróprias e que é preciso de alguma maneira retomar sua competitividade. Para isso é importante identificar a posição competitiva, pois, quando esta é fraca, a retomada da competitividade dificilmente será alcançada pela expansão, mas sim pelo foco nas atividades onde seus recursos e capacidades são mais valorizados ou até reorientações estratégicas com construção de recursos e capacidades distintas. De outra maneira, quando a causa do declínio é decorrente de contração do mercado, mas a firma ainda detém posição competitiva forte, a opção deve ser por reorientações estratégicas com a alavancagem dos recursos e capacidades existente. A criação de novos recursos e capacidades deve ser a ação em casos de fraca posição competitiva em mercados em contração. 


\section{ESTRATÉGIA COMPETITIVA E TURNAROUND}

O capítulo 2 apresentou o estado da arte do conhecimento sobre o turnaround de empresas e o front do conhecimento foi traduzido em seis recomendações acerca das questões que um modelo sobre o turnaround de empresas deve considerar. O presente capítulo discute o conceito de estratégia competitiva ou vantagem competitiva e a contribuição de suas abordagens para o estudo do turnaround de empresas. Na introdução deste trabalho, o segundo problema de pesquisa que se colocou foi: "qual a contribuição das teorias de estratégia para explicar o processo de turnaround de empresas?". No capítulo anterior viu-se que autores relacionados à TBR e OI estão presentes na base teórica que suporta os trabalhos sobre turnaround; compreender de que forma estes conceitos influenciam a literatura de recuperação de empresas é o principal objetivo da presente seção, que deverá por fim atender à pergunta problema suscitada no início do trabalho. Serão levantadas proposições sobre como os conceitos de estratégia competitiva pode ser agregados aos estudos de turnaround.

Mintzberg (1978, p. 941) define estratégia como o conjunto de ações estabelecidas por uma organização em certo momento considerando o ambiente em que está inserida. A estratégia adotada por uma organização é regida por três forças inter-relacionadas: “a) o ambiente, que está em mutação de maneira irregular, desconíinua e com alteração na velocidade de mudança; b) o sistema operacional burocrático (a organização), que acima de tudo busca a estabilidade apesar da característica do ambiente em que está; e c) uma liderança que faz a mediação entre estas duas forças a fim de garantir a estabilidade de uma organização ao mesmo tempo que possibilita que esta se adapte às mudanças do ambiente". Para o autor, a estratégia pode ser compreendida como um plano explícito, desenvolvido conscientemente e propositadamente, elaborado anteriormente à uma tomada de decisão específica. $\mathrm{O}$ autor denomina esta estratégia de "estratégia intencional". Por outro lado, muitas vezes a estratégia se revela com o passar do tempo quando se observa um padrão de tomadas de decisões. Esta segunda alternativa é compreendida como "estratégia realizada", que não passou necessariamente por um processo de "planejamento das ações".

A definição de Mintzberg (1978) sobre estratégia aponta para o que é estratégia em um sentido amplo. Permanece a parte desta definição toda a discussão que existe sobre como é a estratégia, ou como fazer estratégia. Mahoney e Pandian (1992) definem estratégia como 
sendo a busca das firmas por criação de rendas que excedam o custo de oportunidade de seus recursos (firma em vantagem competitiva) e que quatro mecanismos distintos de geração de renda foram propostos na literatura: 1) rendas ricardianas, advindas da posse de recursos valiosos e escassos; 2) rendas empreendedoras (ou "schumpeterianas"), alcançadas pela tomada de risco e atividades empreendedoras; 3 ) rendas de monopólio, existentes por proteção estatal, conluios com elevadas barreiras à entrada de potenciais competidores e criação de barreiras à entrada pelas firmas; 4) quase-renda apropriada de ativos físicos, humanos e dedicados que são idiossincráticos e específicos da firma. Estas rendas são geradas pela diferença entre o primeiro e o segundo melhor uso que este ativo pode ter (Klein, Crawford e Alchian, 1978; Williamson, 1979).

As visões de renda "ricardiana" e "shumpeteriana", apesar de se desafiarem, estão contidas dentro da escola de pensamento estratégico da TBR (Makadok, 2001). A renda monopolista é o conceito de vantagem competitiva defendida pela escola de Organização Industrial (OI), ao passo que a ideia de quase-renda é o argumento da Economia dos Custos de Transação (ECT).

A área do conhecimento da estratégia e mais especificamente os trabalhos que tratam de gestão estratégica apontam para outras abordagens além das três mencionadas (OI, ECT e TBR). Nos anos de 1980 e 1990, além da ECT, a Teoria da Agência (TA) foi bastante utilizada nos trabalhos sobre estratégia (Guerras-Martín, Madhok e Montoro-Sánchez, 2014). Contudo, no presente trabalho as abordagens de estratégia irão se conter ao proposto por Mahoney e Pandian (1992) com os quatro mecanismos de geração de renda: ricardiana, schumpeteriana, monopólio e quase-renda.

A seguir serão discutidas as principais abordagens sobre estratégia competitiva com o objetivo de compreender, a operacionalização do conceito de vantagem competitiva na visão da escola de Organização Industrial (OI), Economia dos Custos de Transação (ECT), e Teoria Baseada em Recursos (TBR) e de melhor compreender a relação entre estas abordagens e os trabalhos sobre turnaround.

\subsection{Teoria da Organização Industrial}

A escola da Organização Industrial (OI) é divida em duas ondas de trabalhos. A primeira associada à "Harvard Tradition" e a segunda à "Chicago Tradition". A primeira tem como 
principais autores Bain e Mason e é uma escola muito pautada em trabalhos empíricos que associam a estrutura da indústria, com a conduta individual das firmas e seu impacto no desempenho (estrutura-conduta-desempenho). A segunda escola emerge na década de 1970 com o objetivo de melhor atender às limitações atribuídas à tradição de Harvard, no qual se destaca o determinismo: estrutura e desempenho.

A escola de Chicago vem com estudos de maior carga micro analítica e econométrica com o intuito de permitir análises empíricas multi setoriais, formação de modelos formais para mercados oligopolistas e o estudo das dinâmicas de mercado e informação assimétrica. Os limites da OI são difusos, mas pode-se dizer que trata da estrutura e comportamento das firmas (estratégia de mercado e organização interna), com foco na eficiência dos mercados em relação à maximização do bem estar social (Tirole, 1988).

No presente trabalho o interesse na escola de OI está na parte de estratégia de mercado e organização interna. Especialmente deve-se dar atenção à importância do conceito de "barreiras à entrada" para a OI. A escola de Organização Industrial foi fundamentada pelas contribuições de Bain ${ }^{16}$ no que se refere ao conceito de barreiras à entrada (Caves e Porter, 1977).

Explicar a estrutura da indústria e como as barreiras à entrada em determinada indústria surgem e são mantidas é o desafio da OI. A questão fundamental que se coloca é a capacidade de explorar ganhos superiores em função de poder de monopólio que permite explorar as "rendas monopolistas". As rendas superiores só são permanentes quando há obstáculos superiores para novos entrantes. Caves e Porter (1977) avançam sobre as proposições iniciais de Bain (1954) e afirmam que a OI e seu conceito de barreiras à entrada podem ser utilizados como uma teoria para descrever a mobilidade não somente de firmas ao tentar entrar em uma nova indústria, mas que tem muito valor como uma teoria de mobilidade entre os segmentos de uma mesma indústria. Os autores defendem que as barreiras à entrada são não somente estruturais, mas também endógenas, isto é, a quase renda planejada por um novo entrante, depende de sua estimativa de ações que uma firma oligopolista irá tomar visando deter novos entrantes. Uma empresa supera seus concorrentes se consegue estabelecer e preservar uma

\footnotetext{
16 Joe S. Bain, "Conditions of Entry and the Emergence of Monopoly," Monopoly and Competition and Their Regulation", E. H. Chamberlin, ed. (London: Macmillan, 1954), 215-41; idem, "Barriers to New Competition" (Cambridge: Harvard University Press, 1956). Other early contributions, like the present study, placed more emphasis on the behavioral foundations of entry barriers than did Bain. See A. G. Papandreou and J. T. Wheeler, "Competition and Its Regulation" (Englewood Cliffs: Prentice-Hall, 1954), Ch. 12; H. R. Edwards, "Price Formation in Manufacturing Industry and Excess Capacity," Oxford Economic Papers, VII (Feb. 1955), 94-118.
} 
posição de superioridade (Porter, 1996). Os custos endógenos (endogenous sunk cost - ESC) são decisões que as firmas devem tomar a fim de manter sua posição competitiva. Pode ser, por exemplo, o investimento em marketing com o objetivo de construir o nome de uma marca gerando o benefício da preferência do consumidor por aquele produto (Sutton, 1991)

Caves e Porter (1977) definem quatro fontes de barreiras à entrada: a) excesso de capacidade produtiva que faz com que a atratividade para entrar na indústria diminua em função de risco de guerra de preços; b) diferenciação do produto com a criação de várias marcas por uma mesma indústria com o objetivo de acessar diferentes curvas de utilidade e reduzir o mercado potencial para novos entrantes. Pode ser também por campanhas de propaganda que elevam o limite de preços do produto fazendo com que o novo entrante tenha que promover ações de promoção, o que reduz a viabilidade do negócio; c) alteração na estrutura de custos com investimentos em diferenciação e investimentos em diferenciação que elevam a proporção de custos fixos e reduz a viabilidade de novos entrantes e pequenas empresas; d) integração vertical que eleva o custo de entrada seja por impor um modelo que exija mais investimentos de novos entrantes em integração para frente ou para trás, ou então por trazer incerteza por entrar sem integração vertical e não ter garantia de aquisição de insumos ou colocação no mercado. Avançando sobre a discussão sobre o que é estratégia e estratégia competitiva, Porter (1996, p. 64) define, “estratégia competitiva diz respeito a ser diferente. Significa a escolha deliberada de um conjunto de atividades distintas a fim de criar uma combinação única de valor $^{17}$. Para o autor o desafio da vantagem competitiva reside em saber se posicionar estrategicamente e para isso é preciso fazer escolhas. Posicionar-se estrategicamente e de maneira sustentável implica em posições que são desfavoráveis (pelo menos parcialmente) às dos concorrentes.

\subsection{Economia dos Custos de Transação - ECT}

Conforme postulado por (Coase, 1937); 1960), qualquer ganho potencial advindo de uma transação deve ser realizado em plenitude, exceto quanto da existência de custos de transações e de "impedimentos legais". Sob a ótica da economia dos custos de transação, as firmas podem alcançar vantagens competitivas por meio da eficiência nas transações (Coase, 1960).

\footnotetext{
17 "Competitive strategy is about being different. It means deliberately choosing a different set of activities to deliver a unique mix of value".
} 
Nesse sentido, Williamson (1991), aponta que a estratégia das firmas reside em economizar custos de transação e, portanto, a firma deve escolher a melhor maneira de transacionar ativos de diferentes especificidades ${ }^{18}$. A especificidade dos ativos é mensurada pelos investimentos realizados para a sua utilização. Quanto maior a diferença do valor de um ativo para sua segunda melhor alternativa de uso (second best alternative), mais especifico ele é. Isto é, os investimentos específicos destinados à sua utilização não tem um uso de igual valor ao objetivo inicial. A diferença entre a primeira e a segunda melhor alternativa é denominada "quase-renda". Ativos de maior especificidade requerem transações mais complexas tipicamente coordenadas via integração vertical ou "hierarquia". Ativos de baixa especificidade são transacionados no mercado e as formas híbridas ou contratuais ocorrem nos casos de especificidade "intermediária" dos ativos. Assim, quando se transaciona algum ativo no mercado, e esta transação passa a ser muito custosa para a organização em função de incerteza de fornecimento, por exemplo, a forma contratual emerge como uma alternativa.

Entende-se que exista uma forma ótima de transacionar ativos e que a estratégia da firma reside na escolha entre mercado, contratos ou hierarquia. A escolha errônea pode significar perda de competitividade e consequentemente performance inferior. Toma-se como exemplo o alto custo da estrutura de governança e o aumento do custo dos insumos. No primeiro caso, é razoável supor que se esta condição leva a firma a resultados declinantes, deve haver uma forma alternativa, mais eficiente, para coordenação de suas atividades. No segundo, a elevação de custo dos insumos deve ocorrer para todos os concorrentes que operam com a mesma estrutura de coordenação. Se alguns estão tendo performance decadente, outros estão tendo resultados positivos (mantendo-se o mercado constante) e então é razoável supor que deve haver forma mais eficiente para coordenação das atividades para fornecimento de insumos.

As argumentações de Coase (1937, 1960a) e Williamson (1991) apresentadas acima alicerçam a teoria da Economia dos Custos de Transação (ECT), base da Nova Economia Institucional (NEI). A ECT contrapõe-se à economia neoclássica ao defender que a fïrma não é uma caixa preta que pode ser explicada por uma função de produção e que a existência de custos de transação positivos desafia os estrategistas no sentido de elaborar distintas estruturas de governança à medida que os mesmos se deparam com diferentes custos de transação. A

\footnotetext{
${ }^{18}$ Williamson define que a melhor estratégia é economizar em custos de transação (economizing is the best strategy).
} 
operacionalização da ECT como uma teoria sobre a estratégia das firmas é compreendida como o alinhamento das estruturas de governança com os atributos das transações, ao que Williamson (2000) denominou economias de primeira ordem (first order economizing). Para a Economia dos Custos de Transação, as firmas alcançam performance superior ao se apropriar da quase-renda gerada pela transação de ativos em estruturas de governança mais adequadas.

\subsection{Teoria Baseada em Recursos}

A Teoria Baseada em Recursos (TBR) é uma escola de estratégia mais recente. Apesar de suas ideias iniciais terem sido lançadas por Edith Penrose (Penrose, 1959), sua consolidação ocorreu mais tardiamente em relação à OI e ECT, tendo origem nos anos 1990. A TBR pode ser dividida em duas alas como proposto por Foss e Stieglitz (2012) e serão discutidas mais à frente: o "alto clero" e o "baixo clero". Henderson (1989) define estratégia como uma ação deliberada da firma com a finalidade de desenvolver uma vantagem competitiva para o negócio. Nesta definição, há uma visão do autor de que estratégia não deve ser somente utilizada para permitir a sobrevivência da firma, mas que confira vantagem competitiva. A estratégia tem como objetivo criar uma diferenciação com relação aos concorrentes. Quanto mais semelhante uma organização é em relação à outra, menor é sua vantagem competitiva. Assim, estratégia é criar diferenças em relação a seus concorrentes e a menos que um negócio tenha uma vantagem única em relação a seus concorrentes, não há razão para sua existência (HENDERSON,1989).

A distinção e superioridade em relação aos concorrentes são a base da vantagem competitiva sempre que os recursos são combinados de maneira apropriada frente às oportunidades do ambiente. Esta definição constitui os princípios básicos da TBR. A vantagem competitiva é caracterizada na TBR pela heterogeneidade dos recursos disponíveis e consequentemente pela natureza da renda (rendas Ricardianas ${ }^{19}$ ) (Peteraf, 1993). Estas duas características posicionam a TBR como uma teoria sobre como a firma constrói sua estratégia de maneira bastante diferente à proposta da escola de organização industrial (OI) que considera que a longo prazo os recursos entre as firmas tendem a ser homogêneos e a renda de uma empresa

\footnotetext{
${ }^{19}$ A renda Ricardiana é um conceito desenvolvido pelo economista inglês David Ricardo em que considera que a heterogeneidade em uma indústria reflete a presença de fatores de produção superiores e que são escassos. Além disso, tais fatores não podem ser rapidamente expandidos e são escassos no sentido de que não podem suprir a demanda. Nesse sentido, empresas que possuem tais fatores de produção têm custos de produção inferiores à média e como em equilíbrio de mercado o preço se iguala ao custo médio, empresas com custos inferiores ganham rendas "sobre normais" (Peteraf, 1993).
} 
em vantagem competitiva tem caráter monopolístico (Porter, 1980). Na OI a performance das firmas é dada pelo seu poder de mercado, enquanto na TBR, é dada pela eficiência, ao combinar recursos heterogêneos.

O modelo de Porter (1980) sobre a vantagem competitiva das firmas é uma análise de como o ambiente externo impacta na performance das firmas sem considerar os diferentes recursos e capacidades que as firmas podem ter. Por outro lado, a TBR analisa como os recursos internos da firma e seu grau de mobilidade podem conferir vantagens competitivas (Barney, 1991). Segundo Wernerfelt (1984) a análise da firma como um conjunto de recursos foi abordada pela primeira vez no trabalho de Penrose (1959), mas recebeu pouca atenção formal até meados dos anos 1980.

Wernerfelt (1984) aponta para existência de outros recursos que tradicionalmente não faziam parte da conceituação tradicional, que eram compostos por capital, trabalho e eventualmente, terra. Neste sentido, o autor exemplifica o que, sob a ótica da TBR pode vir a ser um recurso. Um exemplo é um profissional ímpar no mercado. Este funcionário pode ser considerado um recurso de extremo valor para a firma e este recurso pode vir a conferir vantagens competitivas à firma.

Baseando-se em trabalhos anteriores, Barney (1991) criou um modelo que explica como as firmas criam e mantem vantagem competitiva sustentável na ótica da TBR. Como citado, os recursos da firma são, nesta abordagem, a unidade de análise e definidos por Barney (1991, p. 101) como "ativos, capacidades, processos organizacionais, atributos, informação, conhecimento etc., controlados por uma firma que permitam que esta conceba e implemente estratégias que elevem sua eficiência e eficácia. Na linguagem de análise estratégica tradicional, o recurso das firmas são fortalezas que a firma pode utilizar para conceber e implementar suas estratégias".

Para a TBR é importante definir e distinguir vantagem competitiva e vantagem competitiva sustentável. Barney (1991) diferencia a vantagem competitiva sustentável da vantagem competitiva da seguinte forma:

- Vantagem competitiva: quando a firma está implementando uma estratégia de criação de valor que não está sendo simultaneamente implementada por algum concorrente atual ou futuro. Assim, a vantagem competitiva é uma situação momentânea que pode 
ser rompida a qualquer momento por um concorrente que consiga imitar a estratégia ou seus benefícios associados.

- Vantagem competitiva sustentável: quando a firma tem vantagem competitiva e quando os concorrentes não conseguem imitar os benefícios da estratégia adotada (pois há ambiguidade causal). A vantagem competitiva sustentável é um estado de equilíbrio, pois pressupõe que os benefícios desta posição não podem ser duplicados pelos concorrentes. Ou como definido por Rumelt (1982) que diz que se após uma tentativa de copiar a vantagem competitiva continua existindo, então se pode dizer que é sustentável. No entanto, a vantagem competitiva sustentável não dura para sempre, e pode ser rompida não pela imitação de concorrentes mais por mudanças nas condições do mercado.

Após esta breve definição sobre as bases fundamentais sobre as quais a TBR é construída, é possível avançar sobre o modelo proposto por Barney (1991) que explica a criação e manutenção de vantagem competitiva pelas firmas.

O modelo assume que uma firma alcança e mantém vantagem competitiva sustentável quando: a) possui um recurso valioso capaz de criar valor; b) tal recurso é raro, de forma que o acesso a ele é restrito; c) imitar o recurso em questão ou seus benefícios é uma tarefa com pouca chance de sucesso pela concorrência; e por fim, d) existe organização interna da firma que possibilita a exploração de valor deste recurso. Estes quatro quesitos que definem a existência e manutenção de vantagem competitiva sustentável em função da posse de determinados recursos, serão daqui em diante traduzidos em recursos VRIO (valor, raridade, “imitabilidade" e organização).

Na visão da TBR, as firmas com estrutura e performance superiores assim o são não por apresentarem mecanismos de barreira a entrada, mas por que alcançam custos de produção razoavelmente inferiores ou por apresentarem um produto de qualidade superior ou de performance superior. No entanto esta visão não se mostra completamente adequada para explicar a vantagem competitiva de empresas em indústrias como, por exemplo, a de alta tecnologia. Nestas indústrias “[...] as empresas vencedoras em ambientes globais são aquelas que conseguem demonstrar respostas imediatas, inovação de produtos rápida e flexível associada à capacidade de gerenciamento para coordenar e reimplantar eficientemente e 
competências internas e externas $^{20 \text { " }}$ (TEECE et al., 1997, p. 515). Assim há uma nova forma de alcançar vantagem competitiva, a qual os autores denominam capacidade dinâmica (dynamic capabilities). O conceito de capacidade dinâmica pode ser definido como:

A capacidade da firma em se integrar, construir e reconfigurar suas competências internas e externas de forma rápida como resposta ao ambiente em modificação. As capacidades dinâmicas refletem por tanto a habilidade das firmas em alcançar formas novas e inovadoras de vantagem competitiva considerando as dependências passadas (path dependence) e posições de mercado (TEECE et al., 1997, p. 516).

Outra definição apresentada por Makadok (2001) é de que as capacidades dinâmicas "podem ser compreendida como "bens intermediários" gerados pela firma para conferir uma produtividade superior a seus recursos, assim como certa flexibilidade e proteção para seu produto ou serviço final".

Como anunciado no início da presente seção, Foss e Stieglitz (2012) propõem que a TBR pode ser dividida em duas alas, a primeira associada à análise VRIO que trata de heterogeneidade entre as firmas ("alto clero"). E a outra ala ("baixo clero"), pluri-disciplinar e mais complexa, apoiada em conceitos da gestão de desenvolvimento de produtos e conhecimento, economia evolucionária, pensamento shumpeteriano, aprendizado intelectual, trabalho, liderança e alianças, história dos negócios e pensamento Penrosiano (history matters). Se por um lado os estudos relacionados ao "alto clero" focam na organização de alguns recursos na firma, o "baixo clero" foca na construção, acumulação, gerenciamento da transformação, recombinação de recursos e em particular serviços que podem ser derivados de tais recursos. Dinamismo e aprendizado são chave nesta visão que pode ser compreendida como a abordagem de capacidade dinâmica.

O Quadro 5 abaixo apresenta um resumo das três escolas de estratégia abordadas.

\begin{tabular}{|c|c|c|c|}
\hline $\begin{array}{c}\text { Escola de } \\
\text { estratégia }\end{array}$ & $\begin{array}{c}\text { Natureza da } \\
\text { vantagem } \\
\text { competitiva }\end{array}$ & Mecanismo de geração de renda & Principais autores \\
\hline TBR & Recursos VRIO & $\begin{array}{c}\text { Escolha de recursos VRIO, capazes de } \\
\text { gerar retornos superiores ao valor pelo } \\
\text { qual foi adquirido (renda "Ricardiana"). }\end{array}$ & $\begin{array}{c}\text { (Barney, 1991; Penrose, 1959; } \\
\text { Phuen, 1997; Wernerfelt, 1984) }\end{array}$ \\
\hline
\end{tabular}

\footnotetext{
${ }^{20 " W i n n e r s ~ i n ~ t h e ~ g l o b a l ~ m a r k e t p l a c e ~ h a v e ~ b e e n ~ f i r m s ~ t h a t ~ c a n ~ d e m o n s t r a t e ~ t i m e l y ~ r e s p o n s i v e n e s s ~ a n d ~ r a p i d ~ a n d ~}$ flexible product innovation, coupled with the management capability to effectively coordinate and redeploy internal and external competences".
} 


\begin{tabular}{|c|c|c|c|}
\hline & $\begin{array}{l}\text { Capacidades } \\
\text { dinâmicas }\end{array}$ & $\begin{array}{l}\text { Combinação interna dos recursos de tal } \\
\text { sorte que é possível maximizar seu valor } \\
\text { latente através de rotinas e capacidades } \\
\text { internas da firma (renda } \\
\text { "Schumpeteriana"). }\end{array}$ & $\begin{array}{c}\text { (Schumpeter, 1934; Teece, } \\
\text { Pisano e Shuen, 1997) }\end{array}$ \\
\hline OI & $\begin{array}{l}\text { Posicionamento } \\
\text { estratégico }\end{array}$ & $\begin{array}{l}\text { Rendas advindas da criação de barreiras à } \\
\text { entrada às quais irão deter a entrada de } \\
\text { novos concorrentes no mercado (renda } \\
\text { monopolista). }\end{array}$ & $\begin{array}{c}\text { (Caves e Porter, 1977; Porter, } \\
\text { 1980) }\end{array}$ \\
\hline ECT & $\begin{array}{l}\text { Economias de } \\
\text { primeira ordem } \\
\text { (minimizar custos } \\
\text { de transação) }\end{array}$ & $\begin{array}{l}\text { A economia gerada pela transação de } \\
\text { ativos com a estrutura de governança mais } \\
\text { adequada gera rendas em relação à } \\
\text { situação em que o ativo é transacionado na } \\
\text { sua segunda melhor alternativa de } \\
\text { governança (quase-renda). }\end{array}$ & $\begin{array}{c}\text { (Coase, 1937, 1960; } \\
\text { Williamson, 2000, 1991) }\end{array}$ \\
\hline
\end{tabular}

Fonte: elaborado pelo autor

Estabelecido o conceito de que estratégia é a capacidade das firmas em criar rendas e, dadas as diferentes formas de criação de renda discutidas e resumidas no Quadro 5, a seguir será discutida a relação entre estes mecanismos de geração de renda e os trabalhos sobre o turnaround. Especificamente, deve-se compreender se os trabalhos sobre o turnaround suportam suas proposições em elementos da estratégia competitiva, ainda que de maneira indireta e como se dão as eventuais ligações entre turnaround e estratégia.

\subsection{Contribuições da estratégia competitiva para o turnaround}

Serra et al. (2012) avaliou a evolução dos estudos sobre estratégia competitiva nos primeiros anos da década de 2000 e revelou que predominam a visão baseada em recursos ou TBR e, em menor proporção, os trabalhos da ECT nas publicações dos principais periódicos sobre estratégia. Os autores realizaram um estudo bibliométrico e verificaram que a abordagem da OI esteve presente somente com trabalhos de Michel Porter e no mesmo cluster que a TBR, sugerindo que o autor havia sido citado como um contraponto à TBR. Isto sugere que mais recentemente a abordagem da OI tem sido menos utilizada para explicar a vantagem competitiva das firmas. Ramos-Rodríguez e Ruíz-Navarro (2004) em um estudo anterior argumentam que a pesquisa sobre estratégia oscilou em suas abordagens e que mais 
recentemente as abordagens de TBR, comportamento organizacional ${ }^{21}$ e micro-fundações se tornaram frequentes ao passo que ECT, TA e OI são menos frequentes. A principal questão das pesquisas em estratégia é a criação e manutenção da vantagem competitiva das firmas e neste aspecto desde meados dos anos de 1980 a TBR tem sido dominante (Foss e Knudsen, 2003).

A predominância recente que a TBR tem demonstrado nas pesquisas sobre estratégia também foi observada nas pesquisas sobre turnaround. Como visto no item 2.1.1, há um cluster representado pelos trabalhos da TBR $(\mathrm{C} 4)$ ao passo que autores associados à OI são menos frequentes. A ECT por sua vez não se apresentou como base intelectual para os trabalhos que tratam das estratégias de recuperação de empresas.

Para verificar com maior rigor sobre a predominância da abordagem da TBR e da presença dos autores da OI e ECT nos estudos sobre turnaround, suas contribuições e em que momento as diferentes escolas foram mais influentes, foi investigada a ocorrência de citações de trabalhos ligados à estratégia (OI, ECT ou TBR) na base de dados de trabalhos sobre o turnaround. Isso foi realizado a partir da rede de cocitações, que teve todos os trabalhos ligados à escola de estratégia mapeados. O Gráfico 1, a seguir, apresenta a frequência de citação de autores das escolas de estratégia e o Quadro 6 apresenta quais os autores, à qual abordagem de estratégia pertencem e, o número de citações que receberam pela base de trabalhos de turnaround.

${ }^{21}$ Comportamento Organizacional (Organizational Behaviour) é a uma área de estudos que envolve o entendimento do comportamento dos indivíduos, da interface entre o comportamento dos indivíduos e da firma e do comportamento da firma em si. 


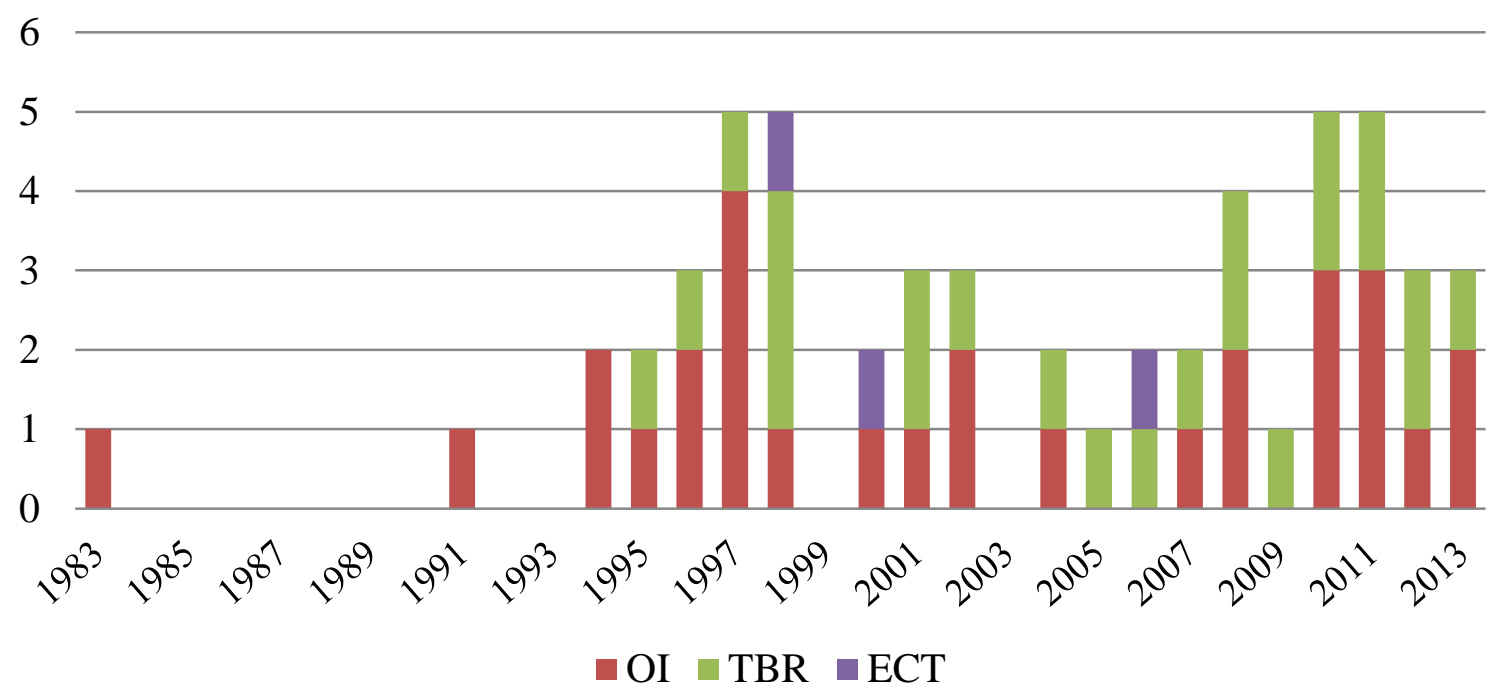

Gráfico 1 - Frequência de citação de autores da OI e TBR pelos trabalhos de turnaround Fonte: elaborado pelo autor

Observa-se que os trabalhos relacionados à OI foram mais influentes ao longo do tempo e que a TBR é citada pela primeira vez no ano de 1995. Como já havia sido mencionado anteriormente, a ECT recebeu pouca atenção pela literatura de que trata do turnaround, de maneira que somente três trabalhos se valeram de argumentos da ECT. A escola de estratégia mais citada foi a OI com 29 trabalhos seguidos pela TBR com 23. O primeiro ano em que um trabalho de estratégia foi citado foi em 1983, com abordagem da OI representada por Michael Porter e acompanhado por quatro outros autores (Quadro 6). A TBR por sua vez foi representada por seis autores diferentes com maior contribuição feita por Jay Barney e Eisenhardt. O único autor representante da ECT foi Oliver Williamson, presente em três trabalhos. No capítulo 2 foi visto que a TBR compunha um cluster de influência sobre os trabalhos de turnaround, ao passo que a OI estava presente em dois outros clusters com aparente menor influência e ECT sem qualquer contribuição. No entanto, observa-se que apesar de a TBR estar presente com um maior número de representantes - o que por sua vez influenciou a formação de um agrupamento destes autores citados conjuntamente - a OI foi mais influente e citada por 29 trabalhos e a ECT pela baixa frequência de citações não surgiu na rede de cocitação.

O trabalho de Ramos-Rodríguez e Ruíz-Navarro (2004) apontou para a evolução da pesquisa sobre estratégia como um pêndulo ente abordagem externa (OI) e interna (TBR) e a ECT com um papel mais ao centro. A hipótese de que as abordagens de estratégia influenciaram de maneira pendular os trabalhos sobre turnaround não é completamente atendida, uma vez que 
a OI se mostrou influente desde o início. No entanto, nota-se que a TBR é incorporada aos trabalhos de turnaround desde 1995, mesmo período apontado por Ramos-Rodríguez e RuízNavarro (2004). Os autores argumentam que a OI esteve influente entre os anos 1970 e 1980, mas só foi citada pela literatura de turnaround desde 1983 com certo atraso. Diferentemente, a TBR que foi influente a partir de 1995 foi observada nos trabalhos de turnaround já naquele ano.

\begin{tabular}{ccc}
\hline Autor & Trabalhos Citados & Escola Estratégia \\
\hline Michael Porter & 25 & OI \\
Jay Barney & 24 & TBR \\
Kathleen Eisenhardt & 20 & TBR \\
Robert Sutton & 17 & TBR \\
David Teece & 12 & TBR \\
Birger Wernerfelt & 9 & TBR \\
Alfred Chandler & 9 & OI \\
Richard Rumelt & 8 & OI \\
Edith Penrose & 7 & TBR \\
Margaret Peteraf & 5 & TBR \\
Joseph Schumpeter & 4 & OI \\
Joe Bain & 3 & OI \\
Oliver Williamson & 4 & ECT \\
\hline
\end{tabular}

Quadro 6- Frequência e autores das escolas de estratégia citados pelos trabalhos de turnaround Fonte: elaborado pelo autor

Para atender ao objetivo de compreender de que forma as escolas de estratégia contribuíram para os trabalhos sobre o turnaround, foram selecionados oito trabalhos que citaram os autores de estratégia e que foram publicados em quatro periódicos distintos, dos quais três com elevado fator de impacto nos últimos cinco anos (Journal of Management - 7,754; Strategic Management Journal - 6,393; Journal of Management Studies - 4,744). Ao todo oito trabalhos foram analisados e o Quadro 7 abaixo introduz estes trabalhos. 


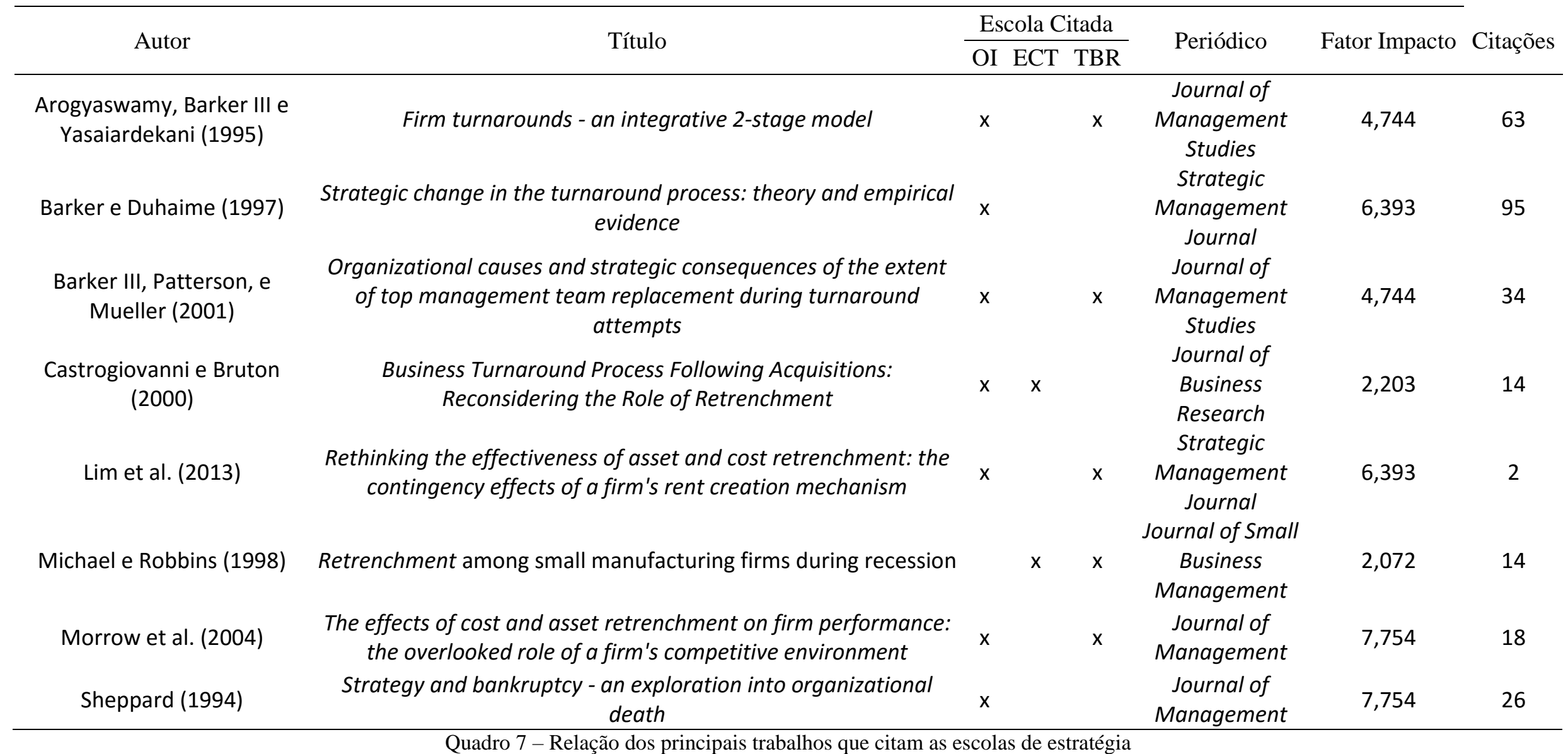

Fonte: elaborado pelo autor 
Com o objetivo de compreender as contribuições de conceitos de estratégia competitiva para os estudos sobre declínio, retrenchment e recuperação, foi feita uma leitura sistemática dos oito trabalhos selecionados e a relação com os conceitos de estratégia competitiva.

Para esta avaliação não se considerou o resultado final alcançado pelo estudo, ou seja, se a abordagem proposta foi corroborada pelos resultados. Como se objetiva somente compreender como os conceitos de estratégia são utilizados pelos autores, a análise foi limitada aos modelos propostos pelos autores. A seguir será apresentado os resultado da avaliação da relação entre as fases do turnaround e as abordagens de estratégia (Quadro 8, Quadro 9 e Quadro 10).

\begin{tabular}{|c|c|c|c|c|c|}
\hline \multirow{3}{*}{ Descrição } & \multicolumn{5}{|c|}{ Estratégia } \\
\hline & \multicolumn{2}{|c|}{ TBR } & \multirow{2}{*}{ OI } & \multirow{2}{*}{ ECT } & \multirow{2}{*}{ NI } \\
\hline & VRIO & $\mathrm{CD}$ & & & \\
\hline $\begin{array}{l}\text { (Sheppard, 1994) } \\
\text { - Correlação entre estrutura de indústria e performance das firmas é alta, assim } \\
\text { uma maneira de diminuir a probabilidade de falência é a diversificação. } \\
\text { - Indústrias com elevada competição tem tendência a ser menos rentáveis e a } \\
\text { menor rentabilidade está relacionada à maior taxa de falência. Assim firmas } \\
\text { que falem estão presentes em um maior número de indústrias de baixa } \\
\text { rentabilidade em relação às firmas que sobrevivem. } \\
\text { - A taxa de crescimento da indústria interfere na probabilidade de uma firma } \\
\text { adquirir os recursos necessários sem entrar em conflito com outros } \\
\text { competidores e assim firmas que falem estão presentes em indústrias de } \\
\text { baixo crescimento em relação às que sobrevivem. } \\
\text { - O elevado market share está relacionado à maior taxa de sobrevivência, pois } \\
\text { permite maior competitividade em custos, capacidade de definir preços e está } \\
\text { correlacionado com elevada rentabilidade. } \\
\text { - Formação de redes e cooperação está associada à maior sobrevivência em } \\
\text { função da capacidade de influenciar o ambiente externo, compartilhar riscos } \\
\text { e custos e adquirir e cooptar recursos externos. }\end{array}$ & & & $\mathrm{x}$ & & \\
\hline $\begin{array}{l}\text { (Arogyaswamy, Barker III e Yasai-ardekant, 1995) } \\
\text { - Má adaptação ao ambiente que após sofrer mudanças tem suas fontes de } \\
\text { vantagem competitiva redefinidas. Outra situação é quando a firma toma } \\
\text { ações que redirecionam sua estratégia e faz com que suas habilidades e } \\
\text { recursos tenham um valor econômico inferior nesta nova situação. } \\
\text { - Ambiente hostil, ou seja, indústria em contração e com perda de valor na } \\
\text { qual a competição se acirra e o número de participantes é drasticamente } \\
\text { reduzido. }\end{array}$ & $\mathrm{X}$ & $\mathrm{x}$ & $\mathrm{x}$ & & \\
\hline
\end{tabular}

Quadro 8 - Relação das fases do processo de turnaround com escolas de estratégia - declínio

Legenda: TBR - teoria baseada em recursos; OI - organização industrial; ECT - economia dos custos de transação; $\mathrm{CD}$ - capacidades dinâmicas; NI - nenhuma abordagem de estratégia associada.

Fonte: Elaborado pelo autor

Somente dois dos oito trabalhos selecionados tratam de declínio, o primeiro é o trabalho de Sheppard (1994), que argumenta que a performance das firmas está fortemente associada à estrutura da indústria e é portanto baseado em argumentos da OI (estrutura-condutadesempenho). $\mathrm{Na}$ abordagem é defendido que o declínio é mais recorrente em empresas 
menos diversificadas, que operam em indústrias com maior competição e de crescimento baixo, e ainda que empresas com baixo market share têm maior probabilidade de declínio. Arogyaswamy et al. (1995) apresenta uma proposta diferente, que diz que as firmas entram em declínio por não conseguir acompanhar as mudanças do ambiente competitivo, que tem sua fonte de vantagem competitiva alterada ou ainda porque a firma tomou ações que a levaram para uma condição na qual seus recursos e capacidades tem menor valor. Esse argumento está em linha com a TBR que aponta para os recursos e capacidades como valor econômico superior e que são fonte de vantagem competitiva. Contudo, os autores argumentam ainda que o declínio pode se dar pelo acirramento da concorrência em um mercado em contração e que levará à diminuição do número de participantes. Esse argumento tem maior aproximação à OI que diz que em indústrias mais competitivas a performance das empresas tende a ser inferior como proposto por Sheppard (1994). Dentre os trabalhos que trataram do declínio os argumentos da ECT não foram diretamente empregados. 


\begin{tabular}{|c|c|c|c|c|c|}
\hline \multirow{3}{*}{ Descrição } & \multicolumn{5}{|c|}{ Estratégia } \\
\hline & \multicolumn{2}{|c|}{ TBR } & \multirow{2}{*}{ OI } & \multirow{2}{*}{ ECT } & \multirow{2}{*}{ NI } \\
\hline & VRIO & $\mathrm{CD}$ & & & \\
\hline $\begin{array}{l}\text { (Arogyaswamy, Barker III e Yasai-ardekant, 1995) } \\
\text { - O retrenchment nada mais é que uma das possíveis estratégias para } \\
\text { elevar a eficiência das firmas, contudo os métodos para elevar a } \\
\text { eficiência irão depender das estratégias de recuperação escolhida pelos } \\
\text { gestores. }\end{array}$ & $\mathrm{x}$ & & & & \\
\hline $\begin{array}{l}\text { (Morrow, Johnson e Busenitz, 2004) } \\
\text { - A dinâmica competitiva da indústria deve ser levada em consideração } \\
\text { no estabelecimento das estratégias de retrenchment. O estágio de } \\
\text { desenvolvimento da indústria (emergente, crescimento, maturidade ou } \\
\text { declínio) é central para essa questão. } \\
\text { Em indústrias em crescimento as firmas devem adotar posição } \\
\text { competitiva agressiva com elevados investimentos em marketing, } \\
\text { redefinir mercados ou investir os recursos em novas tecnologias e } \\
\text { inovação. Ações de retrenchment de custos terão efeitos negativos. } \\
\text { Em indústrias maduras a dinâmica competitiva deve levar ao aumento } \\
\text { da competição por preços exercendo pressão para corte de custos. } \\
\text { Assim o retrenchment de custos deve ter impacto positivo. } \\
\text { Em indústrias em declínio as firmas apresentam comportamento } \\
\text { confuso de adaptação a um ambiente no qual elas não conseguem } \\
\text { exercer influência. Neste caso, a estratégia deve ser a busca por } \\
\text { eficiência na tentativa de manutenção de renda de maneira que o } \\
\text { retrenchment de custos deve ter efeito positivo. }\end{array}$ & & & $\mathrm{X}$ & & \\
\hline $\begin{array}{l}\text { (Lim et al., 2013) } \\
\text { - Retrenchment depende da natureza de geração de renda da firma } \\
\text { (Ricardiana vs. Schumpeteriana) que está relacionada ao padrão de } \\
\text { competição na indústria. } \\
\text { - A renda Ricardiana está relacionada à posse de ativos (recursos) que } \\
\text { foram seletivamente adquiridos no mercado ou construídos } \\
\text { internamente e que permitem custos inferiores aos competidores. Estes } \\
\text { ativos garantem economias de escala. Se neste tipo de firma a estratégia } \\
\text { de redução de ativos for escolhida, a vantagem competitiva estará sendo } \\
\text { destruída. } \\
\text { Firmas que competem na base da inovação suportada por atividades de } \\
\text { alto risco baseadas em capacidades únicas têm renda de natureza } \\
\text { Schumpeteriana e competem por diferenciação. Este mecanismo de } \\
\text { geração de renda envolve alto custo com P\&D, marketing e salários e a } \\
\text { estratégia de retrenchment de redução de custos pode destruir a } \\
\text { vantagem competitiva de firmas nesta situação. }\end{array}$ & $\mathrm{x}$ & $\mathrm{x}$ & & & \\
\hline $\begin{array}{l}\text { (Michael e Robbins, 1998) } \\
\text { - Retrenchment é definido como a ação de liquidação de ativos de } \\
\text { diferentes especificidades. } \\
\text { As firmas devem optar pela liquidação de ativos menos específicos, ou } \\
\text { seja, que podem ser acessados no mercado, em detrimento da } \\
\text { manutenção daqueles ativos de maior especificidade (raros e difíceis de } \\
\text { imitar) e que por sua vez são fonte de vantagem competitiva } \\
\text { sustentável. } \\
\text { São apontados três tipos de especificidade de ativos conforme postulado } \\
\text { pela ECT: especificidade física, especificidade de ativos dedicados e } \\
\text { especificidade de recursos humanos. }\end{array}$ & $\mathrm{x}$ & & & $\mathrm{x}$ & \\
\hline
\end{tabular}

Quadro 9 - Relação das fases do processo de turnaround com escolas de estratégia - retrenchment (continua) 


\begin{tabular}{|c|c|c|c|c|c|}
\hline \multirow{3}{*}{ Descrição } & \multicolumn{5}{|c|}{ Estratégia } \\
\hline & \multicolumn{2}{|c|}{ TBR } & \multirow{2}{*}{ OI } & \multirow{2}{*}{ ECT } & \multirow{2}{*}{ NI } \\
\hline & VRIO & $\mathrm{CD}$ & & & \\
\hline $\begin{array}{l}\text { (Castrogiovanni e Bruton, 2000) } \\
\text { - Divergência entre o resultado de estudos sobre retrenchment sugere } \\
\text { que esta ação pode não ser essencial e sua eficácia está sujeita a alguns } \\
\text { fatores contextuais. Os autores testam os efeitos da injeção de capital } \\
\text { ou incorporação da firma no portfólio de outro negócio, na } \\
\text { performance de turnaround. Ambas as ações são compreendidas como } \\
\text { retrenchment uma vez que levam à folga financeira pretendida na ação } \\
\text { de corte de custos e ativos. } \\
\text { Porter (1980) argumenta que a aquisição de uma empresa em } \\
\text { dificuldades, por uma empresa parente traz um efeito benéfico para } \\
\text { quem a adquire, devido às sinergias e não necessariamente aumenta o } \\
\text { valor de mercado da empresa adquirida e de sua eficiência e que, } \\
\text { portanto, é preciso investigar tal relação. } \\
\text { Os resultados contestam parcialmente a recomendação de Porter (1980) } \\
\text { uma vez que não houve relação significativa entre injeção de capital e } \\
\text { performance mas, a integração de negócios teve impacto positivo na } \\
\text { performance. Além disso, o resultado coloca dúvidas sobre o } \\
\text { argumento de Williamson (1979) de que a diversificação via empresas } \\
\text { parentes muitas vez dá vantagem sobre os competidores, pois permite o } \\
\text { acesso mais rápido e eficientemente a recursos em relação ao mercado } \\
\text { de capitais. }\end{array}$ & & & $\mathrm{X}$ & $\mathrm{x}$ & \\
\hline
\end{tabular}

Quadro 9 - Relação das fases do processo de turnaround com escolas de estratégia - retrenchment (continua) Legenda: TBR - teoria baseada em recursos; OI - organização industrial; ECT - economia dos custos de transação; CD - capacidades dinâmicas; NI - nenhuma abordagem de estratégia associada.

Fonte: elaborado pelo autor

As ações de retrenchment receberam argumentos das três abordagens de estratégia avaliadas. A abordagem mais clara associada à OI foi o trabalho de Morrow et al. (2004) que estabelece que a dinâmica competitiva associada ao estágio de desenvolvimento da indústria irá determinar as ações que devem ser adotadas pelas firmas. Assim as estratégias adotadas em indústrias em crescimento são diferentes das adotadas em indústrias maduras ou em declínio. O trabalho de Lim et al. (2013) estabelece uma relação diferente e baseando-se nos argumentos da TBR, os autores defendem que a natureza de geração de renda da firma é que irá comandar a ação cabível. Se para Morrow et al. (2004) em indústrias em expansão o corte de custos terá um efeito adverso pois reduzirá os investimentos em P\&D e marketing num contexto em que a posição competitiva deve ser agressiva, para Lim et al. (2013) esta ação também terá efeito adverso, mas a razão é que a firma ferirá sua estratégia de geração de renda (schumpeteriana).

Os argumentos da ECT são utilizados em dois momentos e associados ora à TBR outra à OI. Mas é no primeiro caso que sua utilização se torna mais clara. $\mathrm{O}$ trabalho de Michael e Robbins (1998) estabelece que o retrenchment, seja ele de custos ou ativos, irá eliminar os recursos das firmas e que se deve tomar cuidado para que se preservem aqueles que são raros 
e difíceis de imitar, pois não são facilmente adquiridos no mercado e são a fonte de vantagem competitiva da firma (TBR). A definição de recursos dificilmente comercializados no mercado empresta um argumento da ECT (Klein, Crawford e Alchian, 1978) que diz que são "ativos" de elevada especificidade. Na outra abordagem em que a ECT é utilizada, Castrogiovanni e Bruton (2000) questionam a recomendação da ECT de que a diversificação pela fusão ou aquisição de empresas parentas levaria a uma vantagem competitiva sobre os demais pelo acesso facilitado a recursos em relação ao mercado de capitais, mas no estudo, as empresas que realizaram essas ação não tiveram boa performance de recuperação.

A abordagem de Arogyaswamy et al. (1995) não utiliza de maneira direta os elementos da OI e TBR em sua definição do retrenchment, que segundo os autores tem o papel de otimizar a estrutura de custos e melhorar a utilização de ativos. Contudo, é possível depreender deste argumento que a otimização da estrutura de custos de ativos é o último estágio necessário para se alcançar vantagem competitiva sustentável através de recursos na abordagem de Barney (1991). Como mencionado na seção 3.3, o modelo VRIO proposto pelo autor sugere que a vantagem competitiva sustentável é alcançada quando a firma possui recursos valiosos (V), raros (R), difíceis de imitar (I) e que encontram na firma condição de serem explorados de maneira adequada $(\mathrm{O})$. Assim, o retrenchment como ação de otimização da estrutura de custos e ativos pode ser compreendido também como a reorganização da firma para a exploração de seus recursos. 


\begin{tabular}{|c|c|c|c|c|c|}
\hline \multirow{3}{*}{ Descrição } & \multicolumn{5}{|c|}{ Estratégia } \\
\hline & \multicolumn{2}{|c|}{ TBR } & \multirow{2}{*}{ OI } & \multirow{2}{*}{ ECT } & \multirow{2}{*}{ NI } \\
\hline & VRIO & CD & & & \\
\hline $\begin{array}{l}\text { (Sheppard, 1994) } \\
\text { - Estratégias das firmas podem ser separadas entre "estratégias } \\
\text { corporativas" (corporate level strategy) e estratégias de negócios } \\
\text { (business level strategy). No primeiro caso trata-se da escolha sobre os } \\
\text { domínios em que a firma deseja operar (escolha de indústrias e mercados } \\
\text { de atuação). No segundo caso envolve a escolha de como a empresa irá } \\
\text { competir nestas indústrias e mercados. } \\
\text { - Estratégias corporativas envolvem a escolha pela diversificação de } \\
\text { indústrias e mercados e a escolha por indústrias e mercados em } \\
\text { expansão. } \\
\text { Estratégias de negócios envolve o estabelecimento de market share } \\
\text { elevado e tamanho superior. }\end{array}$ & & & $\mathrm{X}$ & & \\
\hline $\begin{array}{l}\text { (Barker III e Duhaime, 1997) } \\
\text { - Capacidade de mudança estratégica depende do tamanho da firma: } \\
\text { firmas maiores podem exercer maior influência no mercado onde atuam } \\
\text { e exercer maior poder de mercado. } \\
\text { - Firmas maiores encontram maior facilidade em romper barreiras à } \\
\text { entrada e de mobilidade uma vez que tem mais condições de controlar o } \\
\text { ambiente pela posse de recursos superiores e poder de mercado. } \\
\text { - Firmas com maior nível de diversificação terão maior capacidade de } \\
\text { executar mudanças estratégica, pois os gestores terão mais opções e } \\
\text { flexibilidade para implementar estratégias pela realocação de recursos } \\
\text { entre os negócios. }\end{array}$ & & & $\mathrm{X}$ & & \\
\hline $\begin{array}{l}\text { (BARKER III et al., 2001) } \\
\text { - Ações de gestão corporativas (corporate level): aquisições de firmas ou } \\
\text { unidades de dentro ou fora da linha de produtos, saída ou entrada em } \\
\text { negócios, joint ventures, contratação e/ou expansão do escopo de } \\
\text { atividades internacionais. } \\
\text { - Ações de gestão dos negócios (business level): a) marketing: eliminar } \\
\text { linhas de produtos ou produtos específicos, criação de linhas ou } \\
\text { produtos, aumento do esforço de marketing em novos clientes e/ou } \\
\text { eliminação de segmentação, elevação do preço médio e redução ou } \\
\text { aumento de dispêndios com clientes; b) manufatura: venda, fechamento } \\
\text { ou realocação de plantas, centralização ou descentralização de } \\
\text { capacidade produtiva; modernização de planta, contratação de } \\
\text { componentes produzidos internamente, produção interna de } \\
\text { componentes adquiridos mercado, pulverização da compra em vários } \\
\text { fornecedores; c) P\&D: aumento ou redução do capital disponível para } \\
\text { pesquisa em novos produtos ou produção ou desenvolvimento comercial } \\
\text { de novos produtos; d)política financeira: pedido de recuperação, } \\
\text { liquidação de ativos não relacionados à produção, suspensão de } \\
\text { dispêndios de capital por longo período de tempo. }\end{array}$ & $\mathrm{x}$ & $\mathrm{x}$ & $\mathrm{x}$ & & \\
\hline
\end{tabular}

Quadro 10 - Relação das fases do processo de turnaround com escolas de estratégia - recuperação (continua) 


\begin{tabular}{|c|c|c|c|c|c|}
\hline \multirow{3}{*}{ Descrição } & \multicolumn{5}{|c|}{ Estratégia } \\
\hline & \multicolumn{2}{|c|}{ TBR } & \multirow{2}{*}{$\mathrm{OI}$} & \multirow{2}{*}{ ECT } & \multirow{2}{*}{ NI } \\
\hline & VRIO & $\mathrm{CD}$ & & & \\
\hline $\begin{array}{l}\text { (Arogyaswamy, Barker III e Yasai-ardekant, 1995) } \\
\text { - Estratégias de recuperação dependem da posição competitiva da firma } \\
\text { (forte ou fraca) e da causa do declínio (baseado em contração da } \\
\text { indústria ou baseado na firma). O declínio quando baseado na firma é } \\
\text { compreendido como a má adaptação da firma ao ambiente externo que } \\
\text { teve suas fontes de vantagem competitiva alteradas. } \\
\text { Declínio baseado na firma } \\
\text { - Posição competitiva forte: reorientação estratégica a fim de alavancar } \\
\text { - } \quad \text { Pocursos e capacidão competitiva fraca: criar novos recursos e capacidades. } \\
\text { Contração cíclica da indústria: } \\
\text { - Posição competitiva forte: manter a posição competitiva e fortalecer } \\
\text { recursos e capacidades. } \\
\text { Posição competitiva fraca: expandir a posição competitiva para } \\
\text { segmentos que dão alto valor aos recursos e capacidades existentes. } \\
\text { Contração prolongada da indústria } \\
\text { Posição competitiva forte: mudanças estratégicas incrementais que } \\
\text { expandam a posição na indústria com a exploração de recursos e } \\
\text { capacidades atuais. } \\
\text { Posição competitiva fraca: redução para segmentos de clientes viáveis } \\
\text { que demandarão novos recursos e capacidades. }\end{array}$ & $\mathrm{X}$ & $\mathrm{x}$ & & & \\
\hline
\end{tabular}

Quadro 10 - Relação das fases do processo de turnaround com escolas de estratégia - recuperação (termina) Legenda: TBR - teoria baseada em recursos; OI - organização industrial; ECT - economia dos custos de transação; CD - capacidades dinâmicas; NI - nenhuma abordagem de estratégia associada.

Fonte: elaborado pelo autor

Os autores que tratam de estratégias de recuperação se valem de argumentos exclusivamente da OI e TBR para fundamentar as recomendações de estratégias de recuperação. No primeiro caso as abordagens estão relacionadas ao determinismo "estrutura-conduta-desempenho" como a proposta de Sheppard (1994) que aponta para ações de recuperação como a escolha de qual indústria atuar e posicionamento estratégico nestas indústrias sendo o market share e o tamanho determinantes. O mesmo argumento é utilizado por Barker III e Duhaime (1997) que afirmam que firmas maiores terão mais condições de impor barreiras à entrada e têm capacidade de influenciar mercados.

Arogyaswamy et al. (1995) aponta para estratégias de recuperação moderadas pela causa do declínio e pela posição competitiva da firma. A estratégia então dependerá de o declínio ser causado por fatores externos como a contração de uma indústria ou ser baseado em questões internas da firma (perda da fonte de vantagem competitiva). Além disso, é importante estabelecer se a posição competitiva da firma é forte ou fraca. A noção de que o declínio baseado em questões internas da firma é função de perda da fonte de vantagem competitiva é uma visão associada à TBR, na qual recursos e capacidades são a fonte latente de desempenho 
superior. Assim, o desenho das estratégias está fortemente pautado na construção, no fortalecimento ou na manutenção de recursos e capacidades. É interessante notar que a visão do declínio baseado na contração cíclica da indústria é fortemente associada ao determinismo da OI que aponta para a estrutura e dinâmica da indústria como peremptórios da performance da firma. Assim, as estratégias de recuperação acomodam argumentos das duas escolas de estratégia (OI e TBR) como sendo suas causas, mas dá maior peso à TBR na definição das estratégias, que são basicamente a decisão entre manter, fortalecer ou construir recursos e capacidades.

Nota-se no Quadro 11 que a TBR e a CD foram as abordagens que estiveram presentes nas três fases do processo de turnaround (declínio, retrenchment e recuperação). A ECT por sua vez teve influência mais efêmera e sua contribuição mais incisiva esteve associada à TBR em um trabalho que trata das ações de retrenchment.

\begin{tabular}{|c|c|c|c|c|}
\hline \multicolumn{2}{|c|}{ Escola de estratégia } & Declínio & Retrenchment & Recuperação \\
\hline \multirow{2}{*}{ TBR } & Recursos VRIO & $\mathrm{X}$ & $\mathrm{X}$ & $\mathrm{X}$ \\
\cline { 2 - 5 } & Capacidades dinâmicas \\
OI & $\begin{array}{c}\text { Posicionamento } \\
\text { estratégico }\end{array}$ & $\mathrm{X}$ & $\mathrm{X}$ & $\mathrm{X}$ \\
\hline ECT & $\begin{array}{c}\text { Economias de primeira } \\
\text { ordem (minimizar } \\
\text { custos de transação) }\end{array}$ & & $\mathrm{X}$ & $\mathrm{X}$ \\
\hline
\end{tabular}

Quadro 11 - As fases do processo de turnaround que receberam suporte da literatura de estratégia Fonte: elaborado pelo autor

3.5 Um modelo de estratégia competitiva para o turnaround de empresas

Na seção 2.3 foi discutido o estado da arte do conhecimento sobre o turnaround e consolidado o front do conhecimento na forma de um modelo de turnaround de firmas (Figura 7). Na proposta o último estágio do processo passa pelo delineamento das estratégias de recuperação, às quais são moderadas pela posição competitiva e pela causa do declínio. Na seção 3.4, 
vimos quais as contribuições das abordagens de estratégia para o desenho das estratégias de recuperação e o modelo de Arogyaswamy et al. (1995) foi o que aparentemente melhor integrou os argumentos da OI e TBR. No entanto, os autores não diferenciam em seu modelo os dois tipos distintos de natureza de geração de renda possíveis dentro da abordagem da TBR. Como visto, esta escola pode ser dividida em dois flancos (alto clero e baixo clero), o primeiro associado à geração de renda pela posse de recursos VRIO (renda ricardiana) e o segundo à criação de capacidades dinâmicas (renda shumpeteriana). A presente seção tem por objetivo adicionar este conceito ao modelo proposto por Arogyaswamy et al. (1995) com o intuito de torná-lo ainda mais preciso no estabelecimento de estratégias de recuperação.

Morrow et al. (2004) argumenta que o estágio de desenvolvimento de uma indústria define a estratégia mais adequada, assim em uma indústria em expansão as firmas competem por inovação ao passo que em uma indústria em contração a competição é por eficiência. Os argumentos de Morrow et al. (2004), claramente influenciados por uma abordagem de OI, podem ser reformulados dentro da abordagem da TBR. Por exemplo, a competição por inovação que envolve tipicamente investimentos em $\mathrm{P} \& \mathrm{D}$ e marketing, na TBR é associada às firmas com padrão de competição por renda schumpeteriana. Por outro lado, a noção de competição por eficiência é típica de firmas com natureza de renda ricardiana, as quais possuem recursos VRIO e alcançam condição de custos médios inferiores. Lim et al. (2013) utiliza essa abordagem (rendas ricardianas versus rendas schumpeterianas) em sua proposição para as ações de retrenchment. Assim, propõe-se estender a aplicação do conceito utilizado por Lim et al. (2013) ao modelo desenvolvido por Arogyaswamy et al. (1995). Mais especificamente propõe-se:

Um modelo de turnaround de firmas deve considerar o papel moderador que a causa do declínio, posição competitiva e natureza de geração de renda tem no estabelecimento de estratégias de recuperação.

A Figura 8 a seguir apresenta a proposição da inclusão da natureza de geração de renda como fator moderador das estratégias de recuperação ao modelo apresentado anteriormente na seção 2.3 . 


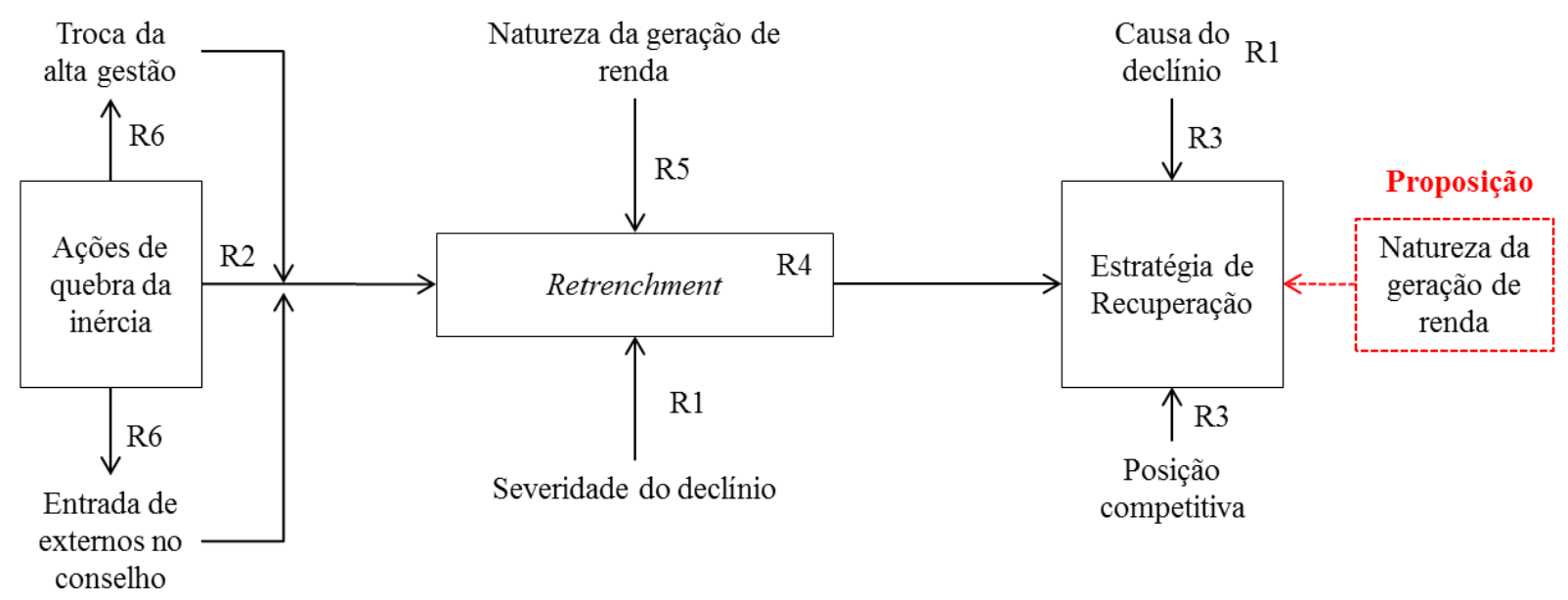

Fonte: elaborado pelo autor

Figura 8 - Modelo proposto de turnaround

Poucas firmas apresentam a condição de declínio e mantem forte posição competitiva, mas isso pode ocorrer quando o declínio é causado por retração de mercado ou quando a firma entra em declínio por razões internas mas mantém forte posição competitiva pois possui recursos e capacidades subutilizados (Arogyaswamy, Barker III e Yasai-ardekant, 1995). Assim, as estratégias para as firmas em situação de posição competitiva forte e declínio interno visa a manutenção desta posição com ações incrementais a fim de melhor explorar recursos e capacidades. Quando o declínio se dá por contração cíclica da indústria ou mesmo contração prolongada, a estratégia visa manter a posição com estratégias incrementais de utilização de recursos e capacidades existentes e até expansão para outros segmentos onde estes recursos e capacidades tem valor (Arogyaswamy, Barker III e Yasai-ardekant, 1995).

Por outro lado, firmas com mecanismo de geração de renda schumpeteriana ou ricardiana, que detém posição competitiva forte, isto é, com recursos ou capacidades de valor, e que entram em declínio por razões internas devem adotar estratégias incrementais para melhor utilização de seus recursos e reformulação de suas capacidades, para manutenção ou mesmo expansão de sua posição competitiva. A inação frente ao declínio irá levar à deterioração de recursos e capacidades e perda da posição competitiva, agravando a situação de declínio. Quando a posição competitiva é fraca, significa que os recursos e capacidades da firma não tem valor naquele mercado em que está atuando. Assim, é necessária uma reorientação estratégica com o foco em determinado segmento em que a firma consiga desenvolver recursos e capacidades com maior valor. 
As proposições de 1 à 8 (p1 à p8), a seguir, dizem respeito às estratégias de recuperação que devem ser adotadas em função da posição competitiva, causa do declínio e natureza de geração de renda.

p1: Firmas com natureza de renda ricardiana, com posição competitiva forte e causa do declínio interno, que adotarem estratégias incrementais para melhor utilização de seus recursos com o objetivo de manter ou mesmo expandir sua posição competitiva, terão performance superior pós turnaround em relação àquelas que não adotarem tais ações.

p2: Firmas com natureza de renda schumpeteriana, com posição competitiva forte e causa do declínio interno, que adotarem estratégias incrementais para recombinar suas rotinas internas e fortalecer suas capacidades dinâmicas com o objetivo de manter ou mesmo expandir sua posição competitiva, terão performance pós turnaround superior àquelas que não adotarem tais ações.

Firmas com posição competitiva fraca, mas que estão em uma indústria estável ou em expansão com declínio ambos decorrentes de questões internas deverão adotar medidas que as leve para uma posição competitiva forte. Considerando o elevado custo de acessar o mercado de fatores estratégicos e o custo de desenvolver novas habilidades e competências, a firma deve focar em segmentos nos quais seus recursos tem maior valor e levam a uma situação de elevada eficiência e onde suas capacidades podem gerar produtos e serviços de maior valor.

p3: Firmas com natureza de renda ricardiana, com posição competitiva fraca e causa do declínio interno, que adotarem reorientação estratégica com foco em segmentos onde recursos podem levar à maior eficiência, terão performance superior pós turnaround em relação àquelas que não adotarem tais ações.

p4: Firmas com natureza de renda schumpeteriana, com posição competitiva fraca e causa interna do declínio, que adotarem reorientação estratégica com foco em segmentos onde capacidades podem levar à geração de maior valor, terão performance pós turnaround superior àquelas que não adotarem tais ações.

A situação mais crítica é encontrada por firmas com fraca posição competitiva em indústrias em contração. Nestes casos a estratégia adotada deve ser de reduzir o negócio para aqueles 
consumidores e segmentos nos quais os recursos e capacidades conferem maior vantagem competitiva. A adoção de reorientação estratégica nestes casos é perigosa, pois uma firma fraca em um ambiente hostil encontrará dificuldade para absorver os custos de uma mudança estratégica (Arogyaswamy, Barker III e Yasai-ardekant, 1995). No entanto, na contramão deste argumento, é sabido que em indústrias em crise, o valor dos ativos no mercado estratégico de fatores é geralmente sobrevalorizado. Em mercados em contração, uma firma com fraca posição competitiva não dispõe de recursos e capacidades valiosos e o baixo custos dos recursos nestes mercados podem ser de alguma maneira atrativo para que a firma recupere ainda que parcialmente, sua força competitiva, inserindo novos recursos e recombinando com os que já dispunha. Esta ação dependerá da capacidade financeira da firma, que geralmente é delicada neste momento, e então a proposta de Arogyaswamy et al. (1995) de reduzir o tamanho e focar em segmentos nos quais os recursos e capacidades encontram maior valor, pode ser a alternativa viável.

p5: Firmas com natureza de renda ricardiana, com posição competitiva fraca em indústrias em crise, que acessarem novos recursos no mercado de fatores estratégicos ou que reduzirem suas operações para segmentos onde recursos tem maior valor, terão performance superior pós turnaround em relação àquelas que não adotarem tais ações.

p6: Firmas com natureza de renda schumpeteriana, com posição competitiva fraca em indústrias em crise, que desenvolverem novas competências ou que reduzirem suas operações para segmentos nos quais suas competências tem potencial de gerar maior valor, terão performance superior pós turnaround em relação àquelas que não adotarem tais ações.

Acessar o mercado de fatores estratégicos pode ser uma estratégia também para firmas em declínio mas com forte posição competitiva em uma indústria em retração. Para estas firmas a estratégia deve ser manter a posição competitiva com os recursos que dispõem, mas a expansão da posição competitiva pode ser viável via mercado de fatores estratégicos. No caso das competências, o momento pode ser oportuno para investir na reorganização de rotinas e construção de novas competências a fim de fortalecer a posição competitiva.

p7: Firmas com natureza de renda ricardiana, com posição competitiva forte em indústrias em crise, que manterem seus recursos e/ou acessarem novos recursos no mercado de fatores 
estratégicos, terão performance superior pós turnaround em relação àquelas que não adotarem tais ações.

p8: Firmas com natureza de renda schumpeteriana, com posição competitiva forte em indústrias em crise, que manterem suas competências e/ou investirem no fortalecimento e criação de novas competências, terão performance superior pós turnaround em relação àquelas que não adotarem tais ações.

A Figura 9 a seguir representa estas oito proposições na forma de recomendação de ações para cada uma das oito situações possíveis. 


\begin{tabular}{|c|c|c|c|c|c|}
\hline & \multicolumn{2}{|c|}{ Declínio causado por fatores internos da firma } & \multicolumn{2}{|c|}{ Declínio causado por retração no mercado } \\
\hline & & \multicolumn{4}{|c|}{ Posição Competitiva } \\
\hline & & Forte & Fraca & Forte & Fraca \\
\hline \multirow{2}{*}{ 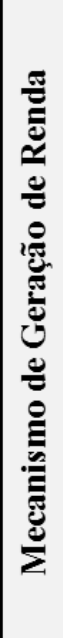 } & 吾 & $\begin{array}{l}\text { Fortalecimento e expansão } \\
\text { da posição competitiva com } \\
\text { ações de reorganização de } \\
\text { recursos com o objetivo de } \\
\text { incrementar eficiência } \\
\text { (reduzir custo médio) }\end{array}$ & $\begin{array}{l}\text { Foco em determinado } \\
\text { segmento de mercado com o } \\
\text { desenvolvimento de recursos } \\
\text { que permitam alcançar alta } \\
\text { eficiência. }\end{array}$ & $\begin{array}{l}\text { Estratégias de manutenção ou } \\
\text { expansão da posição } \\
\text { competitiva onde recursos } \\
\text { tem alto valor e conferem } \\
\text { elevada eficiência e/ou } \\
\text { acesso ao mercado de fatores } \\
\text { estratégicos. }\end{array}$ & $\begin{array}{l}\text { Foco em segmentos onde } \\
\text { recursos tem alto valor e são } \\
\text { capazes de promover elevada } \\
\text { eficiência e/ou acesso ao } \\
\text { mercado de fatores } \\
\text { estratégicos. }\end{array}$ \\
\hline & 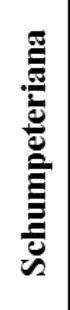 & $\begin{array}{l}\text { Fortalecimento e expansão da } \\
\text { posição competitiva com } \\
\text { ações de reorganização de } \\
\text { rotinas e capacidades com o } \\
\text { objetivo de elevar a criação } \\
\text { de valor (diferenciação) }\end{array}$ & $\begin{array}{l}\text { Foco em determinado } \\
\text { segmento com o } \\
\text { desenvolvimento de } \\
\text { capacidades que permitam a } \\
\text { gerar mais valor. }\end{array}$ & $\begin{array}{l}\text { Estratégias de manutenção ou } \\
\text { expansão da posição } \\
\text { competitiva onde capacidades } \\
\text { atuais podem levar à alto } \\
\text { valor (diferenciação) e/ou } \\
\text { investimento em novas } \\
\text { capacidades. }\end{array}$ & $\begin{array}{l}\text { Foco em segmentos onde } \\
\text { capacidades podem gerar } \\
\text { maior valor e/ou } \\
\text { investimento na criação de } \\
\text { novas capacidades. }\end{array}$ \\
\hline
\end{tabular}

Fonte: elaborado pelo autor

Figura 9 - Modelo de estratégias de turnaround 
No capítulo introdutório, foi citado o caso de turnaround da IBM-UK. A fim de validar o modelo que está se propondo, será feita uma releitura das estratégias de recuperação adotadas no caso discutido por Balgobin e Pandit (2001). No caso da IBM-UK, aquela unidade de negócios teve sua performance drasticamente afetada por uma mudança do padrão de demanda que não foi acompanhada pela empresa. A indústria de computadores passou de um modelo em que as empresas eram verticalmente integradas, dominando desde a fabricação de chips até o desenvolvimento de software e prestação de serviços, para um modelo horizontal em que cada empresa se especializou em um elo específico. As principais indústrias que concorriam com a IBM na época focaram em desenvolvimento de software e serviços (Microsoft) ou produção de chips (Intel) e houve a mudança do padrão de computadores, dos grandes mainframes para PC. O acesso a computadores pessoais passou de artigo de luxo para quase commodities. A IBM - UK não conseguiu acompanhar a mudança e passou de uma capacidade de geração de caixa de próximo a £500 milhões em 1988 para um prejuízo de quase $£ 1,0$ bilhão entre 1991/92.

Apesar do trabalho de Balgobin e Pandit (2001) atribuir o declínio a fatores externos, como a mudança do padrão de mercado, pelo que já foi discutido neste trabalho, não acompanhar mudanças do mercado consumidor é um problema interno à firma. Como sugere Lim et al. (2013), indústrias de alta tecnologia como a que se insere a IBM-UK, tem um padrão de competição muito pautado no investimento em $\mathrm{P} \& \mathrm{D}$, marketing e pessoal. De fato, Balgobin e Pandit (2001) elencam também alguns fatores internos que levaram ao declínio como a demora da IBM-UK em explorar novas tecnologias e que seus produtos não atendiam mais à necessidade. Essa incapacidade da empresa foi dita associada à distância entre as lideranças e o mercado real (a decisão estava concentrada na mão de poucos e distantes do mercado consumidor). O padrão de competição nestas indústrias é baseado na geração de rendas schumpeterianas como sugere Lim et al. (2013), associada à construção de capacidades dinâmicas que levem a rendas por inovação disruptiva.

Como não havia crise da indústria de tecnologia àquela época é possível atribuir o declínio da IBM-UK à questões internas à firma e ainda afirmar que sua posição competitiva foi alterada, de forte, como era anterior ao declínio, para uma posição fraca. Assim, no modelo proposto, as ações de recuperação devem girar em torno da construção de novas capacidades em um segmento específico do mercado (declínio causado por questões internas, renda schumpeteriana e posição competitiva fraca). 
Pela descrição de Balgobin e Pandit (2001) o principal objetivo do CEO à época era transformar a IBM-UK, de uma firma de computadores em geral para uma líder em soluções. Assim, a empresa desinvestiu de segmentos que não faziam parte deste novo conceito e promoveu uma série de mudanças na estrutura organizacional para que cada divisão de negócio fosse responsável por seus resultados conferindo assim mais autonomia para sua ação e cobrando pelos resultados. O foco passou a ser em consultoria e serviços com forte especialização no mercado. A diretriz era passar a ser uma empresa orientada ao cliente e altamente responsiva ao mercado. A eliminação de quatro níveis gerenciais tornou a empresa mais ágil na tomada de decisão e resposta ao mercado. Diversos programas para mensurar a satisfação do atendimento aos consumidores foram implementados, e um novo quadro de competências necessárias foi aplicado aos gestores que deveriam ser mais generalistas e menos funcionais, com o objetivo de fortalecer a capacidade de enxergar tendências e propor soluções.

Como visto, as ações tomadas pela IBM-UK buscaram o foco em um segmento específico, seguido de ações para construir capacidades internas que permitam uma posição de liderança no segmento de serviços e consultoria em TI. As capacidades brevemente apresentadas acima podem sem compreendidas como as capacidades dinâmicas necessárias para a geração de rendas schumpeterianas.

Pela avaliação, ainda que superficial, do caso da IBM-UK à luz do modelo discutido na Figura 9 é possível observar que as ações adotadas pela firma em seu processo de turnaround são bastante próximas ao recomendado no modelo: foco em determinado segmento com o desenvolvimento de capacidades que possam gerar maior valor. 


\section{ESTUDO DE CASO}

Como pôde ser observado nos capítulos 2 e 3, dentre as abordagens das escolas de estratégia, OI e TBR se mostraram dominantes com importantes contribuições para o estudo de turnaround de empresas. Por outro lado, a ECT foi negligenciada pelos estudos que tratam do turnaround e a possibilidade de integrar conceitos da ECT ao processo de turnaround foi pouco explorado. Além disso, o fato de que os trabalhos sobre turnaround vêm buscando a aproximação de seus conceitos em situações de maior especificidade, como por exemplo, a adequação dos conceitos do turnaround à indústrias maduras, à indústrias de alta tecnologia, à firmas com diferentes naturezas de renda e até o efeito de suas proposições em empresas familiares. Isto sugere que testar os conceitos do turnaround em indústrias diversas e organizações de natureza distinta é crucial para melhor compreensão do fenômeno.

O presente capítulo deverá por meio de um estudo de caso, avaliar o processo de turnaround pelo qual passou a Cooperativa Agroindustrial Holambra. A escolha da cooperativa se deu primeiramente para testar os conceitos desenvolvidos pela literatura em uma forma organizacional distinta. Assim como Cater e Scwab (2008) propõem que empresas familiares têm particularidades que fazem com que alguns conceitos defendidos pela literatura de turnaround precisam ser encarados com cautela, a avaliação do turnaround de uma cooperativa deve fornecer argumentos para um modelo de turnaround mais abrangente. Além disso, cooperativas tem uma característica particular com relação à sua estrutura de governança e por esta razão receberam especial atenção pela literatura sob a perspectiva da ECT (Bialoskorski Neto e Marques, 1998; Zylbersztajn, 1994). Assim, a opção por estudar o turnaround de uma cooperativa deve permitir a aproximação da ECT aos estudos de recuperação de empresas.

O uso de casos (clinical cases) apesar de não ser tão difundido foi utilizado em casos clássicos na literatura de economia das organizações e é uma metodologia adequada dentre outras razões para, com certas evidências, testar teorias. Assim, a utilização de um caso pode ser útil para fortalecer ou enfraquecer uma conclusão teórica (Baker e Gil, 2012). No presente capítulo, o caso será explorado com o objetivo de fornecer evidências para testar as recomendações da literatura sobre o processo de turnaround de empresas e também o modelo proposto na Figura 9. 
A característica de maior diferenciação entre uma cooperativa e uma firma comum é o fato de que na primeira o dono também é cliente, isto é, o cooperado geralmente é atendido pela cooperativa com a compra de insumos e serviços e venda de sua produção ao mesmo tempo em que é dono da cooperativa. Não é esta, no entanto, a característica mais desafiadora da gestão das cooperativas. $\mathrm{O}$ fato de os cooperados muitas vezes também serem gestores é que impõe desafios. O duplo papel dos cooperados induz ineficiências principalmente quando as organizações ganham escala (ZYLBERSZTAJN, 2002).

"O cooperado que gerenciou, com sucesso, um empreendimento cooperativo no seu início tenderá a perder eficiência ao ampliar a escala ou a complexidade do seu empreendimento, seja pelo crescimento vertical, seja pelo crescimento horizontal ou pelo dinamismo tecnológico" (ZYLBERSZTAJN, 2002, p.4).

Um aspecto importante em cooperativas diz respeito às suas cotas às quais não são alienáveis e o fato de o cooperado ter que pagar para entrar e para sair da cooperativa; existem, portanto, incentivos perversos para a tomada de decisão em prol da valorização do próprio negócio em detrimento do desempenho da cooperativa (Zylbersztajn, 1994).

O fato das cotas da cooperativa não valorizarem ao longo do tempo leva a um "problema de horizonte", que é a opção dos cooperados por ações de benefício imediato para eles, ainda que a longo prazo esta ação cause danos à cooperativa. Em firmas não cooperativas, sobretudo aquelas com ações listadas no mercado de capitais, o preço da ação é um indicativo de que os gestores estão tomando ações que beneficiarão àquela organização, no médio-longo prazo e exerce pressão sobre os gestores. Em cooperativas esse mecanismo é ausente e contribui para manutenção do problema de horizonte. Outro problema relevante é o do "free rider" (o carona), que acontece sempre que há dificuldades de mensuração da contribuição ou prejuízo marginal que um determinado indivíduo tem em uma relação. Assim, nas cooperativas um cooperado pode, por exemplo, desviar parte dos insumos adquiridos da cooperativa com vantagens exclusivas aos cooperados e ganhar na revenda destes produtos. Um terceiro problema é o custo de influência exercido por cooperados membros de conselhos, comissões ou mesmo gestão, com capacidade de influenciar decisões que podem beneficiar seus negócios individuais, mas atentar para a eficiência da cooperativa (ZYLBERSZTAJN, 2002). 
Assim como todas as firmas, as cooperativas não estão inertes ao comportamento oportunista que pode ser tomado por seus cooperados e que leva a custos de controle significativos. As relações entre cooperativa e cooperados estão sujeitas à assimetria de informação que levam a um maior custo contratual. O custo de controle e o custo contratual levam as cooperativas a apresentarem potencialmente custos de transação elevados que não são mitigados pelo "espírito cooperativista". "O aspecto doutrinário das cooperativas não é suficiente para garantir baixos custos de transação entre a cooperativa e o membro cooperado (ZYLBERSZTAJN, 2002, p.3)”.

\subsection{O caso da Cooperativa Agro Industrial Holambra}

“Cooperativas não tem lucro, tem 'sobra' [...] no processo de reestruturação e recuperação aprendemos que uma cooperativa tem que brigar pela "sobra" S. Veldt (entrevista com o presidente, 10 de março de 2015).

Este caso trata do processo de recuperação pelo qual a Cooperativa Agro Industrial Holambra, passou nos anos 1990. No início daquela década a cooperativa viu a área de produção de seus cooperados reduzir-se a 44\% da área cultivada nos anos de 1980 e em 1996, acumulou prejuízo líquido de $\mathrm{R} \$ 2,9$ milhões (Gráfico 3) e o retorno sobre o capital investido (ROI) foi negativo em 10,93\% (Gráfico 2). Contudo, diferentemente de tantas outras cooperativas e empresas do agronegócio ${ }^{22}$, a Holambra conseguiu se recuperar e oito anos depois já alcançava ROI superior a 10\% e lucro líquido de quase R\$9 milhões. No ano de 2012 a Holambra foi a $25^{\mathrm{a}}$ empresa do agronegócio em termos de crescimento segundo a revista de negócios EXAME. O presente caso deverá avaliar o processo de turnaround pelo qual a Holambra passou entre as décadas de 1990 e 2000.

\footnotetext{
${ }^{22}$ O final da década de 1970 e a década de 1980 foi um período caracterizado por forte instabilidade econômica no Brasil, sobretudo no setor agrícola. A revolução verde que trouxe ganhos significativos de produção fez com que a oferta de alimentos se tornasse tamanha que os preços de commodities agrícolas foram consistentemente inferiores à década anterior. Somado a este cenário, secas e chuvas em excesso provocaram quebras de produção em regiões localizadas no Brasil. Preços baixos associados à quebra de safra levaram muitos agricultores à falência e com eles seus credores, compreendidos por cooperativas e demais fornecedores de insumos. Um caso emblemático foi o da Cooperativa Agrícola Cotia (CAC) que não foi capaz de se recuperar e teve sua falência decretada no ano de 1994, deixando para trás mais de 14 mil cooperados.
} 


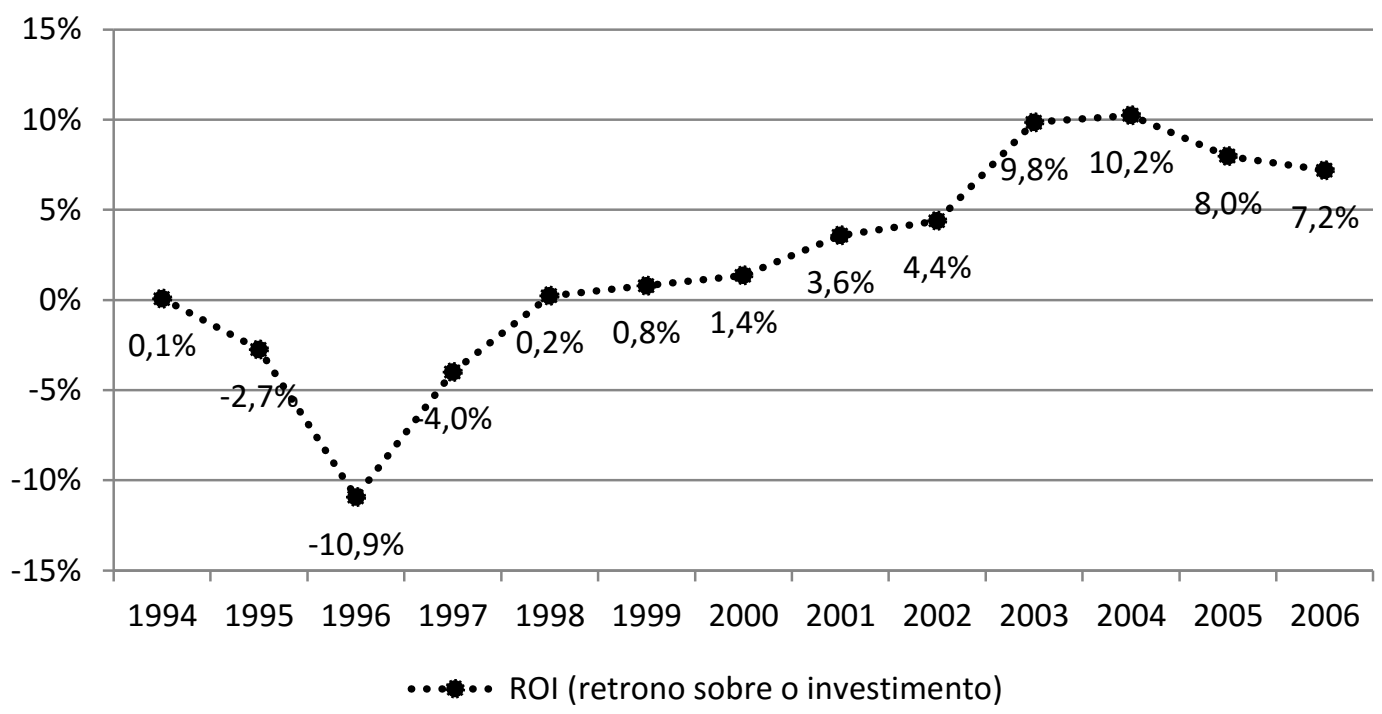

Gráfico 2 - Evolução do retorno sobre o investimento da Holambra entre 1994 e 2006 Fonte: Holambra - documentos internos

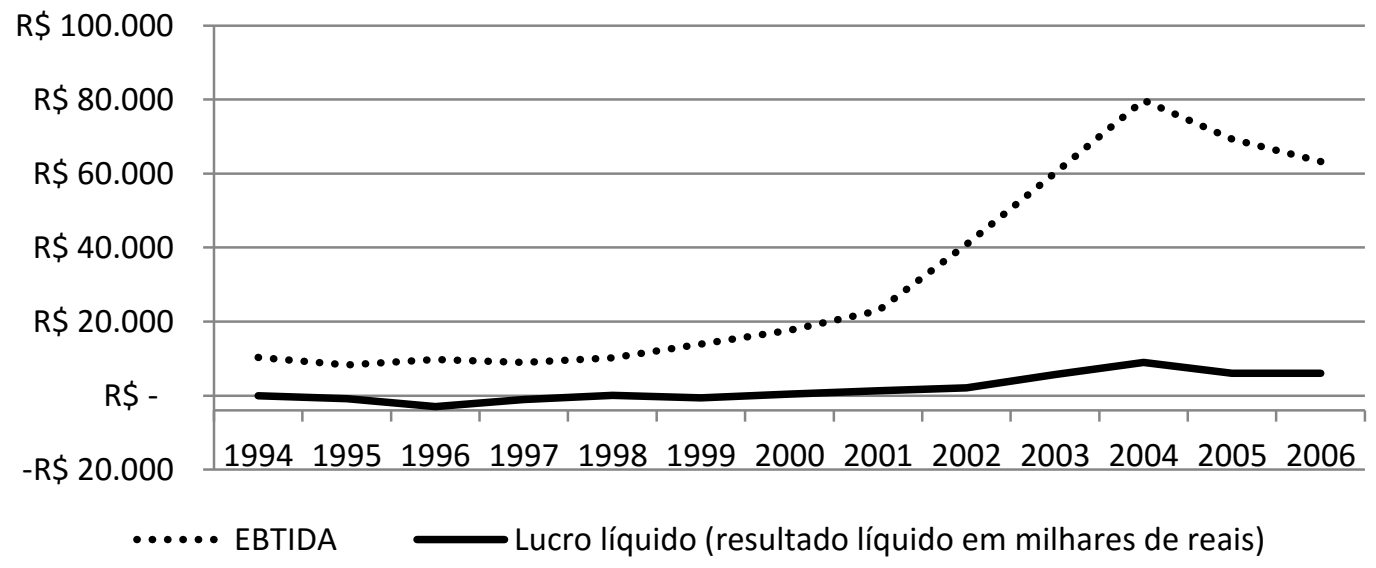

Gráfico 3 - Evolução do EBTIDA e lucro líquido da Holambra entre 1994 e 2006 (milhares de reais) Fonte: Holambra - documentos internos

A Cooperativa Agro Industrial Holambra foi fundada em 23 de dezembro de 1960 no município de Paranapanema/SP, no km 256 da Rodovia Raposo Tavares (SP-270), sob a denominação "Cooperativa de Imigração e Colonização Holambra”. Formada por produtores rurais emigrados da Holanda no programa de emigração do governo holandês e produtores egressos da Cooperativa Agro Pecuária Holambra, sediada no município de Holambra/SP.

O início da cooperativa contou com o financiamento do governo norte americano para aquisição de terras e do governo holandês para a construção de toda a infraestrutura necessária para seu funcionamento, tais como barracão, silos, posto de combustível, residências, supermercado, hospital, igreja, escola e clube. Os primeiros plantios foram de 
arroz e milho, sendo que a cooperativa financiou o primeiro preparo de solo de seus cooperados (Holambra, 2015).

Na ocasião de sua fundação até meados da década de 1980, a cooperativa provia todo o suporte aos seus cooperados, desde assistência técnica até a compra de supermercado, que nos primeiros anos, só podia ser feita na cidade de Avaré, há $60 \mathrm{~km}$ de distância em estrada de terra. Segundo Simon Veldt, presidente da cooperativa por seis mandatos consecutivos, nesse período a cooperativa era associada à "figura de uma mãe", provendo bens coletivos e atendendo a todas as necessidades dos cooperados, desde sua vida particular até seu negócio agrícola. Como parte dos serviços prestados, a cooperativa possuía um supermercado, oficina mecânica, posto de combustível, posto de saúde, escola, oferecia assistência técnica aos cooperados, cuidava de operações bancárias do produtor e logicamente, recebia a produção agrícola e comercializava insumos. A despeito da importância que a cooperativa assumiu para o desenvolvimento da comunidade, o seu foco de seu negócio sempre foi a prestação de serviços de recebimento, beneficiamento, armazenagem e comercialização da produção do cooperado, venda de insumos para a produção e assistência técnica.

\subsubsection{Contexto econômico e a evolução da crise}

No ano de 1965 foi criado no Brasil o Sistema Nacional de Crédito Rural (SNCR), uma medida para promover a geração de excedentes exportáveis e estimular a produção de bens no país. Os anos seguintes foram de prosperidade para a indústria nacional que elevou de maneira excepcional a produção de bens duráveis e o mercado de bens de capital. A política de estímulo à exportação proporcionou forte crescimento da produção de soja, demandada pelo mercado externo (Fürstenau, 1987).

A cooperativa Holambra se formou e desenvolveu suas primeiras atividades em um ambiente de estímulo ao crescimento. Entre os anos de 1967 e 1973, houve forte estímulo por parte do Estado, para a modernização da agricultura com investimentos de médio e longo prazo. No entanto, o crédito rural sempre foi majoritariamente destinado ao custeio da produção (Fürstenau, 1987). Até o final da década de 1970, os produtores associados à cooperativa Holambra alcançaram área cultivada de cerca de 45 mil hectares. A oferta de crédito barato, que foi a tônica da política de expansão e modernização da agricultura, começou a arrefecer a partir de 1976. Essa medida fez parte de um plano maior do Estado brasileiro, de corte de 
investimentos públicos em resposta a desaceleração da economia mundial. O crédito não só passou a ficar mais escasso e caro, como teve alterada a relação crédito para investimentos e crédito para custeio. O governo priorizou o custeio e o crédito para investimentos de médio e longo prazo foi cada vez menor. Assim, em 1983, os grandes produtores só eram atendidos em $40 \%$ da sua necessidade de crédito para custeio. Na década de 1970 esse valor podia alcançar 100\% (Fürstenau, 1987). Esse processo de desmantelamento do SNCR foi o gatilho para a crise que a agricultura nacional passaria na década seguinte.

A cooperativa Holambra sofreu as consequências deste ajuste na economia e em meados da década de 1980 iniciou uma série de mudanças com o objetivo de equilibrar suas contas. O atual presidente da cooperativa, Simon Veldt, faz uma análise daquele momento crítico da história da Holambra:

Na década de 1970 houve oferta muito grande de crédito e os produtores estavam endividados. Na década de 1980, a revolução verde trouxe excedentes de produção mundial, somados a secas na região e necessidade de pagar as dívidas, muitos produtores não conseguiram honrar seus compromissos e a cooperativa foi penalizada" S. Veldt (entrevista com o presidente, 10 de março de 2015).

Ainda antes desse período, quando a oferta de crédito era boa, muitos produtores faliram (década de 1960 e 1970) e alguns voltaram para a Holanda. Nesse período os cooperados não conseguiam honrar com o custo da própria estrutura e a cooperativa, que funcionava como um agente intermediário de repasse de crédito do Banco do Brasil teve que renegociar a dívida com o governo brasileiro e tomou um empréstimo com o banco holandês, Rabobank. Neste período o presidente em curso, Paulo Hoogenboom, adotou medidas impopulares como a restrição parcial ou total de crédito aos cooperados, com o objetivo legítimo de reestabelecer o equilíbrio financeiro da cooperativa. Entre 1985 e 1992, período de mandato do presidente Gustavo Serrarens, outras medidas foram tomadas com o objetivo de alcançar a saúde financeira da cooperativa, reduzir seu endividamento e reestabelecer a força de seus cooperados. A cooperativa buscou focar nas atividades de produção e terceirizou atividades como oficina mecânica, comercialização de peças e supermercado. Como a saúde financeira da cooperativa sempre foi muito dependente do desempenho de seus cooperados, no mandato do presidente Gustavo Serrarens, foi estimulada a diversificação da produção com incentivos para a produção de frutas e flores. Além disso, a experiência ruim com as secas na região fez com que em 1985 fossem implantados os primeiros projetos de irrigação com incentivo da cooperativa (a cooperativa patrocinou uma viagem técnica à região de Guaíra onde já existiam 
os pivôs centrais). Este movimento se fortaleceu nos anos de 1990 e foram adotados massivamente nos anos 2000. Os investimentos em irrigação conferiram maior segurança aos cooperados e assim possibilitou que se capitalizassem, levando a um expressivo crescimento da cooperativa a partir de então. No ano de 2014, por volta de 75 a $80 \%$ da área de agricultura dos cooperados da Holambra foi irrigada.

No final dos anos 1980 o subsidio estatal à produção de trigo foi cessado e a competição com o produto importado foi ainda mais forte, sobretudo com o trigo que vinha da Alemanha com produção subsidiada. Com isso o uso dos pivôs encontrou alternativa com a cultura de feijão, que era plantado em períodos de entre safra com boa produtividade e bom preço. Posteriormente os cooperados passaram a plantar milho irrigado e também algodão.

Em 1993 assume a nova gestão, presidida pelo Sr. Simon Veldt e mais quatro conselheiros, um dos quais já havia tido a experiência de ser superintendente da cooperativa, o Sr. João Beckers. "Na época em que assumi a presidência havia uma necessidade de mudança, e a diretoria anterior estava desgastada (em função dos tempos difíceis que exigiram rigor financeiro) e foi importante trocar a equipe [para dar continuidade às mudanças] (S. Veldt, entrevista com o presidente, 10 de março de 2015)".

Como uma das primeiras ações, a cooperativa contratou uma consultoria para realizar o planejamento estratégico, envolvendo produtores, comissões e diretoria. No entanto, na visão do Sr. Simon "havia muitas divergências e não se chegou a um consenso acerca do futuro da cooperativa". O superintendente na época foi trocado, como resposta à pressão dos cooperados que entendiam que seus anseios não estavam sendo atendidos. Seu substituto, Pedro Hermanns, que era o contador da cooperativa à época, teve como principal trabalho a reestruturação da contribuição das divisões para as atividades operacionais da cooperativa.

Naquela época a cooperativa era estruturada em quatro divisões, a sociedade, com os serviços corporativos, a agrícola, a pecuária e a de perecíveis. Essas três últimas divisões utilizam os serviços prestados pela sociedade. O trabalho desenvolvido por Pedro Hermanns tinha como objetivo alocar a participação de cada divisão nos custos da sociedade da maneira mais correta. Com isso, eventuais "subsídios cruzados" entre as divisões, isto é, uma divisão pagando o custo da outra, são evitados e favorecem a apuração real do resultado de cada divisão para a tomada de decisão. 
No ano de 1994, outro evento externo impõe novos desafios à Holambra. O pedido de falência da CAC dificultou a tomada de crédito para as cooperativas em geral e afetou diretamente os negócios da Holambra e sua capacidade de honrar com compromissos financeiros. Assim, a cooperativa empreendeu um esforço para renegociar sua dívida com o Rabobank. Após trocas de cartas e uma negociação dura de ambos os lados, a cooperativa conseguiu alongar o prazo para mais oito anos e uma taxa de juros bastante atrativa $(8,75 \%$ ao ano).

Entre 1985 e 1994 a Holambra sofreu os efeitos de sucessivas mudanças do ambiente econômico e especialmente da forte restrição de crédito e inadimplência de seus cooperados. Na visão do presidente Simon Veldt, "vários planos econômicos trouxeram mais crise financeira e dificuldade de honrar compromissos. Parte do empréstimo estava em florins (dívida com Rabobank) e a desvalorização da moeda brasileira foi trágica [para a cooperativa] (S. Veldt, entrevista com o presidente, 10 de março de 2015)". Com o agravamento da situação financeira a Holambra passou por um período de restrição de crédito e adotava a política de reter a produção dos cooperados na proporção de seus débitos em aberto. Isto fez com que o cooperado deixasse de comprar insumos na cooperativa e desviasse sua produção para outras empresas, reduzindo assim a volume de venda de insumos e de comercialização de grãos da cooperativa ${ }^{23}$.

Em 1996, ao final de seu primeiro mandato, o presidente Simon Veldt enfrentava o seguinte dilema: Como desenvolver um plano de recuperação capaz de equilibrar a situação financeira da cooperativa (o que poderia atentar para a boa relação com cooperados endividados), aproximando os cooperados e tornando-os mais preocupados e engajados com a recuperação da cooperativa? Este dilema era especialmente importante, pois, a cooperativa já havia empreendido diversos esforços em busca de recuperar sua performance ao longo dos últimos anos. A prestação de serviços não essenciais havia sido cortada, houve restrição de crédito aos cooperados, renegociação de dívidas com credores, incentivo à produção de culturas alternativas com o objetivo de pulverizar o risco climático e variações de preços, estímulo ao

\footnotetext{
${ }^{23}$ Diferentemente de outras cooperativas, a Holambra não compra a produção de seus cooperados, de maneira que toda sua estrutura é focada na prestação de serviços de comercialização ou armazenagem e é cobrada uma taxa de prestação de serviço do cooperado.
} 
investimento em pivôs etc. No entanto, a performance era errática e a sobrevivência da cooperativa continuava incerta.

Ainda que após tentativas diversas das diretorias anteriores para recuperar o desempenho da Holambra não tenham sido suficientes, a cooperativa alcançou algo importante na visão do presidente. Naquele período a cooperativa passou por uma transformação fundamental: "entre 1980 e 1990 a cooperativa teve que fazer a transição de uma cooperativa de colonização para uma cooperativa de produção ${ }^{24}$ (S. Veldt, entrevista com o presidente, 10 de março de 2015)".

\subsubsection{A recuperação}

O processo de recuperação da Cooperativa Agro Industrial Holambra iniciou-se na formação da chapa para o segundo mandato de Simon Veldt. Isto por que, com o intuito de alcançar maior apoio e engajamento dos cooperados em um processo de reestruturação da cooperativa, o presidente Simon convidou para compor sua chapa, os cooperados que mais seriam impactados por eventual falência da cooperativa, isto é, aqueles que participavam com o maior capital social da cooperativa ${ }^{25}$. Apesar de a doutrina cooperativista prever que o voto de cooperados com diferentes capitais sociais tenham o mesmo peso (um homem um voto), a participação no conselho e em comissões confere certo poder no desenho das estratégias da cooperativa. Assim, foram selecionados cinco cooperados dentro do grupo dos $20 \%$ que detém cerca de $80 \%$ do capital social da cooperativa, para compor a chapa do conselho. A reeleição do presidente Simon Veldt foi apoiada e defendida pelo Sr. Pedro Derks, um cooperado e importante formador de opinião entre os cooperados.

Logo no início do mandato, o presidente e conselheiros tomaram uma atitude simbólica com o objetivo de demonstrar que o período de ajustes e reestruturação era algo levado muito a sério pelo conselho: cortaram em $50 \%$ os honorários que receberiam pela sua função. O presidente

\footnotetext{
${ }^{24}$ Como citado anteriormente, no início de suas atividades, a cooperativa dava todo e qualquer suporte a seus cooperados, desde a assistência técnica e serviços relacionados à agricultura até a compra de supermercado, escola e assistência médica. Esta característica era comum às cooperativas de colonização que tinham que apoiar o estabelecimento de famílias em regiões afastadas dos centros urbanos. O capital social representa um montante significativo e é esperado como uma aposentadoria por muitos cooperados.

${ }^{25} \mathrm{O}$ capital social da cooperativa é formado pelo montante pago por cada cooperado no momento de seu ingresso na cooperativa e é função de sua área de produção. Assim, aqueles com maior área de cultivo pagam um valor maior para entrar na cooperativa. A retirada do capital social é prevista no estatuto da cooperativa e definida pela idade do cooperado e tempo que permaneceu associado.
} 
Simon Veldt fez um curso sobre gestão de crises para saber lidar melhor com a situação pela qual a cooperativa estava passando.

Dois cooperados fizeram uma importante contribuição para a gestão financeira da cooperativa, o Sr. Theodorus Swart e o Sr. Henk van Melis colocaram seu patrimônio à disposição de credores ao assinar como avalistas da Holambra. Essa ação "foi essencial para a tomada de crédito [da cooperativa] (S. Veldt, entrevista com o presidente, 10 de março de 2015)".

Com o objetivo de trazer novas práticas de gestão, conselho e presidente organizaram algumas visitas a cooperativas ${ }^{26}$ e trouxeram importantes aprendizados, que segundo o presidente Simon Veldt, foram determinantes neste processo de reestruturação: 1) Na CAPAL Cooperativa Agroindustrial, também uma cooperativa fundada por holandeses, aprenderam que o superintendente da cooperativa não precisava ser engenheiro agrônomo, mas sim que devia entender principalmente de gestão financeira. Assim, buscaram no mercado um profissional com larga experiência administrativa e financeira e contrataram Renzo Guazzelli, em maio de 1997, que tinha vinte anos de experiência no mercado; 2) Na COAMO, de Campo Mourão/PR, aprenderam que a cooperativa deveria lutar pelo lucro. "Por lei uma cooperativa não tem lucro, e sim 'sobra', e não era da cultura da empresa a luta pela sobra" (Simon Veldt); 3) A partir do que foi visto na COCAMAR e COOPERMOTA, a Holambra apreendeu o conceito de "concessão de crédito" e desenvolveu seu próprio modelo, no qual os cooperados eram segmentados em 3 níveis (A, B e C) para concessão de crédito e exigência de garantias. Segundo o presidente Simon, a palavra isonomia era interpretada de maneira parcial pela cooperativa. O significado de isonomia é: tratar todos de maneira igual na medida de suas diferenças ou nas palavras do Simon, "tratar de forma igual os comportamentos e situações iguais". "Então um cooperado que é mais pontual e tem mais garantias deve ser tratado diferente do cooperado que atrasa as contas e não tem garantias reais”. A Holambra, no entanto, tratava de maneira igual cooperados que tinham diferentes comportamentos em relação à cooperativa e isso passou a ser diferente; 4) $\mathrm{Na}$ área financeira, a célula de projetos e

\footnotetext{
${ }^{26}$ As cooperativas escolhidas (CAPAL, COAMO, COCAMAR e COOPERMOTA) são importantes cooperativas na região do vale do Paranapanema e norte do Paraná. A CAPAL é também formada por imigrantes Holandeses e fundada no mesmo ano que a Holambra. A COCAMAR, fundada em 1963 em Maringá/PR, conta atualmente com 12,1 mil associados e está presente também no estado de São Paulo e Mato Grosso do Sul. A COOPERMOTA, fundada na década de 1950 na cidade de Cândido Mota/SP e conta atualmente com 1,9 mil cooperados. Um pouco mais nova a COAMO fundada em 1970 em Campo Mourão/PR está presente em 63 municípios do Paraná, Santa Catarina e Mato Grosso do Sul.
} 
financiamento foi eliminada. Essa célula era responsável pelos pedidos de financiamento dos cooperados e gerenciamento dos repasses. O serviço remunerava a cooperativa em $0,5 \%$ do valor do contrato, mas seu custo para a cooperativa era incerto e sua diluição estava associada à oferta de crédito e desempenho do agronegócio. Esse corte foi um aprendizado trazido da COOPERMOTA.

Ainda com relação à estrutura administrativa e gestão, houve o corte de duas linhas de gerência. Esta mudança além de trazer economias importantes para a cooperativa aproximou superintendência, presidência e conselho, dos gestores, trouxe mais agilidade na tomada de decisão e permitiu maior autonomia aos gerentes para trabalhar com as diretrizes vindas do conselho. Além disso, foi instituída a regra de que cada divisão é responsável pela utilização dos serviços corporativos.

Na década de 1990 a cooperativa passou a fazer parte do um pool de compras (ABCWH Das cooperativas Arapoti, Batavo, Castrolanda, Witmarsum e Holambra), e o desempenho de compras foi aprimorado. $\mathrm{Na}$ época $70 \%$ dos cooperados compravam em outros locais. Houve profissionalização da área de compras e vendas até que passaram a atuar sozinhos. A criação de um sistema de planejamento de compras baseado na safra estimada dos cooperados permitiu que a Holambra pudesse se planejar com maior eficiência e antecipasse a compra com os fornecedores, gerando economias.

Segundo o superintendente, Renzo Guazzelli, os seis primeiros meses de seu mandato foi um período de reestruturação financeira. Naquela época a cooperativa não tinha fluxo de caixa projetado, de forma que o planejamento financeiro era muito dificultado. Além disso, descobriu-se que um colaborador da área financeira tinha causado desfalques significativos para a cooperativa. $\mathrm{O}$ desfalque atingiu as reservas da cooperativa, mas também recursos dos cooperados que estavam no caixa da cooperativa e gerou muita insegurança entre os cooperados com relação a transacionar com a cooperativa. Dentre as atividades de reestruturação financeira, a cooperativa se empenhou na recuperação de crédito com os cooperados devedores e na renegociação de dívidas com bancos (R. Guazzalli, entrevista com o superintendente, 5 de maio de 2015).

$\mathrm{Na}$ época, Renzo Guazzelli, que tinha larga experiência com gestão financeira desenvolveu uma rotina de compras a prazo e venda à vista (anteriormente a compra e a venda era a prazo). 
Com o dinheiro recebido com a venda à vista a cooperativa conseguia renegociar as dívidas das contas a prazo e alcançava descontos importantes para a cooperativa. Como mencionado, naquela época a cooperativa passou por uma mudança de paradigma e voltou suas atenções ao lucro. Uma importante ação na área comercial de venda de insumos foi a adoção de margens flexíveis. Até então era utilizada margem bruta fixa de 5\% com cooperados e 7\% com terceiros. A partir de então, flexibilizaram-se as margens no sentido de não haver limitações para cobrar margens superiores mesmo que para cooperados. Esta ação foi importante para permitir que a divisão de suprimentos passasse a ter resultado positivo.

Mais mudanças no âmbito da estrutura de custos e serviços aos cooperados foram feitas. A assistência técnica de todas as divisões (agrícola, perecíveis e pecuária) eram internalizadas pela cooperativa e o cooperado acessava e pagava somente parte dos custos. No entanto, o serviço estava sendo pouco valorizado e a cooperativa decidiu terceirizá-los. Nessa época foi constituída a Holambra Agrícola, que passou a prestar assistência técnica para grande parte dos cooperados. Houve um sentimento geral de que com isso, o nível de serviço melhorou.

Com relação à estrutura de ativos e dívidas a Holambra adotou uma série de medidas. Com os cooperados, houve um trabalho de renegociação de dívida e venda de ativos de alguns para recuperar o recurso para a Holambra. Como no início a região não ofertava residência, a cooperativa tinha à disposição trinta casas que eram ocupadas pelos seus funcionários. Para manter isso havia uma equipe de manutenção que pesava nos custos da cooperativa. Essas casas foram colocadas à venda com opção de compra para os próprios funcionários e possibilidade de financiamento via Caixa Econômica Federal. Com isso a cooperativa captou recursos que estavam imobilizados sem gerar receitas e reduziu custos com manutenção e mão de obra. Além disso, outras casas que eram ocupadas por cooperados e que eram de posse da cooperativa foram vendidas para pagar empréstimos que tinham sido feitos por cooperados à cooperativa.

Com o objetivo de reverter o cenário de cooperados desviando sua produção da Holambra e comprando insumos em concorrentes, a Holambra instituiu um programa com o objetivo de atrair e fidelizar o cooperado. Esse programa formalizado via acordo de produtores previa desconto no custo de beneficiamento e financiamento dos insumos comprados. Para isso os produtores deveriam informar a quantidade de produtos que seriam entregues na cooperativa em relação à sua produção total. Esta política levou a cooperativa a ter $95 \%$ dos cooperados 
comprando insumos e entregando sua produção na cooperativa em um período de três a quatro anos a partir de 1996. Nesta época houve aumento do volume de vendas na Holambra enquanto outras cooperativas e distribuidores quebraram.

...Um dos problemas da cooperativa naquela época era a falta de credibilidade perante os cooperados. O cooperado não tinha segurança de deixar seu dinheiro na cooperativa, imaginando que o dinheiro poderia sumir como aconteceu antes. Essa política foi importante pois trouxe o cooperado de volta à cooperativa $\mathrm{e}$ reconquistamos sua confiança (R. Guazzalli, entrevista com o superintendente, 5 de maio de 2015)".

\begin{tabular}{|c|c|c|}
\hline Grupo & $\begin{array}{c}\text { Entrega Produção } \\
(\% \text { do total })\end{array}$ & Benefício \\
\hline A & $100 \%$ & $\begin{array}{c}5 \% \text { de desconto no beneficiamento + financiamento de } \\
\text { insumos }\end{array}$ \\
\hline B & $80-100 \%$ & Financiamento de insumos \\
\hline C & $<80 \%$ & Sem benefício \\
\hline
\end{tabular}

Quadro 12 - Programa de incentivo aos cooperados

Fonte: Holambra - documentos internos

As vantagens que a cooperativa oferecia aos cooperados que utilizavam sua estrutura de recebimento de cereais e algodão eram financeiras e compensavam o custo superior de seus serviços. A cooperativa não descontava a quebra técnica ${ }^{27}$ de seus cooperados, a quirera ${ }^{28}$ era vendida e sua receita repassada ao cooperado e o resultado líquido da divisão (sobras) é repartido entre os cooperados que participaram daquela atividade na proporção de suas transações. Assim, a noção de que os cooperados são "donos" do negócio e que participam dos lucros, era evidente transacionar com a Holambra trazia mais valor ao negócio do cooperado.

A performance da cooperativa, mensurada pelo retorno sobre o investimento (Gráfico 2), alcançou pior resultado no ano de 1996, mas já em 1998 teve resultado positivo próximo a zero e seguiu positivo nos anos seguintes. A geração de receita pela operação (EBTIDA) por sua vez, alcançou o pior resultado no ano de 1997 (Gráfico 3). Somente no ano de 2000 é que

\footnotetext{
${ }^{27}$ A quebra técnica é a diferença de peso em decorrência do processo de beneficiamento de grãos.

${ }^{28}$ Quirera é o termo utilizado para o farelo oriundo da quebra de grãos no processo de beneficiamento e armazenagem e que pode ser utilizada na alimentação de animais.
} 
a cooperativa consegue alcançar um resultado final significativo (lucro líquido), quando somou ao final do período, $\mathrm{R} \$ 412$ mil e a partir de então não voltou a registrar prejuízos.

Uma das ações tomadas no processo de reestruturação da cooperativa foi o encerramento de atividades não essenciais, terceirização de atividades e redução dos níveis gerenciais. $\mathrm{O}$ Gráfico 4 a seguir, demonstra a relação entre o custo da mão de obra terceirizada e os desembolsos com salários e benefícios de empregos diretos. Observa-se que até 1997, a cooperativa tinha um desembolso médio próximo a $20 \%$ com terceiros em relação ao que era gasto com empregos diretos. A partir de 1998 essa relação salta para cerca de $30 \%$ e se mantém próximo a este patamar até 2003 , quando então volta a subir e chega a alcançar $47 \%$ no ano de 2005. O aumento da participação de desembolsos com terceiros em relação a empregos diretos não foi somente substituição, observa-se certo ganho de eficiência quando se considera a relação entre valor total com mão de obra (desembolso com terceiros e empregos diretos) e o faturamento total. Nota-se que a partir de 1996 a relação caiu de 11,3\% em 1996 para 3,2\% no ano de 2003. Esse incremento em produtividade pode ser corroborado com a relação de faturamento por colaborador (Gráfico 5). Entre 1994 e 1998, o crescimento médio anual (CAGR\%) da produtividade da mão de obra foi de $17 \%$ ao passo que entre 1998 e 2002 esse crescimento foi de 28\%. As ações de redução de níveis gerenciais e a terceirização de atividades podem explicar este crescimento. No entanto, é importante mencionar que a melhor utilização da capacidade instalada, sobretudo de armazenagem exerceu contribuição determinante para o aumento do faturamento sem necessariamente modificar o quadro de colaboradores. No ano de 1998 o faturamento da divisão agrícola com o beneficiamento da produção dos cooperados representou $28 \%$ do faturamento total, ao passo que no ano de 2002 a relação passou para 40\%, com a mesma capacidade estática de armazenagem.

Outro indicador dos ganhos substanciais que a cooperativa alcançou, resultado das ações adotadas a partir de 1997, foi a redução relativa das despesas operacionais. O Gráfico 6 mostra que a proporção entre despesas operacionais e faturamento caiu consideravelmente no ano de 1998 , alcançando $12,9 \%$ do faturamento, ante $18,3 \%$ no ano anterior e de $7,7 \%$ em 2002.

A liquidação de ativos não essenciais deve ter contribuído também para a redução de despesas operacionais. No Gráfico 7 é possível observar que a relação entre ativo permanente sobre o 
total de ativos caiu de 45\% em 1998 para cerca de 24,5\% em 2002. Entre os anos de 1994 e 2000, com exceção do ano de 1996, a Holambra reduziu ano a ano seu ativo imobilizado, conforme mostra o Gráfico 8. No período (1994 a 2000), a redução total dos ativos físicos foi de 25,3\%. A partir de 2001 até 2004 (ano do investimento em expansão de silos) a variação de ativos imobilizados foi positiva em $32,4 \%$, demonstrando o retorno a investimentos de longo prazo.

Ao final dos anos 1990, $70 \%$ da produção dos cooperados era irrigada, reduzindo risco e alcançando maior estabilidade financeira e a partir de então houve o crescimento vertical dentro da propriedade, que conferiu maior vantagem competitiva aos cooperados, com a produção alcançando níveis superiores e estável.

A recuperação iniciada em 1996/1997 encontrou outro obstáculo em janeiro de 1999, quando por efeito de mudança da política cambial do Banco Central brasileiro, o Real sofreu uma desvalorização muito forte em relação ao dólar e as dívidas da cooperativa com fornecedores, que estavam em dólar, mais do que dobraram. Isso exigiu renegociação de dívidas também com fornecedores.

No início dos anos 2000, as multinacionais estavam endividadas e a cooperativa já estava capitalizada e conseguia bons preços de aquisição de insumos. No ano de 2004 foi possível a primeira expansão em armazenagem de grãos desde a década de 1980, com a construção de seis novos silos. As sobras alcançadas passaram a fomentar pesquisa em cereais e frutas ${ }^{29}$ e o retorno dos filhos de cooperados, muitos deles agrônomos, formados nas mais diversas regiões do país, trouxe para a Holambra muito conhecimento, que foi aplicado na produção local. Desde os anos 2000 os colaboradores passaram a ter participação nos resultados da cooperativa e no ano de 2004, a cooperativa ofereceu aos principais gestores e parte dos produtores um MBA in company.

Por volta do ano de 2003 e 2004 a Holambra já havia alcançado uma situação de performance positiva de maneira consistente. A seguir será analisada uma série de informações do demonstrativo de resultados do exercício (DRE) e do balanço patrimonial (BP) da

\footnotetext{
${ }^{29}$ A Reserva de Assistência Técnica e Educacional e Reserva Legal (RATES) é um fundo obrigatório ao qual a cooperativa deve alocar $10 \%$ da sobra gerada pela operação com os cooperados e $100 \%$ da sobra gerada pela operação com terceiros.
} 
Cooperativa Agro Industrial Holambra, entre os anos de 1994 e 2006. A pesar de a crise pela qual a cooperativa passou ter se iniciado quase uma década antes, as mudanças de plano econômico na década de 1980 e início da década de 1990 tornam os dados anteriores a 1994 difíceis de serem interpretados, principalmente pela troca da moeda em 1993/94. Além disso, como mencionado anteriormente, o processo de recuperação da Holambra, inicia-se de maneira determinante no segundo mandato do Sr. Simon Veldt.

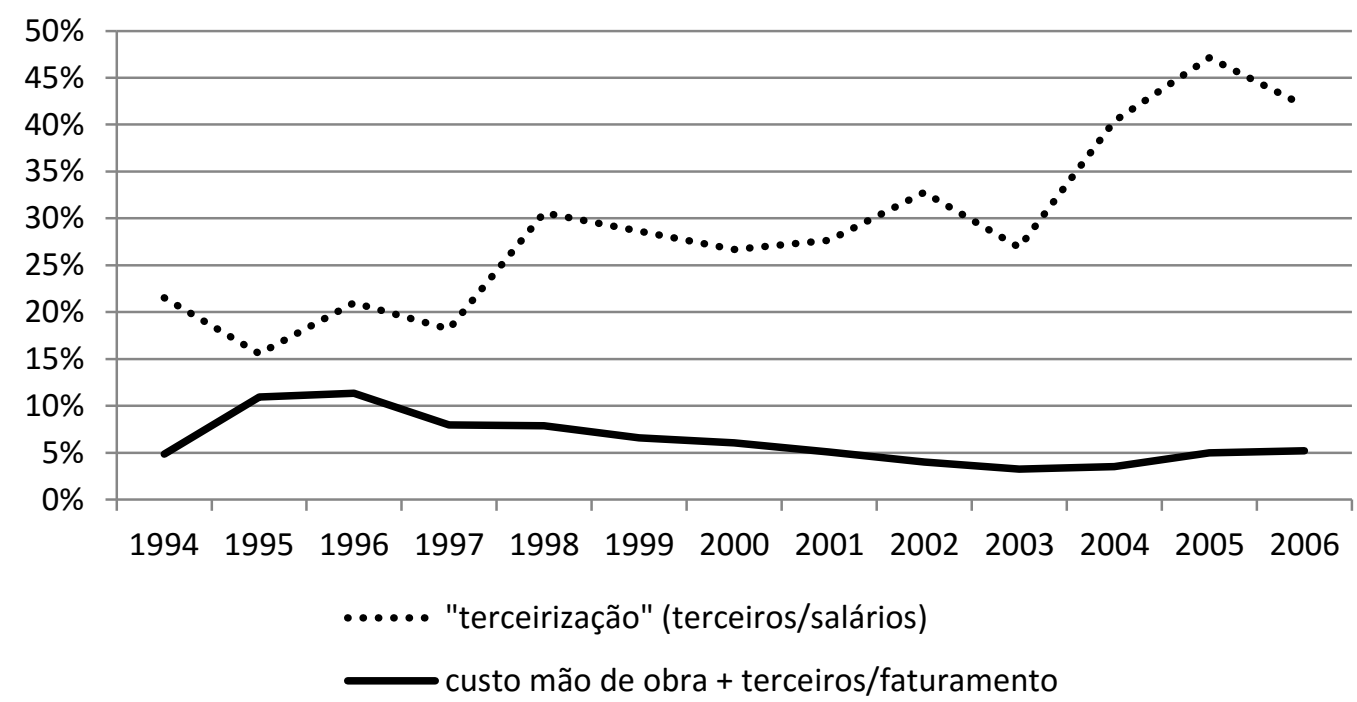

Gráfico 4 - Relação entre custo da mão de obra, participação de terceiros e faturamento da Holambra entre 1994 Fonte: Holambra - documentos internos e 2006

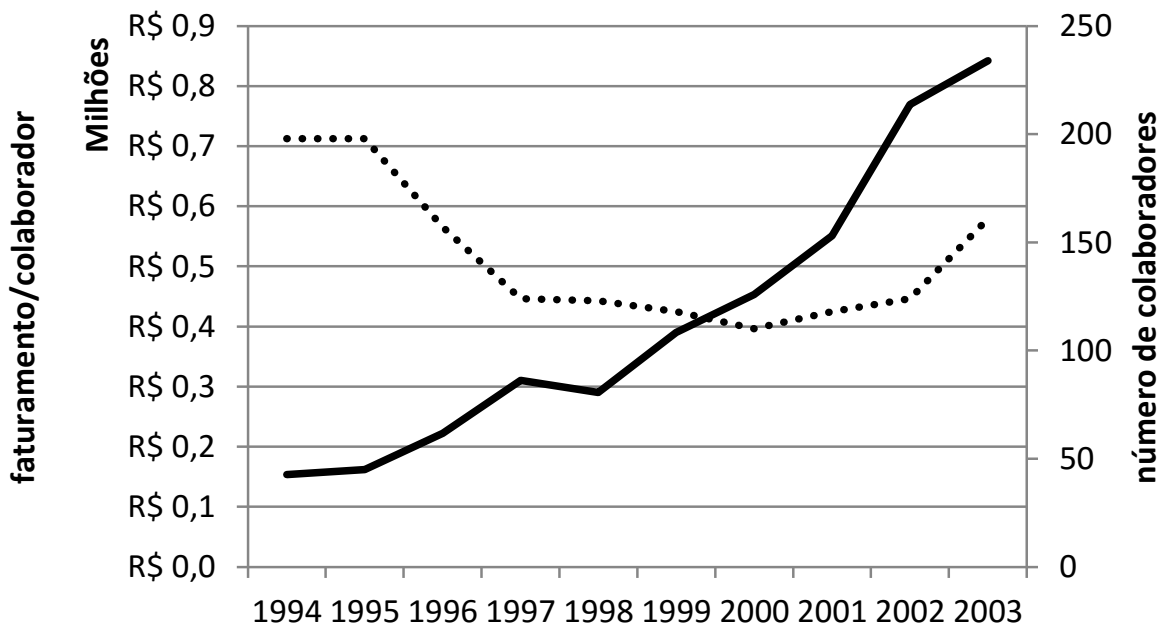

faturamento por colaborador $\quad$...... número de colaboradores

Gráfico 5 - Evolução do faturamento por colaborador da Holambra entre 1994 e 2006 Fonte: Holambra - documentos internos 
$19,0 \%$

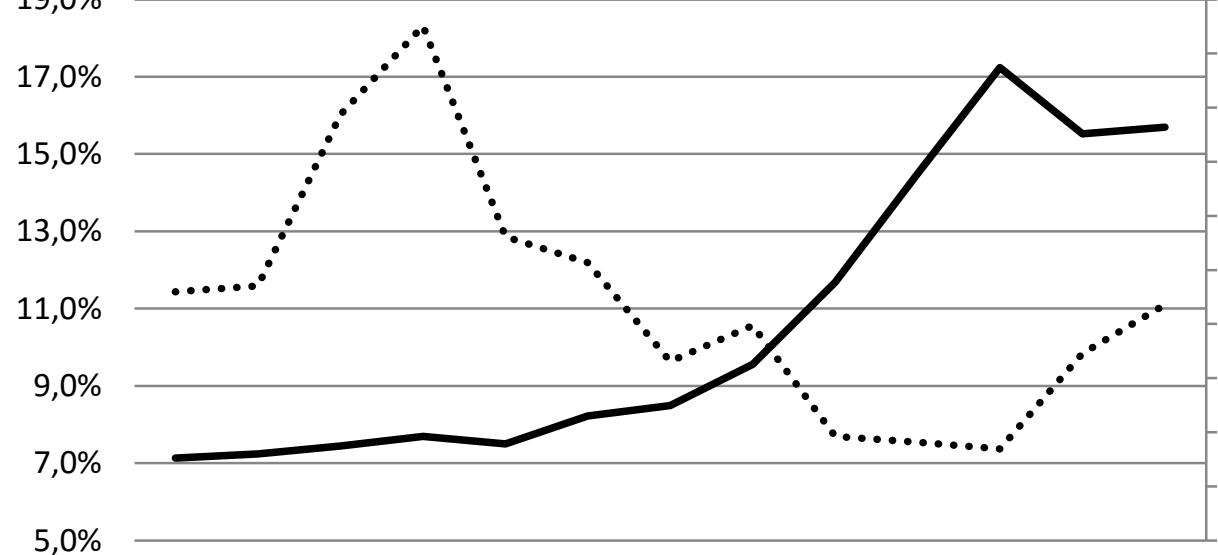

$\mathrm{R} \$ 200.000$

$\mathrm{R} \$ 180.000$

$\mathrm{R} \$ 160.000$

$R \$ 140.000$

$\mathrm{R} \$ 120.000$

$\mathrm{R} \$ 100.000$

$\mathrm{R} \$ 80.000$

$\mathrm{R} \$ 60.000$

$\mathrm{R} \$ 40.000$

$\mathrm{R} \$ 20.000$

1994199519961997199819992000200120022003200420052006

$\mathrm{R} \$$ -

Despesa operacional/faturamento

Faturamento (Total de receitas)

Gráfico 6 - Relação entre faturamento e despesas operacionais da Holambra entre 1994 e 2006 Fonte: Holambra - documentos internos

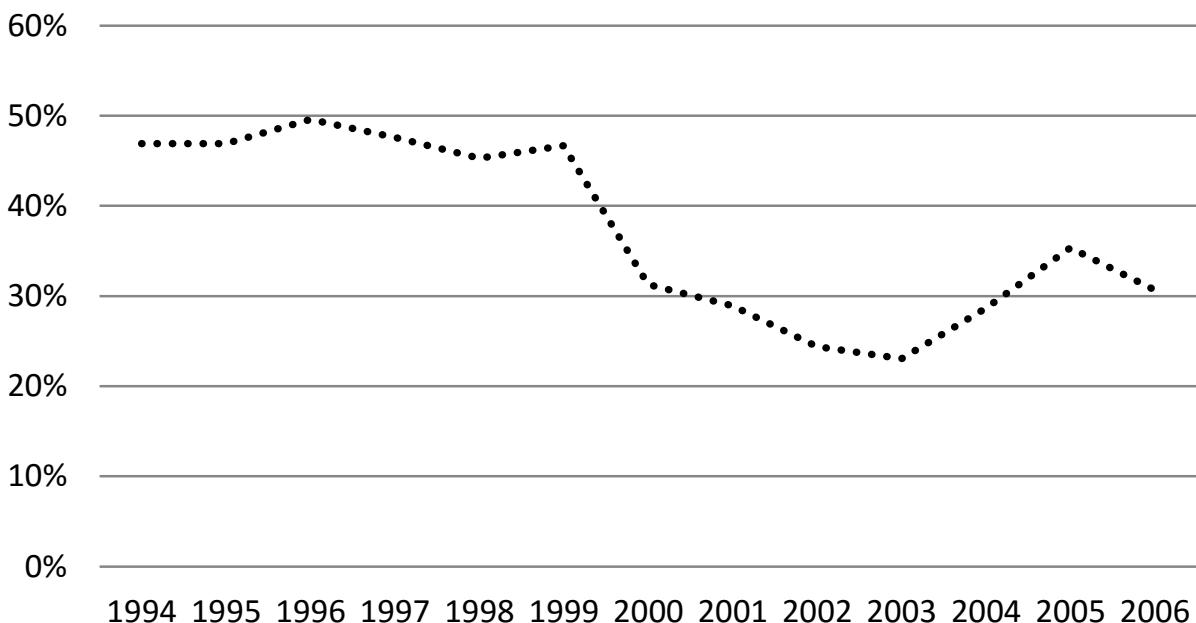

-.... ativo permanente/ativo total

Gráfico 7 - Relação entre ativo permanente e ativo total da Holambra entre 1994 e 2006 Fonte: Holambra - documentos internos 


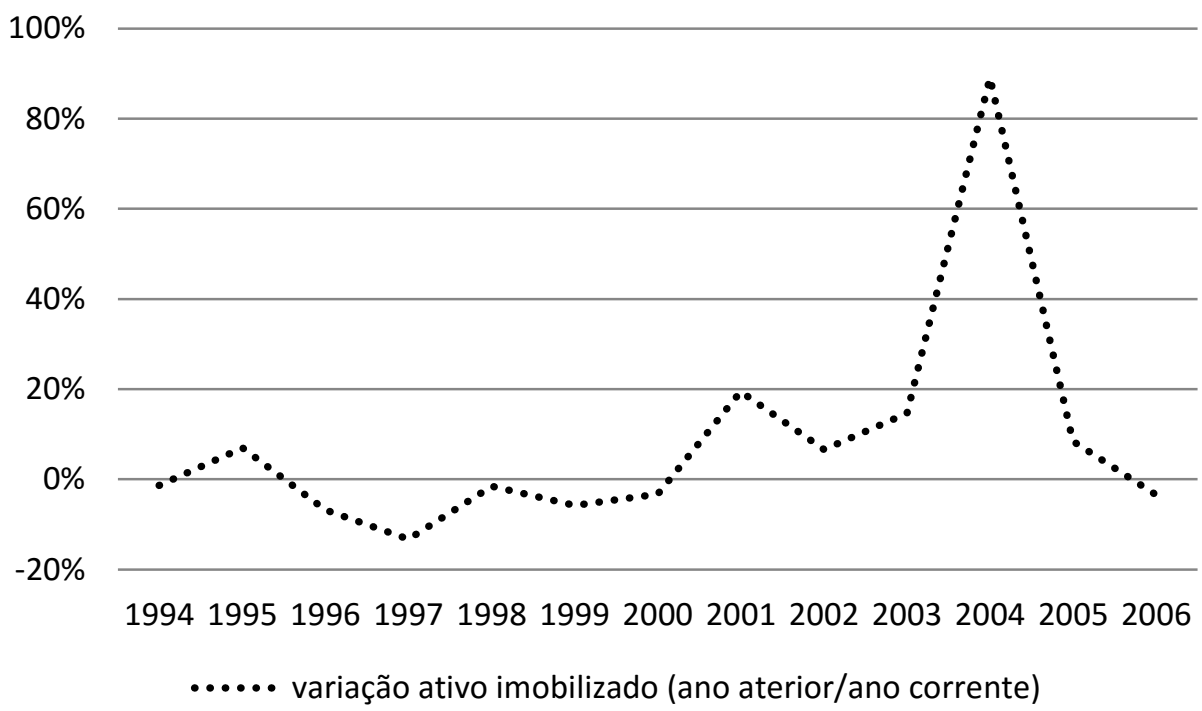

Gráfico 8 - Variação (\%) do valor de ativos imobilizados pela Holambra entre 1994 e 2006 Fonte: Holambra - documentos internos

\subsubsection{Discussão e conclusões do caso}

A recuperação da Cooperativa Agro Industrial Holambra não foi um processo de turnaround facilmente delimitado no tempo. A instabilidade financeira causada por importantes mudanças econômicas e alterações das regras do jogo (taxa de juros, restrição de crédito, mudança de moeda e alterações cambiais), se prolongou por mais de uma década. "Foi um período de estagnação econômica e queda de rentabilidade" (Simon Veldt, 2015). Diversas ações foram tomadas ao longo da década de 1980 e 1990, mas o processo de turnaround estudado tem como marco central o ano de 1996, que coincidiu com o término do primeiro mandato do até então presidente Simon Veldt, que seria reeleito no ano seguinte. Este marco é exatamente o "ponto da virada", a partir do qual os resultados financeiros da cooperativa melhoraram paulatinamente.

No modelo proposto na secção 3.5, o processo de recuperação passa pela quebra da inércia da organização e dois fatores principais são apontados como gatilhos para que a empresa saia da condição de letargia: 1) a troca da alta gestão; e 2) a entrada de externos no conselho. No caso da Holambra, a troca da alta gestão ocorreu diversas vezes entre a década de 1980 e 1990, mas como visto no ano de 1997 esse processo se mostrou mais intenso. Apesar de não ter havido a troca da presidência, o superintendente foi alguém externo sem qualquer conhecimento anterior daquela cooperativa e com um perfil diferente: pela primeira vez não era engenheiro agrônomo e tinha muita experiência com gestão e finanças. No modelo de 
governança da cooperativa, o presidente assume o papel de presidente do conselho sendo o principal representante do interesse dos cooperados, e não atua como executivo. O papel de executivo é desempenhado pelo superintendente. Além disso, uma parcela substancial da alta gestão foi eliminada. A proposição do modelo indica a troca da alta gestão como estratégia para quebra da inércia, mas no caso analisado, observou-se também a eliminação de níveis gerenciais.

Além da substituição da alta gestão, o conselho foi renovado, e desta vez, de uma maneira singular. Compuseram o conselho de administração, aqueles cooperados com maior interesse financeiro no resultado da cooperativa, isto é, aqueles com maior participação no capital social. Ademais, dois cooperados além do presidente Simon, tornaram-se avalistas dos empréstimos da cooperativa. Esta estrutura de conselho e avalistas passou a monitorar de maneira muito próxima a situação financeira da cooperativa exercendo pressão por resultado sobre a presidência e superintendência.

Ambas as condições acerca da quebra da inércia foram observadas no caso do turnaround da Holambra. A troca da alta gestão e a entrada de externos no conselho foram condições importantes para catalisar o processo de mudança pelo qual a cooperativa passaria nos anos seguintes. A entrada de um gestor externo e bastante especializado foi apontada por Zylberstajn (2002) como necessária para preservar a eficiência das cooperativas quando alcançam certa escala de operação.

Além disso, o corte de linhas gerenciais, além de imediato impacto em custos, permitiu maior agilidade e proximidade da alta direção com os gestores de $1^{a}$ linha. No caso da IBM-UK ação semelhante foi observada e segundo Balgobin e Pandit (2001) estava relacionada à construção de capacidades dinâmicas. Assim, ainda que a Holambra tenha sido categorizada como uma organização que compete por rendas ricardianas, a construção de capacidades dinâmicas parece ser também necessária. Essa relação já foi discutida por outros autores que afirmam que o antagonismo, recursos versus capacidades, deve ser posto de lado para uma abordagem de complementariedade e não substituição (Makadok, 2001).

Há que se atentar para o fato de que, parte da crise da Holambra pode ser explicada pela particularidade de cooperativas que muitas vezes tem o cooperado ocupando também o papel de agente. Conforme apontado por Zylberstajn (1994), como a noção de direito sobre o 
resíduo é vaga, dado que o ganho do cooperado com a cooperativa advém menos de distribuição de sobras e mais das transações entre as partes, o cooperado na figura de gestor pode tomar decisões que não são interessantes à cooperativa em longo prazo (problema de horizonte). Anterior a 1997 a cooperativa teve cooperados atuando com certa dose de auto interesse, fato observado em investimentos em estruturas que beneficiariam majoritariamente ao cooperado que tomou a decisão, como a construção de uma fábrica de ração para suínos. A viabilidade deste negócio era dependente da produção deste cooperado e quando este teve sua produção interrompida, a cooperativa sofreu os impactos financeiros.

Ao aproximar os cooperados com maior participação no capital social da cooperativa, está se tornando aqueles que seriam mais afetados por uma conduta de auto interesse e imediatista tomada tanto pelos gestores quanto por eles mesmo -, próximos à tomada de decisão e monitores das ações dos gestores. Como mencionado, o capital social varia em função da área de produção do cooperado, e pode ser resgatado pelo cooperado quando este atinge certa idade. Assim, ainda que o direito sobre o resíduo em cooperativas seja difuso - pelo fato de que o ganho dos cooperados advém mais da transação com a cooperativa e menos das sobras ao final do ano -, a perda do capital social por um cooperado pode ter um impacto significativo e seu patrimônio e expectativa de renda futura com a cooperativa. Portanto, sob a ótica de direitos de propriedade, ao aproximar cooperados com maior capital social à tomada de decisão e monitoramento da gestão, estás e fortalecendo o direito sobre a propriedade deste grupo posto que têm grande interesse na maximização do desempenho de longo prazo da cooperativa.

As medidas de quebra da paralisia estratégica são seguidas pela fase de cerceamento de custos e liquidação de ativos, determinado em certa medida pela natureza da geração de renda e pela severidade da situação de turnaround, como apresentado no modelo da Figura 7. Firmas competem por geração de renda ricardiana ou schumpeteriana e as estratégias de retrenchment adotadas são função dessa natureza de geração de renda. Assim, firmas com renda ricardiana deverão adotar medidas majoritariamente de corte de custos, não alterando sua estrutura de ativos, compreendidos como seus recursos geradores de rendas. No caso de firmas com renda tipicamente schumpeteriana, a fonte de vantagem competitiva são suas rotinas e capacidades dinâmicas passíveis de criar inovações que levam a rendas superiores e, portanto, o foco da fase de retrenchment deve ser mais em ativos e menos em custos, uma vez que estes são necessários para suas atividades de geração de renda. 
Naquela época a cooperativa atuava com a venda de insumos para os cooperados, prestação de serviços de beneficiamento e armazenagem de grãos e algodão, produção de ração para aves, venda de medicamentos veterinários e comercialização e revenda de frutas e flores produzidas pelos cooperados. A cooperativa dispunha para tal uma estrutura de armazéns para cereais, indústria para produção de ração e galpões para armazenagem e comercialização de insumos, flores e frutas.

No entanto, o negócio principal da cooperativa era o recebimento e armazenagem de grãos e algodão e a venda de insumos. A competição no setor de beneficiamento e armazenagem se dá basicamente pelo custo de operação, assim aqueles com o menor custo médio deverão se sobressair sobre os demais. Ações de ganho de eficiência operacional com a otimização da utilização dos ativos devem ser adotadas. Havendo a necessidade de geração de caixa imediata, a ação de retrenchment em um negócio desses deve visar primeiramente cortes de custos e não em ativos, uma vez que esses são a verdadeira fonte latente de geração de renda. Além disso, em uma indústria em crise, os ativos geralmente são precificados abaixo da sua capacidade futura descontada de geração de caixa e a opção por liquidá-los irá geralmente gerar menos receita do que com sua operação. Assim, espera-se que as ações para esta unidade de negócios se concentrem, na fase de retrenchment, em gerar caixa a partir de cortes de custos gerais. A liquidação de ativos só deve ser observada em situações financeiras com risco iminente de falência.

Como à época a severidade da situação não chegava ao ponto de a Holambra correr o risco de falência, espera-se a tomada de ação no sentido de redução de custos gerais. E foi justamente isto que se observou. Segundo o presidente à época, a Holambra passou a partir de 1997 a olhar com muito mais atenção para a última linha de seu DRE e tornaram-se focados no lucro líquido. A redução de pessoal, tornando a empresa mais enxuta foi a principal ação daqueles dois anos (1996 e 1997) quando a equipe foi reduzida a cerca de dois terços do seu tamanho em 1995, com impactos positivos no custo da operação. Entre 1997 e 1998 as despesas operacionais em relação ao faturamento tiveram uma redução de 5,2\%. Houve sim liquidação de ativos, mas como citado, não eram relacionados à atividade produtiva, e sim à antiga Holambra, aquela Cooperativa de Colonização que estava definitivamente sendo deixada para trás. A liquidação destes ativos não produtivos, como as casas de funcionários, gerou economias operacionais à cooperativa. 
É importante ressaltar além da geração de caixa pela liquidação de ativos e corte de custos, a renegociação de dívidas, ações de recuperação de crédito e gestão de fluxo de caixa. Isto sugere que o retrenchment deve ser complementado por política financeira orientada à geração de caixa independentemente da alteração positiva ou negativa do faturamento.

As causas do declínio de performance da Holambra podem ser atribuídas em grande parte à crise pela qual passava a agricultura brasileira e à instabilidade político-econômica. Diferentemente de outras cooperativas, como o caso da CAC que tinha dezenas de milhares de cooperados, a Holambra se manteve pequena e focada em atender às necessidades do cooperado e retornando seu "lucro" ao cooperado. O crescimento da Holambra ocorreu em primeiro lugar pelo crescimento vertical dos cooperados, com adoção de tecnologias novas e incremento de produtividade. Em segundo lugar, em números de cooperados o crescimento se deu em parte pela entrada das gerações seguintes e em outra pela entrada de novos cooperados com um perfil semelhante. Na crise econômica a cooperativa sofreu assim como as demais empresas e cooperativas do setor, mas a Holambra com sua política restritiva de crédito e política de retenção da produção entregue pelos cooperados devedores, se encontrava em meados de 1997 com uma baixa adesão de seus cooperados para a entrega de grãos e compra de insumos. A posição competitiva da cooperativa era enfraquecida uma vez que dispunha de recursos capazes de gerar elevada eficiência, mas estava ameaçada, pois já não conseguia reter mais nem seus próprios cooperados. Para os cooperados o custo de transação de fazer negócios com a cooperativa era elevado. Como a reputação da cooperativa estava em baixa em função dos problemas internos apresentados, a incerteza em transacionar com a cooperativa era alta e reduzir tais custos era determinante para reestabelecer esta transação.

Conforme depoimento do superintendente Renzo Guazzelli, os cooperados estavam muito inseguros e incertos com relação ao futuro da cooperativa e frequentemente ele era abordado por cooperados com o intuito de conhecer melhor aquele que estava assumindo a superintendência. Em alguns casos cooperados assumiram uma postura agressiva contra essa mudança por desconfiar que um estranho a eles não poderia melhorar a situação da cooperativa.

“Os cooperados vinham na minha sala sem ter uma pauta para conversar, vinham aqui para me conhecer, saber o que eu pensava (Renzo Guazzelli - superintendente)". 
No contexto de causa do declínio causado por retração do mercado, mecanismo de geração de renda tipicamente ricardiana e posição competitiva fraca, o modelo proposto (Figura 9) indica que a estratégia de turnaround eficiente é aquela que foca os esforços em segmentos onde os recursos têm alto valor e são capazes de promover elevada eficiência (hipótese 5).

A Holambra não liquidou seus ativos relacionados às atividades de maior importância econômica (grãos, algodão e insumos), mas também não adotou ações de incremento em ativos produtivos ou investimentos operacionais. O que se observou a partir de 1997 foi a intensificação da utilização da capacidade latente de seus ativos. A política de incentivos à entrega de grãos na cooperativa e compra de insumos visou fortalecer a imagem da Holambra frente a seus cooperados. Após as ações restritivas de crédito, cobrança e execução de dívidas de cooperados e desfalques com cooperados que tinham dinheiro na cooperativa, sua reputação estava em cheque e o esforço dos anos seguintes foi o de recuperar a confiança dos cooperados.

Cada divisão da cooperativa reviu na época seu acordo de produtores no qual estabelecia que as sobras fossem distribuídas na proporção de sua participação na operação. Assim, quanto mais o produtor entregasse sua produção na cooperativa e comprasse insumos da cooperativa, maior participação ele teria nas eventuais sobras.

As estratégias de visar a sobra e incentivar o produtor a transacionar com a cooperativa fortaleceu a noção de que o cooperado tem direito ao resíduo. Essa diretriz teve um importante papel disciplinador sobre os gestores no sentido de conduzir o negócio com uma eficiência tal que o resíduo fosse alocado ao cooperado ao final do ano. O preço dos serviços prestados pela cooperativa ao cooperado não era inferior ao praticado no mercado, eventualmente era até superior, mas pelo fato de a cooperativa não descontar a quebra técnica, repartir as receitas da quirera com o cooperado e distribuir as sobras, foram incentivos importantes para tornar o cooperado fidelizado à cooperativa. Zylberstajn (2002) aponta para estratégias de fidelização com o intuito de evitar a quebra contratual. No caso da Holambra, o mecanismo de fidelização foi utilizado para reestabelecer uma relação que havia sido rompida muito em função da incerteza relacionada a transacionar com a cooperativa. 
"O que importa para as cooperativas é a percepção de que a relação com o cooperado não pode ser tomada como estável por natureza, mas deve ser fomentada e trabalhada estrategicamente, de acordo com cada situação particular. Mecanismos formais e informais se complementam e devem ser tratados pela alta gestão da cooperativa (Zylberstajn, 2002 p.15)";

Foss e Foss (2005) apontam para a importância das práticas de redução de custos de transação pelo fortalecimento dos direitos de propriedade. Isto porque custos de transação (custo de transacionar, proteger e capturar direitos de propriedade) influenciam o valor que o dono de determinado recurso pode apropriar dele. No caso da Holambra, os incentivos criados são mais do que simplesmente artifícios para fidelização, podem ser compreendidos como fatores redutores de custo de transação. Portanto, para o caso específico de cooperativas, considerando que o esvaziamento da cooperativa pela baixa adesão de seus cooperados pode leva-la à bancarrota, criar mecanismos que reduzem custos de transação entre cooperativa e cooperado é essencial para a manutenção das transações.

A Cooperativa Agro Industrial Holambra alcançou a recuperação à qual se candidatou quando promoveu a mudança profunda em sua estrutura principalmente a partir de 1997. O processo não foi linear, e como mencionado, alguns percalços pelo meio do caminho forçaram a adoção de ações corretivas (renegociações de dívidas e ações judiciais contra cooperados). Dentre os principais elementos de mudança, a Holambra alterou sua estrutura de gestão, tornando os principais gestores responsáveis pelas suas ações (accountability), aproximou os associados com maior capital social e tornou-os não só monitores da gestão, mas responsáveis pelos resultados. Estas ações estão em linha com o que se esperava na primeira fase do processo de turnaround que previa ações para quebra da inércia.

A gestão financeira profissional e capacidade de renegociar dívidas e buscar créditos com produtores foram essenciais para a sobrevivência durante a recuperação. Além disso, a liquidação de ativos não produtivos gerou o caixa para honrar compromissos financeiros e reduziu despesas operacionais, tornando a cooperativa mais leve. Nesta fase de retrenchment observou-se que o foco foi de fato na redução de custos e quando houve a liquidação de ativos estes não estavam relacionados aos recursos geradores de rendas, como previsto pela teoria. 
O modelo apresentado na Figura 9, previa que para firmas em condição de declínio causado pelo mercado, rendas ricardianas e posição competitiva fraca deveriam manter o "foco em segmentos onde recursos e capacidades tem alto valor são capazes de oferecer elevada eficiência". No caso da Holambra, observou-se que as ações de recuperação giraram em torno de alavancar operações com as atividades de grãos, algodão e comercialização de insumos, para as quais a cooperativa tinha recursos de alto valor, mas que não estavam sendo explorados em sua plenitude. E que, além disso, houve um esforço razoável para eliminação de custos.

Apesar da tentativa em separar as fases do processo de turnaround observa-se que no caso da Holambra a separação entre retrenchment e recuperação não é exatamente bem delimitado no tempo. Isto pode ter ocorrido pelo fato de que a situação de turnaround da Holambra não era tão grave a ponto de a cooperativa ter que tomar medidas mais drásticas na fase de retrenchment. Isto sugere que quando a situação de turnaround é menos grave, é possível que as firmas adotem primeiras ações de cerceamento de custos e ativos para avaliar posteriormente a necessidade de se prosseguir com ações mais intensas. Mas no caso de cooperativas outro elemento pode ser ainda mais determinante. A manutenção de alguns negócios e operações pode estar associada ao objetivo da cooperativa que é de atender o cooperado. Na Holambra, a fábrica de rações ainda que fosse uma atividade de pouco interesse econômico para a cooperativa, era de interesse do cooperado.

A Figura 10 a seguir, apresenta as ações tomadas pela Holambra, dentro do modelo proposto de turnaround e o modelo de estratégias em turnaround (Figura 8 e Figuras Figura 9). Além disso, adicionou-se o papel da redefinição contratual como ocorreu no caso da Holambra com o intuito de reduzir incerteza e, por conseguinte, custos de transação e o fortalecimento de direitos de propriedade, a partir da aproximação de cooperados com maior capital social ao conselho, influenciando positivamente o processo de turnaround, como pôde ser observado no caso da Holambra. . 


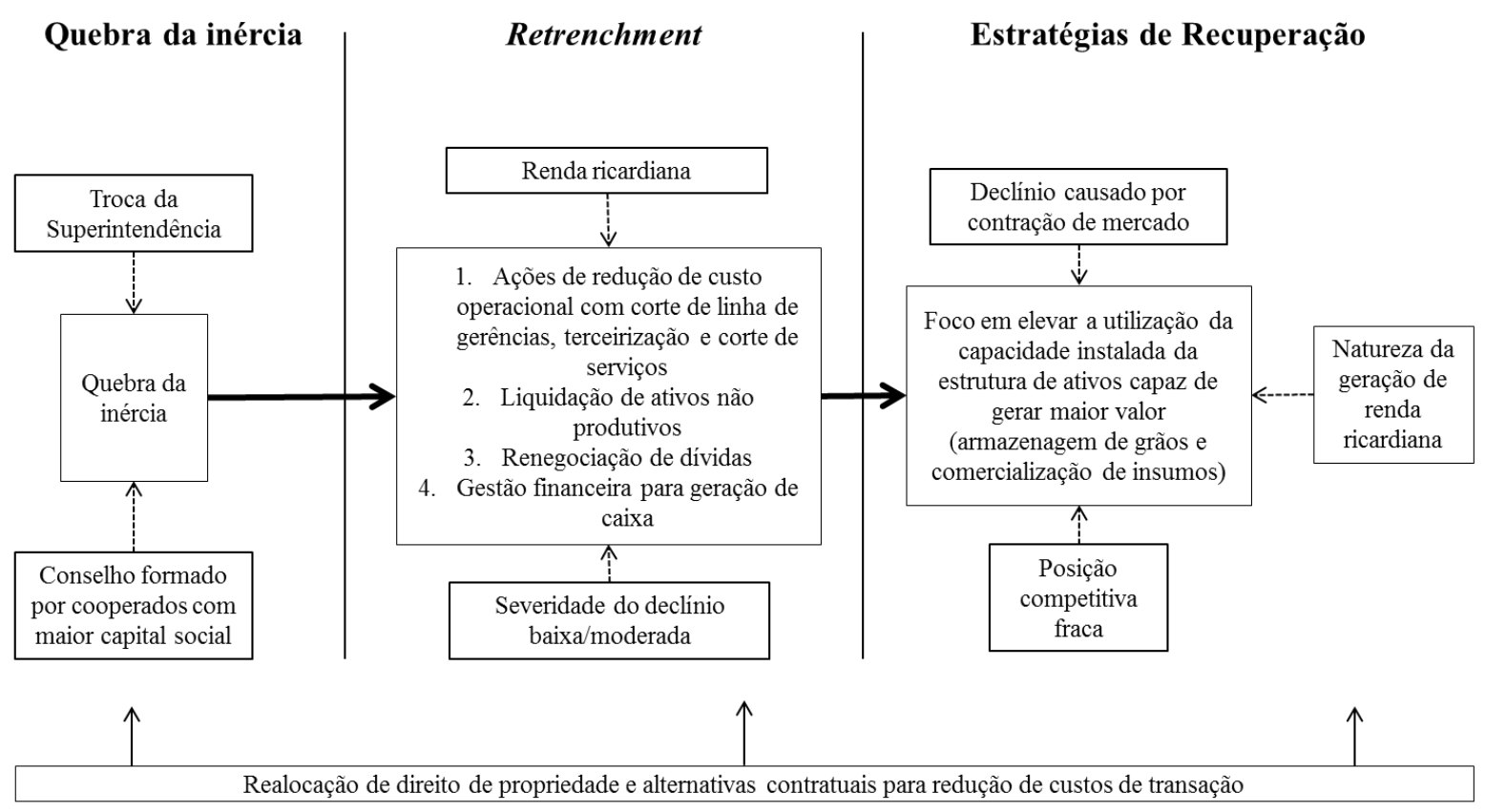

Fonte: elaborado pelo autor

Figura 10 - O processo de turnaround da Holambra 


\section{CONCLUSÕES}

O presente estudo tinha como objetivos principais o entendimento do estado da arte do conhecimento sobre o turnaround de empresas e as contribuições das abordagens de estratégia para os trabalhos sobre recuperação de empresas. Para atender aos objetivos foi conduzido um estudo bibliométrico, seguido de uma análise qualitativa da interface turnaround - estratégia, com recomendações para um modelo de processo de turnaround e proposições para ações de recuperação baseadas em estratégia competitiva. No modelo proposto, as proposições foram utilizadas e discutidas no caso de recuperação da Cooperativa Agro Industrial Holambra. A seguir serão discutidas as principais conclusões alcançadas pelo presente trabalho, suas limitações e caminhos futuros para o desenvolvimento de pesquisas em turnaround de empresas.

O estudo bibliométrico, que compreende a rede de cocitação de trabalhos, rede de palavras chave e rótulos gerados pelo programa CiteSpace se mostrou bastante adequado para a compreensão de como está organizada a literatura sobre o turnaround de empresas e suas influências teóricas. A rede de cocitação de trabalhos deixou bastante evidente que a base teórica em turnaround é diversa e que os trabalhos acessam geralmente várias áreas do conhecimento. Além disso, a rede de palavras foi suficiente para entender os principais temas tratados pelos trabalhos e como se conectam. Como exemplo, a Figura 4.

que apresenta a rede de cocitação de palavras chave, evidenciou a predominância de trabalhos que tratam de declínio, de estratégias de recuperação e de retrenchment, e ainda, que este último termo faz a ligação entre o declínio e a estratégia de recuperação. Posteriormente, vimos que o retrenchment é uma ação necessária em decorrência do declínio e que geralmente está associada ao início do processo de recuperação. Assim, o presente estudo traz uma contribuição importante para a técnica de bibliometria, que é relativamente nova, na medida em que demonstra suas aplicações e estressa seus resultados com análises qualitativas que ao final do processo dão um valor ainda maior para os resultados alcançados.

O entendimento do estado da arte do conhecimento de turnaround de empresas, primeiro objetivo do presente trabalho foi atendido na medida em que sua base intelectual foi caracterizada, as linhas de estudo foram identificadas, divergências e convergências foram apontadas e houve um esforço de se mostrar a fronteira atual de desenvolvimento do tema. É 
importante ressaltar que, a tentativa de se capturar o "estado da arte" do conhecimento científico em determinado campo, tende a refletir certa subjetividade da visão do autor (Ramos-Rodríguez e Ruíz-Navarro, 2004), sendo, portanto, uma limitação do trabalho, relacionada ao método utilizado. Não obstante, por se mostrar um campo de estudos extremamente abrangente, o trabalho ficou limitado à análise das diversas questões em torno do turnaround a partir de alguns estudos principais e esta é uma das principais limitações desta dissertação. $\mathrm{O}$ aspecto da tomada de decisão e o papel dos gestores, por exemplo, recebeu menor atenção no presente estudo, em detrimento de maior aprofundamento das questões relacionadas ao retrenchment e estratégias de recuperação. Entretanto, não significa que o aspecto humano no processo de turnaround seja menos importante. Recentemente, estudos na área de estratégia tem voltado sua atenção para os micro fundamentos relacionados à tomada de decisão no contexto da estratégia competitiva (Foss, 2011). Observamos que os estudos de turnaround ensaiaram abordagens relacionadas à tomada de decisão e esta deve ser uma das frentes de desenvolvimento dos trabalhos sobre turnaround.

A noção do "duplo pêndulo" que influenciou os trabalhos sobre estratégia ao longo das últimas décadas também teve influência nos trabalhos sobre turnaround. Sobretudo, nota-se que os trabalhos mais recentes trouxeram contribuições da TBR e elementos de uma teoria comportamental à reboque do que estava ocorrendo no campo da estratégia. Ademais, observou-se que a ECT não teve influência significativa nos trabalhos de turnaround. Sua operacionalização mais marcante foi quando integrada à TBR, em que recursos VRIO foram assumidos como ativos de elevada especificidade, não sendo, portanto, uma contribuição às pesquisas de turnaround, mas sim ao estudo de estratégia. Um esboço sobre como elementos da ECT podem ser adicionados aos estudos de turnaround foi discutido no caso da cooperativa Holambra apresentado no capítulo 4. Além disso, a importância da tomada de ações para definição mais alinhada dos direitos de propriedade com os objetivos da cooperativa, foi evidenciada pelo caso e tida como uma das ações primordiais para sustentar o longo processo de recuperação. A importância da definição correta de alocação de valor criado e das formas contratuais como elemento para reduzir incerteza são importantes, sobretudo para criar condições para recuperação de empresas em decadência. Vale observar que embora o caso trate de uma cooperativa, a questão da definição dos direitos de propriedade diz respeito a todas as firmas e merece uma investigação já que as empresas não necessariamente se apropriam de rendas econômicas dos recursos criados (Kim e Mahoney, 2007). 
A teoria existente sobre turnaround aborda a inércia como sendo algo associado à cognição dos gestores e tem utilizado elementos de uma abordagem comportamental para explica-la. Contudo, como visto no estudo de caso da cooperativa Holambra, a inércia pode ser algo além da questão da cognição. Considerando que existem assimetrias de informação e dificuldade de proteção do direito de propriedade e que um cooperado-gestor ou gestor pode tomar ações em benefício próprio, pode-se dizer que a questão da inércia de certa maneira está também associada às estruturas de governança impróprias ou à ausência de mecanismos de monitoramento e incentivos capazes de proteger o resíduo. Em outras palavras, os gestores que deveriam ser responsáveis pela mudança podem estar agindo de maneira a capturar a renda gerada e não têm interesse em romper o status quo. Entendendo-se a inércia desta maneira quebra-la pode significar simplesmente o realinhamento de contratos com o intuito de reduzir custos de transação e assegurar os direitos de propriedade sobre o resíduo. No limite, a situação de captura do resíduo por outrem que não o principal, pode inclusive ser interpretada como uma possível causa do declínio em situações em que o desalinhamento é intenso a ponto de afetar a rentabilidade do negócio. Zylberstajn (2002) apontou para o problema da influência em cooperativas, quando justamente os cooperados próximos à gestão influenciam políticas para o benefício particular.

Outro ponto observado e que está associado ao fato de a organização estudada ser uma cooperativa, diz respeito à existência de custos de transação elevados entre cooperativa e cooperado levando à fuga deles. Este problema identificado por Zylberstajn (2002) como um "problema de fidelização" ocorreu no caso da Holambra devido à incerteza relacionada à operação com a cooperativa, que levou o cooperado a buscar transações de menor custo na concorrência. A alternativa encontrada envolveu a definição de uma política de incentivos que elevou o benefício da transação com a cooperativa. A despeito destas duas interfaces entre o turnaround e ECT mencionadas acima, e que são de alguma maneira exclusiva à questão de cooperativas, a integração de conceitos da ECT aos argumentos do turnaround permanece pouco evidente. Os argumentos propostos por Zylberstajn (2002) foram, no entanto, corroborados pelo presente estudo.

De maneira geral, outra contribuição importante do trabalho foi de demonstrar como a linha de trabalhos sobre o turnaround se mostrou um campo fértil para aplicação e teste dos 
conceitos e teorias desenvolvidos pela área da estratégia e sugere que pode haver ainda mais integração de abordagens de estratégia com as pesquisas sobre a recuperação de empresas.

O estudo de caso apontou para o turnaround como um processo dinâmico em que suas fases se confundem e que apesar de a literatura tentar retratá-lo como um encadeamento de ações, na prática observa-se que se trata mais de uma orquestração de ações. Portanto, esta é uma limitação do presente estudo e da literatura existente, que anseia colocar o processo de turnaround em um modelo linear e com uma lógica própria, quando na verdade, recuperar uma empresa, é um processo de tentativa e erro e está sujeito à interpretação dos gestores. Não obstante, os avanços da literatura e a contribuição que o presente estudo trás, são importantes para a vida real na medida em que aponta os inúmeros fatores que devem ser considerados pelos gestores em cada momento do processo de turnaround.

No mais, apesar de o caso da Holambra não ter avaliado em profundidade o período de declínio, a noção de que o declínio pode ser prolongado e que suas consequências levam a mais declínio ganha certo suporte quando observamos que no caso da Holambra, as ações erráticas de tentativa de recuperação ao longo da década de 1980 e início de 1990 não foram suficientes para tirá-la daquela situação. Além disso, fica difícil definir exatamente as causas do declínio. Se no início foi por uma questão do mercado, depois questões internas influenciaram a manutenção daquela situação e eventualmente até agravaram-na (não é possível checar este argumento, pois informações sobre a performance durante o declínio anterior a 1994, não estão disponíveis). Esta noção de que o declínio é um processo dinâmico e que seus efeitos iniciais levam a mais declínio corrobora com o trabalho de Hambrick e Daveni (1988).

A contribuição das escolas de estratégia para o tema fica clara quando avaliamos, sobretudo os trabalhos que tratam do processo de retrenchment e estratégias de recuperação. Como evidenciado pela análise de cluster, os trabalhos da TBR e CD são os mais salientes e surgem com mais frequência entre os trabalhos, seja para explicar retrenchment ou recuperação.

Houve certa limitação com relação ao entendimento da interface estratégia-turnaround na seção 3.4, uma vez que não foram avaliados todos os trabalhos que citaram as escolas de estratégia (somente os de maior fator de impacto ponderado foram considerados) e por isso, outras abordagens podem ter sido deixadas de lado. 
As proposições que foram levantadas na seção 3.5 não puderam ser testadas em sua plenitude e é verdade que o estudo de caso não pode por princípios nos fornecer resultados comprobatórios, mas sua aplicação e interpretação indicam que as variáveis utilizadas fazem sentido e que sua aplicação em trabalhos estatísticos pode ser um caminho para trabalhos futuros. Como sugere Baker e Gil (2012), estudos clínicos têm dentre outras funções, indicar hipóteses testáveis. Uma limitação importante é a operacionalização do conceito de recursos e capacidades dinâmicas, que inclusive é uma das críticas à TBR.

Por fim, propõe-se que os próximos estudos sobre turnaround busquem maior integração com abordagens das escolas de estratégia, uma vez que estas se mostraram úteis para a avaliação das etapas do processo de turnaround e contribuem para a construção de uma teoria mais completa sobre a recuperação de empresas. 


\section{REFERÊNCIAS}

ALTMAN, E. I. Financial rations, discriminant analysis and the prediction of corporate bankruptcy. The Journal of Finance, v. XXIII, n. 4, p. 589-609, 1968.

Corporate financial distress and bankrupcty: a complete guide to predicting and avoiding distress and profiting from bankruptcy. [s.l: s.n.].

AROGYASWAMY, K.; BARKER III, V. L.; YASAI-ARDEKANT, M. Firm turnarounds: an integrative two-stage model. Journal of Management Studies, v. 32, n. 4, 1995.

BAKER, G. P.; GIL, R. Clinical papers in organizational economics. In: The Handbook of Organizational Economics. [s.1.] Princenton University Press, 2012. p. 1368.

BALGOBIN, R.; PANDIT, N. Stages in the turnaround process: the case of IBM UK. European Managment Journal, v. 19, n. 3, p. 301-316, 2001.

BARKER III, V. L.; DUHAIME, I. M. Strategic change in the turnaround process: theory and empirical evidence. Strategic Management Journal, v. 18, p. 13-38, 1997.

BARKER III, V. L.; PATTERSON, P. W. Top management team tenure and top manager causal attributions at declining firms attempting turnarounds. Group \& Organization Management, v. 21, p. 304-336, 1996.

BARKER III, V. L.; PATTERSON, P. W. J.; MUELLER, G. C. Organizational causes and strategic consequences of the extent of top management team replacement during turnaround attempts. Journal of Management Studies, v. 38, n. 2, p. 235-269, 2001.

BARNEY, J. Firm resources and sustained competitive advantage. Journal of Management, Journal of Management. v. 17, n. 1, p. 99-120, 1991.

BIALOSKORSKI NETO, S.; MARQUES, P. V. Agroindústria cooperativa: um ensaio sobre crescimento e estrutura de capital. Gestão \& Produção, v. 5, n. 1, p. 60-68, 1998.

BRUTON, R. E.; KEBLER, R. W. The "half-life" of some scientific and technical literatures. American Documentation, v. 11, p. 18-22, 1960.

CAMERON, K. S.; SUTTON, R. I.; WHETTEN, D. A. Issues in organizational decline. In: CAMERON, K. S.; SUTTON, R. I.; WHETTEN, D. A. (Eds.). . Readings in organizational decline: frameworks, research and prescription. Boston: Ballinger, 1988. p. 3-19.

CASTROGIOVANNI, G. J.; BRUTON, G. D. Business Turnaround Process Following Acquisitions: Reconsidering the Role of Retrenchment. Journal of Business Research, v. 48, p. 25-34, 2000.

CATER, J.; SCHWAB, A. Turnaround strategies in established small family firms. Family Business Review, v. XXI, n. 1, p. 31-50, 2008. 
CAVES, R. E.; PORTER, M. E. From entry barriers to mobility barriers: conjectural decisions and contrieved deterrence to new competition. The Quarterly Journal of Economics, v. 91, n. 2, p. 241-262, 1977.

CHEN, C. CiteSpace II : detecting and visualizing emerging trends and transient patterns in scientific literature. Journal of the American Society for Information Science and Technology, v. 57, n. 3, p. 359-377, 2006.

CHEN, C.; IBEKWE-SANJUAN, F.; HOU, J. The structure and dynamics of cocitation clusters : a multiple-perspective cocitation analysis. Journal of the American Society for Information Science and Technology, v. 61, n. 7, p. 1386-1409, 2010.

COASE, R. H. The nature of the firm. Economica, v. 4, n. 16, p. 386-405, 1937.

_. The problem of social cost. Journal of Law and Economics, v. 3, p. 1-44, 1960.

CYERT, R. M.; MARCH, J. G. A behavorial theory of the firm. [s.l.] Prentice-Hall, 1963.

DAILY, C. M.; DALTON, D. R. CEO and director turnover in failing firms: an ollusion of change? Strategic Management Journal, v. 16, p. 393-400, 1995.

DAVENI, R. A. The aftermath of organizational decline: a longitudinal study of the strategic and managerial characteristics of declining firms. Academy of Management Journal, v. 32, n. 3, p. 577-605, 1989.

DIERICKX, I.; COLL, K. Asset stock accumulation and sustainability of competitive advantage. Management Science, v. 35, n. 12, p. 1504-1512, 1989.

EISENHARDT, K. M.; MARTIN, J. A. Dynamic capabilities: what are they? Strategic Management Journal, v. 21, n. 10-11, p. 1105-1121, 2000.

FOSS, K.; FOSS, N. J. Resources and transaction costs: how property rights economics furthers the resource-based view. Strategic Management Journal, v. 26, n. 6, p. 541-553, 2005 .

FOSS, N. J. Strategy, economic organization, and the knowledge economy: the coordination of firms and resources. New York: Oxford University Press, 2005.

Why micro-foundations for resource-based theory are needed and what they may look like. Journal of Management, v. 37, n. 5, p. 1413-1428, 2011.

FOSS, N. J.; KNUDSEN, T. The resource-based tangle: towards a sustainable explanation of competitive advantage. Managerial and Decision Economics, v. 24, n. 4, p. 291-307, 2003.

FOSS, N. J.; STIEGLITZ, N. Modern resource-based theory(ies). In: DIETRICH, M.;

KRAFFT, J. (Eds.). . Handbook on the Economics and Theory of the Firm. [s.l: s.n.]. p. 608.

FÜRSTENAU, V. A política de crédito rural na economia brasileira pós 1960. Ensaios FEE, v. 8, n. 1, p. 139-154, 1987. 
GUERRAS-MARTÍN, L. Á.; MADHOK, A.; MONTORO-SÁNCHEZ, Á. The evolution of strategic management research: recent trends and current directions. BRQ Business Research Quarterly, v. 17, n. 2, p. 69-76, 2014.

HAMBRICK, D. C.; DAVENI, R. A. Large corporate failures as downward spirals. Administrative Science Quarterly, v. 33, p. 1-23, 1988.

HAMBRICK, D. C.; SCHECTER, S. M. Turnaround strategies for mature industrial-product business units. Academy of Management Journal, v. 26, n. 2, p. 231-248, 1983.

HOFER, C. W. Turnaround strategies. Journal of Business Strategy, v. 1, n. 1, p. 19-31, jun. 1980.

HOLAMBRA, C. A. I. Holambra: histórico. Disponível em:

<http://www.holambra.com.br/cont.php?p=historico>.

HOSKISSON, R. R.; HITT, M. A.; WAN, V. P. Theory and research in strategic management: swings of a pendulum. Journal of Management, v. 25, n. 3, p. 417-456, 1999.

HUSSAIN, N. et al. Kodak stunning journey of fortune to misfortune ( a case study -

financial analysis ). Research Journal of Finance and Accounting, v. 5, n. 17, p. 127-141, 2014.

KIM, J.; MAHONEY, J. T. Appropriating economic rents from resources: an integrative property rights and resource-based approach. International Journal of Learning and Intellectual Capital, v. 4, n. 1/2, 2007.

KLEIN, B.; CRAWFORD, R. G.; ALCHIAN, A. A. Vertical integration, appropriable rents and the competitive contracting process. Journal of Law and Economics, v. 21, p. 297-326, 1978.

LIM, D. S. K. et al. Rethinking the effectivness of assest and cost retrenchmen: the contigency effects of a firm's rent creation mechanism. Strategic Management Journal, v. 34, p. 42-61, 2013.

MAHONEY, J. T.; PANDIAN, J. R. The resource-based view within the conversation of strategic management. Strategic Management Journal, v. 13, p. 363-380, 1992.

MAKADOK, R. Toward a synthesis of the resource based and dynamic capability views of rent creation. Strategic management journal, v. 22, n. August 1999, p. 387-401, 2001.

MICHAEL, C.; ROBBINS, D. K. Retrenchment among small manufacturing firms during recession. Journal of Small Business managment, n. July, p. 35-46, 1998.

MINTZBERG, H. Patterns in strategy formation. Management Science, v. 24, n. 9, p. 934948, 1978.

MONTEIRO, G. F. A.; ZYLBERSZTAJN, D. A property rights approach to strategy. Strategic Organization, v. 10, n. 4, p. 366-383, 2012. 
MORROW, J.; JOHNSON, R. A.; BUSENITZ, L. W. The effects of cost and asset retrenchment on firm performance: the overlooked role of a firm's competitive environment. Journal of Management, v. 30, n. 2, p. 189-208, abr. 2004.

MUELLER, G. C.; BARKER, V. L. Upper echelons and board characteristics of turnaround and nonturnaround declining firms. Journal of Business Research, v. 39, p. 119-134, 1997.

NDOFOR, H. A.; VANEVENHOVEN, F.; BARKER III, V. L. Software firm turnarounds in the 1990s: an analysis of reversing decline in a growing, dynamic industry. Strategic Management Journal, v. 34, p. 1123-1133, 2013.

NEWMAN, M. E. J. Modularity and community structure in networks. Proceedings of the National Academy of Sciences of the United States of America, v. 103, n. 23, p. 8577-82, 6 jun. 2006.

ONEILL, H. M. Turnaround and recovery: what strategy do you need ? Long Range Planning, v. 19, n. 1, p. 80-88, 1986.

PEARCE II, J. A.; ROBBINS, D. K. Retrenchment remains the foundation of business turnaround. Strategic Management Journal, v. 15, n. 5, 1994.

PEARCE II, J. A.; ROBBINS, K. Toward improved theory and research on business turnaround. Journal of Management, v. 19, n. 3, p. 613-636, 1993.

PENROSE, E. The theory of the growth of the firm. New York: Wiley, 1959.

PETERAF, M. A. The cornerstones of competitive advantage: a resource-based view. Strategic Management Journal, v. 14, n. 3, p. 179-191, 1993.

PORTER, M. E. Competitive strategy: techniques for analyzing industries and competitors. First ed.New York: The Free Press, 1980.

PORTER, M. E. What is strategy? Havard Business Review, v. nov-dec, p. 60-78, 1996.

RAMOS-RODRÍGUEZ, A.-R.; RUÍZ-NAVARRO, J. Changes in the intellectual structure of strategic management research: a bibliometric study of theStrategic Management Journal, 1980-2000. Strategic Management Journal, v. 25, n. 10, p. 981-1004, 2004.

ROBBINS, D. K.; PEARCE II, J. A. Turnaround: retrenchment and recovery. Strategic Management Journal, p. 287-309, 1992.

RUMELT, R. P. Diversification strategy and profitability. Strategic Management Journal, v. 3, p. 359-369, 1982.

RUMELT, R. P. Precis of inertia and transformation. In: MONTGOMERY, C. A. (Ed.). . Resources in an evolutionary perspective: towards a synthesis of evolutionary and resource-based approaches to strategy. Norwell: Kluwer Academic Publishers, 1995. p. $101-132$. 
RUMELT, R. P.; SCHENDEL, D. E.; TEECE, D. J. Fundamental issues in strategy. A research agenda. Boston: Harvard Business School Press, 1994.

SCHENDEL, D. E.; PATTON, G. R. Corporate Stagnation and Turnaround. Journal of Economics \& Business, v. 28, n. 3, p. 236, 1976.

SCHENDEL, D.; PATTON, G. R.; RIGGS, J. Corporate turnaround strategies: a study of profit decline and recovery. Journal of General Management, v. 3, n. 3, p. 3-12, 1976a.

Strategic responses to technological threats. Business Horizons, $1976 \mathrm{~b}$.

SCHUMPETER, J. A. The theory of economic development. Cambridge, MA: Harvard University Press, 1934.

SERRA, F. A. R. et al. A pesquisa em administração estratégica nos primeiros anos do século xxi: um estudo bibliométrico de citação e cocitação no strategic management journal entre 2001 e 2007. Revista Eletronica Estratégia de Negócios, v. 5, n. 2, p. 257-274, 2012.

SHEPPARD, J. P. Strategy and bankruptcy - an exploration into organizational death. Jounral of Management, v. 20, n. 4, p. 795-833, 1994.

SLATTER, S. Corporate Recovery: Successful Turnaround Strategies and their Implementation. London: Pinguin, 1984.

STARBUCK, W. H.; GREVE, A.; HEDBERG, B. L. T. Responding to crises. Journal of Business Administration, v. 9, p. 111-137, 1978.

SUDARSANAM, S.; LAI, J. Corporate Financial Distress and Turnaround Strategies : An Empirical Analysis. British Journal of Management, v. 12, p. 183-199, 2001.

SUTTON, J. Sunk costs and market structure: price competition, advertising, and the evolution of concentration. Cambridge, MA: The MIT Press, 1991.

TEECE, D. J.; PISANO, G.; SHUEN, A. Dynamic Capabilities and Strategic Management. Strategic Management Journal, v. 18, n. 7, p. 509-533, 1997.

TIROLE, J. The Theory of Industrial Organization. [s.1.] The MIT Press, 1988.

TRAHMS, C. A.; NDOFOR, H. A.; SIRMON, D. G. Organizational decline and turnaround: a review and agenda for future research. Journal of Management, v. 39, n. 5, p. 1277-1307, 25 jan. 2013.

WERNERFELT, B. A resource-based view of the firm. Strategic Management Journal, v. 5, n. 2, p. 171-180, abr. 1984.

WHETTEN, D. A. Organizational growth and decline process. Anual Review of Sociology, v. 13, p. 335-358, 1987.

WILLIAMSON, O. The new institutional economics: taking stock, looking ahead. Journal of Economic Literature, v. 38, n. 3, p. 595-613, 2000. 
WILLIAMSON, O. E. Transactions cost economics: the governance of contractual relations. Journal of Law and Economics, v. 22, p. 233-261, 1979.

Strategizing, Economizing and Economic Organization. Strategic Management Journal, v. 12, n. Special Issue: Fundamental Research Issues in Strategy and Economics, p. 75-94, 1991.

ZYLBERSZTAJN, D. Organizações de cooperativas: desafios e tendências. Revista de Administração, v. 29, n. 3, p. 23-32, 1994.

ZYLBERSZTAJN, D. Quatro estratégias fundamentais para cooperativas agrícolas. São Paulo: [s.n.]. 


\section{APÊNDICE}

\section{(\$. FEAUSP}

DECLARAÇÃo

Eu, SIMON VELDT, declaro que concordo em participar, como voluntário, e autorizo 0 uso das informaçōes obtidas da COOPERATIVA AGROINDUSTRIAL HOLAMBRA, bem como a divulgaçăo do nome da empresa, em trabalhos, assim como dissertaçăo, artigos e livros, provenientes do estudo intitulado "LUTA PELA SOBREVIVENCIA: UM MODELO DE ESTRATÉGIA COMPETITIVA PARA O TURNAROUND DE EMPRESAS". O pesquisador responsável pelo estudo é o aluno de mestrado FERNANDO DE CESARE KOLYA, do Programa de Pós-Graduaçăo em Administraçăo (PPGA) da Universidade de São Paulo, nº USP: 5668752, que pode ser contatada pelo e-mail fernando.kolya@usp.br. A pesquisa é realizada sob a orientaçăo e responsabilidade da Professora Dra MARIA SYLVIA MACCHIONE SAES, também da Faculdade de Economia, Administraçäo e Contabilidade da Universidade de São Paulo. Os responsáveis pela pesquisa assumem o compromisso de compartilhar o material produzido antes de sua publicação e de não divulgar informações que não estejam de acordo com a politica de privacidade da empresa.

Paranapanema, 07 de Julho de 2015.

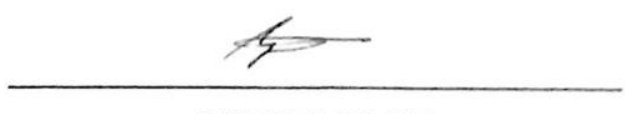

SIMON VELDT 